\title{
V. Aristokratische domus und Heiligenerinnerung: die städtischen Titelkirchen
}

Während die Bautätigkeit Konstantins und der Mitglieder seiner Familie sich im wesentlichen auf die Coemeterialbasiliken im Suburbium Roms konzentrierte, wurde die Entwicklung der christlichen Sakraltopographie innerhalb der Stadt von den Initiativen anderer Gruppen getragen und folgte anderen zeitlichen Rhythmen. Charles Pietri hat diesen schrittweisen Ausbau des innerhalb der Stadt gelegenen christlichen Raums als ein „second établissement chrétien" bezeichnet und die tragende Rolle aristokratischer Stifter für diesen Vorgang hervorgehoben. Im Zuge der zunehmenden Konversion der senatorischen Oberschicht im Laufe des 4. Jh. flossen zugleich auch deren finanzielle Ressourcen und euergetische Energien in die römische Kirche ein: An die Stelle der kaiserlichen Familie, deren Aktivitäten nach der intensiven Bautätigkeit der konstantinischen Dynastie deutlich nachließen, traten nun vermögende Mitglieder der stadtrömischen Aristokratie, deren Tätigkeit mit Blick auf die christliche Sakraltopographie Roms in der Zeit seit dem letzten Drittel des 4. Jh. von ähnlich zentraler Bedeutung war wie die kaiserliche Baupolitik in der ersten Hälfte des 4. Jh. ${ }^{1}$

Ihren sichtbarsten und nachhaltigsten Ausdruck fand dieser Beitrag der stadtrömischen Eliten zur Christianisierung des städtischen Raums in der Errichtung von Kirchen, die zum Teil in den Wohnanlagen ihrer Stifter erbaut wurden. Schon Johann P. Kirsch hatte in seiner 1918 erschienenen Studie zu den römischen Titelkirchen aus der Beobachtung, dass zahlreiche dieser tituli noch bis zum ausgehenden 5. Jh. nicht nach einem Heiligen oder einem städtischen Viertel, sondern nach einem Bischof oder einer nicht näher bestimmbaren Person benannt wurden, die Schlussfolgerung gezogen, dass es sich bei den Namensträgern der tituli um Hauseigentümer gehandelt habe, die ihre domus für liturgische Versammlungen von Gemeindemitgliedern zur Verfügung gestellt hätten. Bereits in vorkonstantinischer Zeit seien diese Wohnhäuser aus dem Privatbesitz in das Eigentum der Kirche übergegangen und hätten den römischen Presbytern gleichzeitig als Kultstätten und als

\footnotetext{
Pietri 1976, Bd. 1, 461-573, der diesen Ausbau der christlichen Sakraltopographie als eine von Damasus (366-384) bis zu Sixtus III. (432-440) reichende Phase periodisiert. Zur Beobachtung, dass seit Damasus verstärkt finanzielle Energien aristokratischer Euergeten in die römische Kirche einströmten, vgl. zuletzt auch Lizzi Testa 2004 (a), 105-114.
} 
Wohnräume gedient. ${ }^{2}$ Die Grundlage für Kirschs Hypothese bildeten Ausgrabungen unter den heute noch lokalisierbaren Titelkirchen, die deutlich machen, dass sich diese Gebäude häufig über antiken Wohnanlagen (domus, insulae) aus vorkonstantinischer Zeit erhoben. ${ }^{3}$ Gegen diese lange vorherrschende Auffassung, dass die römischen Titelkirchen ursprünglich vorkonstantinische domus ecclesiae gewesen seien, machte erstmals Charles Pietri gewichtige archäologische und terminologische Einwände geltend, indem er darauf hinwies, dass bei keinem der vorkonstantinischen Vorgängerbauten der römischen Titelkirchen Anzeichen für eine liturgische Nutzung nachweisbar seien. ${ }^{4}$ Da bei den wenigen uns bekannten Beispielen für Hauskirchen des 3. Jh. nur kleinere Umbauten für erweiterte Versammlungsräume oder bestimmte Funktionsbereiche, wie etwa Baptisterien, vorgenommen wurden, ${ }^{5}$ jedoch eindeutige liturgische Architekturelemente fehlen, die einen kirchlichen Versammlungsraum als einen solchen kennzeichnen und von der

$2 \quad$ Vgl. Kirsch 1918, 3f.; 175f. und passim. Ein Forschungskonsens bezüglich der genauen Anzahl und Lokalisierung der Titelkirchen ist bisher noch nicht erzielt worden; vgl. z. B. Saxer 2001 (a), 554f., der bis zum Ende des 5. Jh. von 25 tituli ausgeht, während Guidobaldi 1989, 386-391 für denselben Zeitraum 29 Titelkirchen veranschlagt. Die wichtigsten Quellen für die Anzahl und Benennung der römischen Titelkirchen sind die Unterschriftenlisten zweier römischer Synoden von 499 und 595, bei denen die Presbyter mit dem Zusatz tituli NN unterzeichneten (vgl. MGH AA XII, 410-415 u. Gregor I., epist. 5, 57 a [MGH Epist. I, 366f.]); hinzu kommen Inschriften, in denen Titelkleriker erwähnt werden (vgl. eine - unvollständige - Auflistung bei Saxer 2001 [a], 556f.). Als Ausgangsbasis für die Situation des 4. und 5. Jh. kann die Synodalliste von 499 dienen, die 29 tituli aufführt. Die von der Forschung häufig (z. B. Baldovin 1987, 115; Saxer 2001 [a], wie oben) vorgenommene Reduzierung dieser Zahl auf 25 entspringt dem Versuch, für das ausgehende 5. Jh. auf eine Anzahl von Titelkirchen zu kommen, die sich mit den zeitgleichen Angaben zur bischöflichen Stationsliturgie korrelieren lässt: So umfasste die Stationsliturgie unter Bischof Hilarus (461-468) 25 Titelkirchen und der in der ersten Hälfte des 6. Jh. redigierte Liber Pontificalis lässt in einigen anachronistischen Nachrichten über liturgische Maßnahmen von Bischöfen der vorkonstantinischen Zeit erkennen, dass er ebenfalls die Existenz von 25 tituli voraussetzt (vgl. LP I, 122, 143, 164). Dementsprechend werden in der Unterschriftenliste von 499 der titulus Pammachii und der titulus Byzantis aufgrund der hagiographischen Überlieferung der passio Gallicani als zwei Bezeichnungen aufgefasst, die auf dasselbe Gebäude zu beziehen sind; der titulus S. Laurentii gilt als Dublette für den titulus Damasi oder den titulus Lucinae, die beide eine Kirche mit Laurentiuspatrozinium hatten; der titulus Romanus wird als ein Verschreiber gewertet und der titulus Nicomedis mit dem titulus S. Matthaei gleichgesetzt. Dieser Ansatz ist insofern überzeugend, als jüngere Forschungen deutlich gemacht haben, dass man zwischen dem titulus als einer verwaltungsrechtlichen Kategorie und dem Kirchengebäude, der ecclesia, unterscheiden muss, was einen Teil der Doppelbenennungen erklärt (vgl. u. Anm. 32). Man wird daher von 25 Titelkirchen am Ende des 5. Jh. ausgehen, da die Synode von 499 offenbar den gesamten Klerus Roms versammelte. Eine neuere systematische Darstellung zu den römischen Titelkirchen seit der Studie von Kirsch 1918, die auch den Zugewinn an epigraphischen und archäologischen Erkenntnissen verarbeiten würde, ist ein dringendes Desiderat. Synthesen zur Entwicklung der römischen Titelkirchen während des 4. und 5. Jh. bieten Pietri 1989; Saxer 2001 (a), 553-565.

$3 \quad$ Kirsch 1918, 17-116.

$4 \quad$ Pietri 1978; ergänzend zu dems. 1976, Bd. 1, 17-29; 461-514.

5 Vgl. die Übersicht bei White 1997, 121-257 mit der Kirche von Dura-Europos als bekanntestem Beispiel. Nestori 1999 stellt die literarischen Testimonien für Hauskirchen zusammen. 
Hausarchitektur abheben würden, ist die Frage nach dem Verhältnis der tituli zur Kulttopographie der vorkonstantinischen Zeit damit zwar nicht eindeutig negativ beantwortet. Es kommt jedoch hinzu, dass auch die Bezeichnung titulus nicht vor dem 3. Viertel des 4 . Jh. nachweisbar ist, ${ }^{6}$ und dass der mit diesem Begriff bezeichnete Vorgang einer Eigentumsübertragung, bei dem ein bestimmtes Kirchengebäude innerhalb des bischöflichen Aufsichtsbereichs vom Bischof mit eigenen Gütern ausgestattet wurde, die seinem unmittelbaren Zugriff entzogen und der Verwaltung durch die für den titulus zuständigen Presbyter unterstellt wurden, ${ }^{7}$ sich erst in dem Moment entwickeln konnte, in dem die römische Gemeinde über eine eindeutig als solche definierte Bischofskirche verfügte: Erst unter diesen Voraussetzungen machte es Sinn, zwischen einer matrix ecclesia oder Bischofskirche und weiteren Kirchengebäuden zu differenzieren, die - bis zu einem gewissen Grad - als selbstständige Verwaltungseinheiten aus der bischöflichen

$6 \quad$ Der älteste inschriftliche Beleg stammt aus dem Jahr 377 und erwähnt einen Cinnamius lector tituli Fasciole ICUR II, 4815 (gefunden in S. Paolo f.l.m.).

Grundlage für diese Interpretation des Begriffs titulus als eine vom Bischof vorgenommene Besitzübertragung, bei der liturgisches Gerät und Liegenschaften zur Ausstattung und Erhaltung der Kirche an diese übertragen und damit an die Titelkirche gebunden und der Verfügung des Bischofs entzogen wurden, ist, dass der Liber Pontificalis von vier der römischen Titelkirchen die formale Einrichtung eines titulus (titulum constituit) mit einem derartigen Stiftungsvorgang festgehalten hat; vgl. Biographien von Silvester (314-335) (titulus Aequitii [LP I, 170], titulus Silvestri [LP I, 187]), Damasus (366-384) (titulus Damasi [LP I, 212]) und Innozenz I. (401-417) (titulus Vestinae [LP I, 220f.]). Bei vier weiteren Titelkirchen wird vom Liber Pontificalis nur kurz die Gründung durch den Bischof ohne eine entsprechende Angabe zur Ausstattung mit liturgischen Gerätschaften und mit Liegenschaften erwähnt (vgl. die Zusammenstellung der Belege bei Vielliard 1928). Pietri 1976, Bd. 1, 90-96, 569-573; ders. 1978, 7 erklärt die Einrichtung von tituli seit dem 4. Jh. aus dem Bestreben von aristokratischen Stiftern, die von ihnen gegründeten Kirchen durch einen titulus, verstanden als ,acte juridique qui établi la légitimité d'une donation“ (Pietri 1976, Bd. 1, 95), der Verfügungsgewalt des Bischofs zu entziehen und damit den Fortbestand ihrer Stiftung zu garantieren. Dabei ist jedoch zu berücksichtigen, dass es in formaler Hinsicht nicht der Stifter, sondern der Bischof war, der durch die Errichtung eines titulus diese Festlegung vornahm. Dies kommt nicht nur in der oben aufgeführten Terminologie des Liber Pontificalis zum Ausdruck, der erst zu Beginn des 6. Jh. redigiert wurde und daher möglicherweise eine Rechtspraxis widerspiegelt, die im 4. Jh. noch nicht bestanden hat. Auch die etwa hundert Jahre früher von einer karthagischen Synode im Jahr 419 verabschiedeten canones in causa Apiarii lassen dasselbe Verhältnis zwischen Bischof und titulus erkennen, indem sie festlegen, dass es einem Bischof nicht erlaubt sei, das Vermögen seines titulus widerrechtlich für die Bischofskirche (matrix ecclesia) in Besitz zu nehmen (nec episcopo liceat matri (!) ecclesiae rem tituli sui usurpare (canones in causa Apiarii 34 [CC 149, 111, orientiert an der Lesart F]). Die auf den Bischof bezogene Wendung titulus suus signalisiert, dass er derjenige ist, dem der titulus seine Entstehung verdankt. - Pietris Auffassung zur juristischen Bedeutung des Begriffs titulus im Sinne einer Eigentumsübertragung an die römische Kirche und zum Ursprung der tituli in nachkonstantinischer Zeit hat sich mittlerweile größtenteils durchgesetzt; vgl. u. a. Guidobaldi 1989, 383-385; dens. 2003, 5; Marazzi 1998, 29f.; Hillner 2006, 60-62. Keine Berücksichtigung finden Pietris Ergebnisse bei Lampe 1989; Jost 2000, Bd. 1, 121-126. Cecchelli 1985, 303; dies. 2000, 179f. hält weiterhin an der Theorie fest, dass einige der römischen tituli auf Kultstätten in vorkonstantinischer Zeit zurückgehen. 
Verwaltung ausgegliedert wurden. Diese Voraussetzungen wiederum waren in der römischen Gemeinde erstmals mit der Gründung der Lateranbasilika durch Konstantin gegeben, und es ist sicher kein Zufall, dass der Liber Pontificalis die Wendung, dass ein römischer Bischof einen titulus eingerichtet habe (titulum constituit), erstmals in Verbindung mit Bischof Silvester (314-335) überliefert. ${ }^{8}$

Dort, wo Titelkirchen nicht nach Heiligen oder städtischen Vierteln, sondern nach Stiftern benannt waren, liegt der durch die Namensgebung signalisierte private Ursprung also nicht in vorkonstantinischen domus ecclesiae, sondern in den domus, die während des 4. und frühen 5. Jh. von ihren Besitzern durch Umbauten in Kirchen umgewandelt wurden, und deren Bedeutung für die Entstehung der römischen Titelkirchen vor allem seit den letzten zwanzig Jahren, zum Teil bedingt durch neue Grabungen und archäologische Untersuchungen, ${ }^{9}$ nachdrücklich herausgestellt worden ist: Von den 17 Titelkirchen Roms, die sich noch über ihren antiken Vorgängerbauten erheben, und deren Zustand ein Bild von der Abfolge der antiken Bauten erlaubt, sind fünf nachweislich in den Anlagen repräsentativer domus, die die privilegierten Wohnverhältnisse ihrer Besitzer im 4. Jh. widerspiegeln, errichtet worden. ${ }^{10}$ Hinzu kommen weitere Titelkirchen, bei denen die

$8 \quad$ Vgl. die vorige Anm. In konstantinischer Zeit scheint nicht nur die Trennung zwischen Bischofskirche und Titelkirchen, sondern auch die zwischen städtischen Kirchen und außerhalb der Stadt gelegenen coemeteria begründet worden zu sein: Analog zur Wendung titulum constituit begegnet der Ausdruck coemeterium constituit erstmals unter Silvesters Nachfolger Marcus (336) (LP I, 202: bic [scil. Marcus] fecit duas basilicas, unam via Ardeatina,... quem cymiterium constituit). Demnach wurden offenbar bereits in konstantinischer Zeit die Grundlagen für die Ausdifferenzierung dreier liturgischer Zonen (bischöfliche, presbyterale, coemeteriale) gelegt, wie sie in den Quellen erstmals im frühen 5. Jh. hervortritt (vgl. die Bemerkungen von Bischof Innozenz I. zur Fermentumspraxis in seinem Brief an Decentius v. Gubbio aus dem Jahr 416: Hier wird anlässlich der sonntäglichen Messliturgie unterschieden zwischen dem Bischof, den in den tituli zelebrierenden Presbytern und den per cimiteria diversa constituti presbyteri, die im Unterschied zu den Titelpresbytern das fermentum nicht erhalten [Innozenz I., epistula ad Decentium 92-101]).

$9 \quad$ Vgl. dazu Guidobaldi 1989, dens. 1993. Über jüngste Untersuchungen zu den römischen tituli im Rahmen eines umfassenden Forschungsprojektes unterrichtet Cecchelli 1999; vgl. auch dies. 2001. Grundlegend bleiben auch weiterhin die Einzelstudien zu den Titelkirchen von Krautheimer im Corpus basilicarum urbis Romae.

10 Der titulus Aemilianae/SS. Quattuor Coronatorum wurde in einer aula des 4. Jh. errichtet, die Guidobaldi 1986, 192f., für den Teil einer domus hält; Krautheimer, in: Corpus IV, 31-33 ebenso Geertman 1975, 4 gehen hingegen davon aus, dass die Titelkirche erst unter Honorius I. (625628 ) in dieser aula eingerichtet wurde und sich zuvor an einer anderen Stelle befand. Ähnlich ist die Situation in S. Balbina, wo der titulus s. Balbinae in einer aula des 4. Jh. errichtet wurde (vgl. Guidobaldi 1986, 181f. [kritisch Cecchelli 2000 (a), 433]; allerdings ist nicht sicher, dass der titulus s. Balbinae, erstmals 595 erwähnt, bereits im 5. Jh. existierte, die Gleichsetzung mit dem titulus Tigridae, die Guidobaldi 1989, 391, vornimmt, ist hypothetisch). Der in den 430er Jahren errichtete titulus apostolorum (S. Pietro in Vincoli) überbaute eine Domusaula, die im 4. Jh. mit einer Apsis versehen worden war (als eine Vorgängerkirche aufgefasst von Krautheimer, in: Corpus III, 195-223, 226f.; Guidobaldi 1986, 171-175; Bartolozzi Casti 1997-1998, 246-255; skeptisch Brenk 2003, 49). Der titulus Chrysogoni machte in den beiden Seitenwänden seines einschiffigen Grund- 
Umwandlung einer spätantiken domus in eine Kirche möglich erscheint. ${ }^{11}$ Die Entstehung der tituli ist damit, wie bereits von Pietri vermutet, zu einem nicht unerheblichen Teil im Ambiente der vermögenden aristokratischen Oberschicht Roms zu suchen, deren Bedürfnis nach Repräsentation im 4. Jh. in der Anlage aufwendiger Wohnhäuser zum Ausdruck kam, wie sie durch literarische Zeugnisse und zahlreiche archäologische Beispiele belegt sind. ${ }^{12}$

Dieser Vorgang einer Umwandlung repräsentativer Domusanlagen in Kirchenbauten lässt sich zeitlich weiter eingrenzen. Während einige frühe tituli von den Bischöfen Silvester (314-335), Marcus (336), Iulius (337-352) und Liberius (352-366) ins Leben gerufen wurden, ${ }^{13}$ machte sich ab der damasianischen Zeit verstärkt die Initiative nichtbischöflicher Stifter bei der Gründung von Titelkirchen bemerkbar: Von Damasus (366-384) bis zu Caelestinus (422-432) wurden 10 Titelkirchen errichtet, die keine bischöflichen Gründungen waren und überwiegend auf das Konto nichtklerikaler Stifter gingen. ${ }^{14}$ Bei mehreren dieser Kirchen lässt sich eine Umwandlung von domus-Anlagen, wie sie oben beschrieben wurde, nachweisen. Hinzu kommen weitere Kirchengründungen, die zwar nicht den Status einer Titelkirche

risses Gebrauch von Mauern, die vermutlich zu einer domus gehörten (Cecchelli 1999, 232-238, die den Bau der Kirche in das frühe 5. Jh. datiert); eine ähnliche Situation liegt auch vor beim titulus Marci (ebd., 228) und beim titulus Clementis (Anfang des 5. Jh. Anlage einer dreischiffigen apsidalen Basilika, die auf dem Grundriss eines Vorgängerbaus, vermutlich einer domus des 3. Jh., errichtet wurde und ihn transformierte [vgl. Guidobaldi 1992, Bd. 1, 97-116 u. 125-156]; Umbauarbeiten, die während des 4. Jh. in der domus vorgenommen wurden, könnten im Zusammenhang mit der Umwandlung der domus in einen christlichen Kultbau noch vor Errichtung der Basilika um 400 stehen [vgl. ebd., 119-122]). Zur Anlage des titulus Pammachii/SS. Iohannis et Pauli, der zu Beginn des 5. Jh. eine domus überbaute, vgl. Brenk 2003, 82-113 und u., S. 379-381, 397 f. Der titulus Gaii/S. Susannae wurde in karolingischer Zeit an anderer Stelle neu errichtet; die aula unterhalb der heutigen Kirche ist kein antiker Bau (so zuletzt Bonanni 1995, 587f.; gegen Guidobaldi 1989, 389).

11 Unter dem titulus Caeciliae, der in seiner heutigen Form auf einen Bau des 9. Jh. zurückgeht, befinden sich Überreste zweier Wohnanlagen, die im 4. Jh. miteinander verbunden wurden; ob sie bereits als liturgischer Versammlungsraum genutzt wurden und den antiken titulus Caeciliae darstellen, ist jedoch fraglich (vgl. Krautheimer, in: Corpus I, 104; Parmegiani/Pronti 1995, 1072). Beim titulus Sabinae ist nur nachweisbar, dass er im Bereich eines repräsentativen Vorgängerbaus angelegt wurde (vgl. u., S. 354, Anm. 101). Im Fall des titulus Damasi deutet die Weihinschrift seines bischöflichen Stifters darauf hin, dass er in einer domus der Familie des Damasus errichtet wurde (vgl. Krautheimer 1995, 962; die Ausgrabungen haben bisher noch keine eindeutigen Hinweise auf eine derartige domus erbringen können, vgl. ebd., 961f.). Von einer generellen Verbindung sämtlicher tituli Roms mit Domusanlagen geht Guidobaldi 1999 (a), 65 aus.

12 Vgl. dazu u., S. 335-337.

13 Vgl. die auf den Ergebnissen von Pietri 1976 beruhende Zusammenfassung von Saxer 2001 (a), $554 f$.

14 Dass daneben auch vermögende Kleriker an der Errichtung der tituli beteiligt und nicht nur Laien als Titelgründer tätig waren, ist in einzelnen Fällen nachweisbar (vgl. Hillner 2006). 
erhielten, aber ebenfalls auf einer Umwandlung privater Domusarchitektur in Kirchenräume beruhten. ${ }^{15}$

Seit der zweiten Hälfte des 4. Jh. - so lässt sich zusammenfassend festhalten - verstärkten sich die Initiativen von vermögenden Laienstiftern zur Christianisierung der stadtrömischen Topographie. Sie vollzogen sich in einem räumlichen Bereich, der für die Repräsentation und Kommunikation der römischen Eliten in dieser Zeit von zentralerer Bedeutung war als je zuvor: ${ }^{16}$ Wie die Forschungen vor allem der letzten Jahre deutlich gemacht haben, nahm nicht nur in Rom, sondern im gesamten Mittelmeerraum seit dem 4. Jh. die Tendenz zu, aristokratischen Status nicht mehr im öffentlichen Bereich der opera publica, sondern in den domus, die deutlich an Repräsentativität gewannen, zu inszenieren. ${ }^{17}$ In einer Zeit, in der das Verhältnis von Patronen und Klienten zunehmend von einer Wahrnehmung wachsender Distanz und Macht geprägt war, ${ }^{18}$ führte diese Entwicklung auch zu einer Blüte der domusArchitektur, die für den Umgang der potentes mit ihren Klienten einen zere-

15 Aus der Umwandlung einer Basilika in der domus des Iunius Bassus, die später in den Besitz von Flavius Valila überging und von diesem testamentarisch der Kirche vermacht wurde (zwischen 471 und 483), ging die Kirche S. Andrea in Catabarbara hervor (vgl. Guidobaldi 1986, 184-186). Ähnliche Abmessungen hatte eine domus-Aula, die allerdings erst unter Honorius I. (625-638) in die Kirche S. Lucia in Selcis umgewandelt wurde (vgl. Serlorenzi 2004, 357-362). Anders verhält es sich hingegen bei den uns bekannten Xenodochien Roms aus der Zeit bis zum ausgehenden 5. Jh.: Sowohl das Xenodochium der Anicier als auch das Xenodochium der Valerier, vermutlich beide in der zweiten Hälfte des 5. Jh. gegründet, wurden offenbar nicht in Privathäusern, sondern in opera publica eingerichtet (vgl. überzeugend Santangeli Valenzani 1996-1997, 205-210, der das Xenodochium der Anicier in der porticus Minucia und das Xenodochium der Valerier in den Märkten des Trajansforums lokalisiert; davon, dass sich das Xenodochium a Valeriis in einer domus der Valerier auf dem Caelius befunden habe, gehen demgegenüber zuletzt weiterhin Brenk 2003, 114f. u. Hillner 2003, 143, dies. 2004, 173 aus). Vom Xenodochium des Pammachius in Porto ist nicht mehr bekannt als die Tatsache, dass es von dem im Jahr 410 verstorbenen Neffen des C. Caeionius Rufius Volusianus und Briefpartner des Hieronymus gegründet wurde (Hier., epist. 66, 11).

16 Die Gründungen der tituli vollzogen sich demnach in einem spezifischen historischen Kontext; dies wird verkannt von Curran 2000, 40f., Anm. 249, wenn er bemerkt, die Nachweise, dass zahlreiche tituli in Wohnhäusern angelegt worden seien, hätten trotz der Einwände Pietris gegen eine Identifizierung von Titelkirchen und vorkonstantinischen domus ecclesiae die Bedeutung der Hausarchitektur für die römischen Titelkirchen erwiesen: Im 4. Jh. warf die Nutzung privater Architektur zu liturgischen Zwecken andere Fragen und Probleme auf als in vorkonstantinischer Zeit.

17 Speziell für Rom im 4. Jh. vgl. die Bilanz von Guidobaldi 1999 (a), 57f. Zur Anlage von Peristylhäusern mit ausgeprägten und aufwendig gestalteten Repräsentations- und Interaktionsbereichen für Patrone und deren Klienten (Empfangsaulen; Speisesäle mit mehreren Apsiden; Marmorintarsien und Mosaiken an den Wänden) vgl. allgemein Ellis 1988, bes. 565-576; Baldini Lippolis 2001, 47-94; speziell für Rom Guidobaldi 1999 (a), 62-64. Zu einer seit dem 3. Jh. einsetzenden Verlagerung der Repräsentation der Eliten in den privaten Raum vgl. allgemein Borg/Witschel 2001, bes. 88, 113-116.

18 Brown 1995 (1978), 29f., 75f. Für Rom vgl. den eindrücklichen Bericht von Ammian in seinem Exkurs über den senatus populusque Romanus (Amm. 18, 4, 10. 23. 27). 
moniellen Rahmen schuf. In Rom ist die Entstehung großer aristokratischer Wohnanlagen nicht nur archäologisch nachweisbar, ${ }^{19}$ sondern auch aus literarischen Äußerungen der Zeit bekannt. ${ }^{20}$

Die Inszenierung von aristokratischem Status in den spätantiken domus Roms, deren gesellschaftliche Bedeutung als Zentren sozialer und politischer Kommunikation und die zunehmende Verlagerung der Repräsentation der römischen Eliten in den privaten Bereich wird vor allem in der Aufstellung von Statuen fassbar, deren Errichtung im öffentlichen Raum durch die Präsenz des Prinzeps in Rom traditionell Beschränkungen und Vorbehalten unterworfen war. ${ }^{21} \mathrm{Im}$ spätantiken Rom konzentrierten sich senatorische Ehrenstatuen daher vor allem auf den privaten Raum der domus und der ihr angeschlossenen horti sowie auf Forenanlagen, die auf Privatbesitz errichtet worden waren. ${ }^{22}$ Die domus und private Anlagen wurden damit zu Schauplätzen einer intensiven politischen Kommunikation zwischen den Gemeinden und Kollegien und ihren Patronen: Statuarische Ehrungen, ${ }^{23}$ die dem Geehrten für seine Leistungen dankten und ihn und seine Angehörigen durch diese Zuweisung von Ehre auf weitere Leitungen verpflichteten, versinnbildlichten und aktualisierten die gesellschaftliche Bindungskraft zwischen den beiden Seiten. Die Themen und Inhalte dieser Kommunikation im privaten Bereich unterschieden sich dabei nicht signifikant von Statuenehrungen im öffentlichen Raum. ${ }^{24}$ Für die domus des spätantiken Rom galt da-

19 Zur Blüte einer aufwendig inszenierten domus-Architektur in Rom und Ostia in dieser Zeit vgl. Guidobaldi 1986; dens. 1993; Lind Hansen 1997. Aus Rom sind die archäologischen Überreste von etwa 170 domus aus dem 4. und 5. Jh. bekannt, von denen sich etwa 30 bestimmten Besitzern zuordnen lassen (vgl. die Bilanz von Guidobaldi 1999 [a], 55; eine katalogartige Übersicht bei Baldini Lippolis 2001, 262-276).

20 Olympiodor, fragm. 41, 1 (Blockley) bezeichnet die typische domus der römischen Aristokraten als eine Stadt mittlerer Größe mit eigenem Hippodrom, Foren, Tempeln und Thermen. Derselbe Olympiodor bietet auch differenzierte Angaben zu den Reichtümern, die sich in den Händen der Eigentümer dieser domus konzentrierten: 4000 Pfund Gold für die größten Häuser, 1000-1500 Pfund für die domus „zweiter Klasse“ (fragm. 41, 2 [Blockley]). Der Manichäer Secundinus hob die Marmorpracht der domus Aniciana hervor (CSEL 25, 895) und spielte damit möglicherweise auf die luxuriöse Ausstattung der römischen domus des Petronius Probus an (vgl. Paul. Med., vita Ambr. 25, 2).

21 Eck 1992, 365f., 375f.; zu den rechtlichen Voraussetzungen einer Statuenehrung im öffentlichen Raum vgl. Bauer 1997, 51.

22 Vgl. Niquet 2000, 25-33 (domus); Bauer 1997 (private Foren). Auch für den privaten Bereich galt allerdings seit der Mitte des 4. Jh., dass die Errichtung von Ehrenstatuen vom Kaiser genehmigt werden musste, wenn die Ehrung durch öffentliche Auftraggeber - eine Gemeinde oder Provinz - vorgenommen wurde (vgl. Niquet 2000, 77f.). Im öffentlichen Raum Roms fanden senatorische Statuen vor allem auf dem Trajansforum Aufstellung (vgl. Bauer 1996, 132f.; Niquet 2000, 18-20).

23 Vgl. die Übersicht der Statuendedikationen für Angehörige der senatorischen Oberschicht Roms in der Spätantike bei Niquet 2000, 262-283. Dedikationen durch den Senat im privaten Raum sind eine seltene Ausnahme (vgl. ebd., 24f.).

$24 \quad$ Vgl. Eck 1992, bes. 363. 
mit in verstärktem Maße das, was Plinius bereits für das 1. Jh. festgehalten hatte, dass durch die Statuenaufstellungen der öffentliche Raum des Forums in die Privathäuser Einzug gehalten habe. ${ }^{25}$

Unter den historischen Voraussetzungen einer derartigen Konzentration der gesellschaftlichen und politischen Kommunikation auf den privaten Raum im Rom des 4. und frühen 5. Jh. stellt sich nahezu zwangsläufig die Frage, welche Auswirkungen die Anlage von Kirchen in aristokratischen Häusern auf die Repräsentation der städtischen Eliten innerhalb der christlichen Gemeinde hatte, und welche Rolle traditionelle Räume und Formen privater Kommunikation und Autoritätsbildung in der Relation zur christlichen Gemeindeöffentlichkeit spielten. Virulent wird diese Frage vor allem mit Blick auf die Heiligenverehrung, die neben dem Suburbium Roms nun auch zunehmend den innerhalb der Mauern gelegenen städtischen Raum erfasste, da die Gründung zahlreicher Titelkirchen mit der Etablierung von Heiligenpatrozinien verbunden war. Nach einer maßgeblich von Peter Brown vertretenen These waren die Gemeinden des 4. Jh. starken Spannungen zwischen Bischöfen und vermögenden Laien ausgesetzt, die ihren Einfluss auch innerhalb der christlichen Gemeinden geltend zu machen versuchten - Spannungen, die besonders in der Auseinandersetzung um den Heiligenkult Gestalt gewonnen hätten: Als eine Ressource außerordentlicher Macht seien die Heiligengräber von Bischöfen, die vor allem im späteren 4. Jh. als regelrechte „Impresarios“ der Heiligenverehrung in Erscheinung getreten seien, einer drohenden Kontrolle durch Laien und damit einer „Privatisierung“ der Heiligenmemoria entzogen worden. ${ }^{26}$ Vor dem Hintergrund dieses Deutungsmusters stellt sich die Frage nach den Auswirkungen, die die Gründung von tituli mit Heiligenpatrozinien in aristokratischen Wohnhäusern hatte. War die Heiligenmemoria eine Ressource, die dazu genutzt wurde, die Macht und Einflussmöglichkeiten eines Patrons gegenüber seinen Freunden und Klienten im privaten Raum zu demonstrieren? Und in welchem Maße bildeten die Titelkirchen und privaten Heiligenoratorien in den domus der Stadt Räume und Kristallisationspunkte von Formen kollektiver Identitätsstiftung, die sich einer amtskirchlichen Kontrolle entzogen?

\footnotetext{
25 Plin., nat. 34, 17: mox forum et in domibus privatis factum atque in atriis, honos clientium instituit sic colere patronos.

26 Brown 1981, 23-49.
} 


\section{1. Die Heiligenverehrung in den römischen Titelkirchen}

Auf den ersten Blick versprechen diese Fragen, was die Heiligenverehrung in den römischen Titelkirchen betrifft, nur geringen Ertrag, da nach einer von Kirsch begründeten und einhellig akzeptierten Forschungsmeinung die Titelkirchen ursprünglich nicht nach Heiligen, sondern nach ihren Stiftern benannt waren, die erst im Laufe des 6. Jh. von der legendarischen Tradition in den Rang von Heiligen erhoben wurden. ${ }^{27}$ Eine wesentliche Stütze für diese Theorie bildet die Unterschriftenliste einer römischen Synode aus dem Jahr 499, in der die Personen, nach denen die römischen tituli benannt waren, ohne das Attribut sanctus erscheinen: Von drei Ausnahmen - dem titulus s. Laurentii, titulus s. Matthaei und dem titulus s. Sabinae - abgesehen, würden, so Kirsch, alle anderen Namensgeber der Titelkirchen ohne eine explizite Kennzeichnung als Heilige aufgeführt (z. B. titulus Vestinae). Dem stellt Kirsch eine vergleichbare Unterschriftenliste aus dem Jahr 595 entgegen, in der alle römischen tituli nach Heiligen benannt sind - teilweise, indem die Namensgeber der Liste von 499 durch Heilige ersetzt wurden, teilweise, indem sie selbst das Attribut sanctus erhielten und auf diese Weise zu Heiligen gemacht wurden. Diese Unterschiede zwischen den beiden Listen interpretiert Kirsch als einen schlagenden Hinweis darauf, dass im Jahr 499 die Titelkirchen noch beinahe ausschließlich Träger einer Stiftermemoria gewesen seien, während im Laufe des 6. Jh. die Erinnerung an die Stifter sich durchgehend in ein Heiligengedenken verwandelt habe. Nach dieser Schlussfolgerung hätte die Frage nach einer Heiligenverehrung in den römischen Titelkirchen des ausgehenden 4. und frühen 5. Jh. nur wenig Sinn, da eine Ausstattung der tituli mit Heiligenpatrozinien erst im Laufe des 6. Jh. erfolgte wäre.

Diese These muss man jedoch modifizieren. Zwar ist unbestreitbar, dass die römischen Tituli nach ihren Gründern benannt wurden: Dies ist nicht nur in Einzelfällen sicher belegt, ${ }^{28}$ sondern entspricht auch einer Praxis, die auch noch in der Zeit, in der eine Benennung von Kirchen nach Heiligen allgemein

$27 \quad$ Vgl. für das folgende Kirsch 1918, 6-12, dessen Schlussfolgerungen kanonische Geltung erlangt haben, vgl. u. a. Pietri 1978, 6f.; Niero 1982, 163; Cucsito 1987, 267f.; zuletzt Jost 2000, Bd. 1, 127-133; Saxer 2001 (a), 559f.

28 Im Martyrologium Hieronymianum hat sich die kalendarische Kommemoration zweier römischer Titelgründer erhalten: in titulo Cyriaci iuxta Diocletianas conditoris tituli (14. April) und Romae Eusebii conditoris tituli sui (14. August); zur Rekonstruktion dieser Tageseinträge vgl. Kirsch 1924, 51-53 u. 171f. Beim titulus Pudentianae und titulus Aemilianae handelt es sich um Adjektive von Gründernamen (Pudens bzw. Aemilius), die sich später zu Eigennamen verselbständigt haben (titulus der ecclesia Aemiliana > titulus Aemilianae; zur Benennung von Kirchen nach den Adjektiven der Gründernamen vgl. die folgende Anm.). 
üblich wurde, gängig war. ${ }^{29}$ Dennoch ist die Auffassung, dass die römischen Titelkirchen erst im Verlauf des 6. Jh. den Namen von Heiligen erhalten hätten, zu schematisch und gründet auf einer nur oberflächlichen Heranziehung der Unterschriftenliste von 499. Zum einen ist in bestimmten Fällen, wie dem titulus Vestinae, bekannt, dass die Kirche bereits bei ihrer Gründung unter Innozenz I. (401-417) den Heiligen Gervasius und Protasius geweiht und zu diesem Zweck vermutlich mit Reliquien ausgestattet worden ist. ${ }^{30}$ In der Liste von 499, wo die Titelkirche als titulus Vestinae erscheint, spiegelt sich dieses Heiligenpatrozinium jedoch nicht wider: Alle drei auf der Synode anwesenden Presbyter unterzeichneten mit NN presbyter tituli Vestinae. ${ }^{31}$ Diese Diskrepanz ist dadurch zu erklären, dass der Ausdruck titulus im engeren Sinne nicht das Kirchengebäude selbst bezeichnet, sondern den Status, über den eine Titelkirche in Relation zur Bischofskirche verfügte: Die innerhalb der Stadtmauern gelegenen tituli bildeten - ähnlich wie die coemeteria außerhalb der Stadt - semiautonome Strukturen neben der römischen Bischofskirche, die vom römischen Bischof konstituiert wurden und über eine begrenzte Eigenständigkeit verfügten. ${ }^{32}$ Diese Differenzierung zwischen dem titulus als eigenständiger

29 Für prominente Beispiele vgl. u. a. in Rom selbst die basilica Constantiniana (LP I, 172); in Mailand die basilica Ambrosiana (Ambr., epist. 77, 2; Paul. Med., vita Ambr. 14, 2; 48, 2); in Ravenna die ecclesia Ursiana (ca. 400 von Bischof Ursus errichtet; vgl. Agnell., LP 23).

30 LP I, 220: eodem tempore dedicavit (scil. Innozenz I.) basilicam sanctorum Gervasi et Protasi ex devotione cuiusdam inlustris feminae Vestinae... quae femina suprascripta testamenti paginam sic ordinavit, ut basilica sanctorum martyrum ex ornamentis et margaritis construeretur venditis iustis extimationibus.

31 MGH AA XII, 411f., nr. 2, 10, 25. Dasselbe gilt für den titulus Pammachii/Byzantis der Unterschriftenliste von 499, für den in dieser Zeit bereits die Benennung nach den beiden Titelheiligen Johannes und Paulus gebräuchlich war, wie die Symmachusvita des Liber Pontificalis zeigt (LP I, 261).

32 Im Liber Pontificalis werden die tituli mit „Pfarrkirchen“ verglichen (LP I, 164 bic (scil. Marcellus) ... XXV titulos in urbe Roma constituit quasi diocesis; diocesis und parrocbia bezeichnen im spätantiken und frühmittelalterlichen Sprachgebrauch eigenständige Bezirke auf dem Territorium von Bistümern, die als Vorläufer der mittelalterlichen Pfarrkirchen gelten können [zur Terminologie vgl. Müller 1933; zu den Frühformen und Entwicklungsstadien des Pfarrkirchensystems, das in seiner entwickelten Form freilich erst seit dem 11./12. Jh. begegnet, s. Reynaud 1999]). Ähnlich werden auch die römischen coemeteria den parrochiae zur Seite gestellt (LP I, 157: hic (scil. Dionysius) presbiteris ecclesias dedit et cymiteria et parrocias diocesis constituit). Ebenso wie coemeterium ist titulus im Liber Pontificalis ferner in der Regel kein Ausdruck für ein sakrales Gebäude, sondern für eine Verwaltungseinheit: tituli und coemeteria werden nach der Terminologie des Liber Pontificalis nicht errichtet oder geweiht (facere, construere, dedicare), sondern eingerichtet (constituere); vgl. LP I, 170: bic (scil. Silvester) fecit in urbe Roma ecclesiam in praedium cuiusdam presbiteri sui, qui cognominabatur Equitus, quem titulum romanum constituit iuxta termas Domitianas; LP I, 187: hisdem temporibus constituit beatus Silvester in urbe Roma titulum suum in regione III iuxta thermas Domitianas; LP I, 212: bic (scil. Damasus) constituit titulum in urbe Roma basilicam, quem ipse construxit, LP I, 220: in quo loco beatissimus Innocentius ex delegatione inlustris feminae Vestinae titulum Romae constituit. Diese Verwaltungsorganisation ist bereits für das frühe 5. Jh. gesichert. In einem 416 verfassten Brief an Decentius v. Gubbio vergleicht der römische Bischof Innozenz I. die tituli und coemeteria Roms mit den parrochiae in Decentius' Bistum: Nur weil die tituli innerhalb des Stadtgebietes liegen, ist der römische Bischof in der Lage, an Ostern das fermentum in die Titelkirchen zu schicken; Decentius hingegen kann 
Verwaltungseinheit und dem zu einem titulus gehörigen Kirchengebäude (ecclesia, basilica $)^{33}$ ist dort von Interesse, wo - wie beispielsweise beim titulus Vestinae - die Bezeichnungen nicht deckungsgleich sind. In solchen Fällen bietet also die Benennung eines titulus nach einem Stifter in der Synodalliste von 499 keine automatische Gewähr dafür, dass das dazugehörige Kirchengebäude nicht nach einem Heiligen benannt war, auch wenn dies aus der Nomenklatur der Titelpriester nicht hervorgeht.

Zum anderen verdeutlicht ein genauerer Blick in die Unterschriftenliste des Jahres 499, dass die Presbyter keineswegs so einheitlich unterzeichneten, wie es die tabellarische Zusammenstellung bei Kirsch suggeriert. ${ }^{34}$ Bei der Titelkirche der Sabina unterschrieb einer der Titelpriester mit presbyter tituli sanctae Sabinae, während seine beiden Kollegen mit presbyter tituli Sabinae unterzeichneten. ${ }^{35}$ Ähnliche Uneinheitlichkeiten lassen sich auch mit Blick auf den titulus Caeciliae und den titulus Clementis feststellen. ${ }^{36}$ Dies zeigt nicht nur, dass neben Laurentius, Matthaeus und Sabina gegen Ende des 5. Jh. die Namensgeber zweier weiterer tituli (Clemens und Caecilia) als Heilige galten. Es macht auch deutlich, dass die Tatsache, dass ein Name in der Liste ohne das Attribut sanctus erscheint, nicht als eine Gewähr dafür angesehen werden kann, dass

das in seinen ländlichen parrochiae ebensowenig tun wie der römische Bischof in den außerhalb der Stadt gelegenen cimeteria (Innozenz I., epist. ad Decentium 1. 92-101). Offensichtlich hatten die tituli (im Bereich der Stadt Rom) und die coemeteria (in ihrer unmittelbaren Umgebung) eine ähnliche Funktion wie die parrochiae, die auf dem Territorium von Decentius' Bistum lagen; zur Interpretation vgl. auch Fiocchi Nicolai 1999, 451-453.

33 Die Unterscheidung zwischen dem titulus im engeren Sinne und dem zu einem titulus gehörigen Kirchengebäude, der ecclesia, wird besonders deutlich in einer römischen Synode vom 6. 11. 501, die die Unveräußerlichkeit von Kirchengut durch den römischen Bischof verfügte und den „Presbytern der Kirchen in allen tituli der Stadt Rom“ dieselbe Pflicht auferlegte: pari etiam ecclesiarum per omnes Romanae civitatis titulos qui sunt presbyteri vel quicumque fuerint adstringi volumus lege custodis (MGH AA XII, 450; zur Datierung der Synode in das Jahr 501 [nicht 502] vgl. Wirbelauer 1993, 21-34). Die Differenzierung zwischen titulus und ecclesia hat zuletzt Guidobaldi 2003 überzeugend herausgearbeitet. - Im Unterschied zu den späteren „Pfarrkirchen“ lässt sich nicht nachweisen, dass die römischen tituli über ein festes Territorium verfügten. Sie gehen vielmehr auf einzelne Stiftungen zurück (s. o., Anm. 7), die dem Unterhalt eines Kirchengebäudes dienen sollten. Die Existenz mehrerer tituli für eine Kirche (s. o., Anm. 2) ist daher zum Teil dadurch zu erklären, dass hier unterschiedliche Stiftungen zusammengelegt und einem einzigen Kirchengebäude zugeordnet wurden (titulus Pammachii u. titulus Byzantis). Eine andere Ursache für die Doppelbenennungen ist, dass man sich entweder nach der Bezeichnung des titulus oder nach dem Heiligenpatrozinium der zugehörigen Kirche richtete (titulus Lucinae [oder titulus Damasi] = titulus s. Laurentii; titulus Nicomedis = titulus s. Matthaei).

34 Die Akten der Synode von 499 sind herausgegeben von Mommsen, in: MGH AA XII, 399-415 (für die Unterschriften der römischen Titelpresbyter vgl. 410-415); die Zusammenstellung von Kirsch findet sich in dems. 1918, 7f.

35 Valens presbyter tituli sanctae Sabinae (MGH AA XII, 411, nr. 8); Abundantius presbyter tituli Sabinae (nr. 30); Victorinus presbyter tituli Sabinae (nr. 58).

36 Servus dei presbyter tituli sancti Clementis (nr. 24; zwei weitere Presbyter unterzeichneten mit presbyter tituli Clementis); Marcianus presbyter tituli sanctae Caeciliae (nr. 3; ohne Heiligenattribut erscheint Caecilia hingegen bei einem anderen Titelpresbyter [nr. 54]). 
der Träger dieses Namens nicht als Heiliger galt: Die Varianten bei Sabina, Caecilia und Clemens legen nahe, dass die Kennzeichnung eines Titelheiligen als sanctus nicht als verpflichtend angesehen wurde. Zur Gewissheit erhoben wird diese Vermutung mit Blick auf die Titelkirche der beiden Apostel Petrus und Paulus, die in der Liste von 499 nicht explizit als Heilige gekennzeichnet wurden: alle drei Titelpresbyter unterzeichneten mit presbyter tituli apostolorum. ${ }^{37}$

Angesichts der Tatsache, dass die Sprachregelung der Unterschriftenliste von 499 keine sichere Aussage darüber erlaubt, ob ein Heiligenpatrozinium an einer Titelkirche bestand oder nicht, erscheint es geraten, die Hypothese, dass die Titelkirchen in der Regel erst während des 6. Jh. Heiligenpatrozinien erhielten, im folgenden zur Disposition zu stellen. Diese Überprüfung führt zu dem Ergebnis, dass von den 25 in der Synodalliste von 499 aufgeführten Titelkirchen mehr als die Hälfte, nämlich mindestens 13, bereits während des 5. Jh. über ein Patrozinium verfügt haben dürften. Dabei handelt es sich um folgende tituli:

1. Titulus Damasi. Die Stiftungsinschrift der von Bischof Damasus (366-384) gegründeten Kirche zeigt, dass die Kirche zwar nicht direkt dem Laurentius geweiht war, Damasus seine Gründung jedoch mit der Hilfe des Heiligen (Laurenti saeptus martyris auxilio) vorgenommen hat. ${ }^{38}$ Von einer Reliquienübertragung ist in der Inschrift nicht die Rede; auch deutet sie nicht auf ein Kirchenpatrozinium des Heiligen Laurentius hin: ${ }^{39}$ Die Hilfe (auxilium) des Laurentius, von der Damasus spricht, ist vielmehr als ein auf ihn persönlich bezogenes Patronat zu verstehen, das im Nachhinein als Patrozinium für die Kirche aufgefasst worden ist.

2. Titulus Vestinae. Eine nicht näher bekannte illustris femina Vestina ließ unter Bischof Innozenz I. (401-417) testamentarisch eine Basilika errichten und den Heiligen Gervasius und Protasius weihen. ${ }^{40}$ Anders als beim titulus Damasi kann man bei dieser ex devotione vorgenommenen Stiftung sicher von einer Überführung von Reliquien der beiden Heiligen ausgehen, die bald nach ihrer Auffindung durch Ambrosius im Jahr 386 in Oberitalien und Gallien weite Verbreitung fanden und dort zur Rekondierung in Kirchen bestimmt waren. ${ }^{41}$

37 Ebd., nr. 39, 42, 49. In der Unterschriftenliste von 595 erscheint die Titelkirche hingegen als titulus sanctorum apostolorum (Gregor I., epist. 5, 57a [MGH Epist. I, 367]).

38 Damas., epigr., nr. 58: haec Damasus tibi, Christe deus, nova tecta dicavi, / Laurenti saeptus martyris auxilio.

39 Anders beispielsweise die etwa zur selben Zeit entstandene Stiftungsinschrift, die Ambrosius an der basilica apostolorum in Mailand anbringen ließ: condidit Ambrosius templum dominoque sacravit / nomine apostolico munere reliquiis; vgl. Delehaye 1930, 7.

40 LP I, 220.

41 Die beiden Mailänder Heiligen befanden sich unter den Reliquien, die Victricius von Rouen von Ambrosius v. Mailand erhielt und für den Bau seiner Basilika verwendete (Victric., 6 [geschrieben 395/397]). In ähnlicher Form stattete auch Gaudentius v. Brescia (gest. 410) seine Basilika 
Da die Titelkirche der Vestina seit dem 6. Jh. nicht nach Gervasius und Protasius, sondern nach dem Heiligen Vitalis benannt wurde, ${ }^{42}$ könnten zusammen mit den Reliquien von Gervasius und Protasius auch die Reliquien dieses Heiligen, an deren Auffindung in Bologna im Jahr 393 Ambrosius ebenfalls beteiligt gewesen war, bei der Einrichtung der römischen Titelkirche zum Einsatz gekommen sein. Hippolyte Delehaye hat dies zum Anlass für die Vermutung genommen, dass die Reliquien der drei Heiligen nicht direkt aus Mailand, sondern über Ravenna nach Rom gelangt seien, da in S. Vitale in Ravenna der Namenspatron Vitalis gemeinsam mit Gervasius und Protasius verehrt wurde. ${ }^{43} \mathrm{Da}$ diese Verbindung zwischen diesen drei Heiligen in Ravenna jedoch vermutlich nicht vor dem 6 . Jh. hergestellt wurde, ${ }^{44}$ ist diese Annahme als unbegründet abzulehnen.

3. Titulus Clementis. Clemens wird in der Synodalliste von 499 als Heiliger bezeichnet; die Spuren eines Heiligenpatroziniums reichen jedoch weiter, bis in das 4. Jh., zurück. Bischof Zosimos (417-418) hielt 417 in einer sancti Clementis basilica eine Verhandlung gegen den pelagianischen Presbyter Caelestius ab, über deren Verlauf er in einem Synodalschreiben berichtete. Aus den Äußerungen des Zosimos geht eindeutig hervor, dass mit Clemens der Apostelschüler und dritte Bischof Roms gemeint war. ${ }^{45}$ Dass es sich bei dieser basilica Clementis um die römische Titelkirche handelte, erscheint unstrittig. Auf den titulus Clementis dürfte auch eine Bemerkung des Hieronymus zu beziehen sein, der Rom im Jahr 385 endgültig den Rücken kehrte und noch aus der Zeit seines römischen Aufenthalts Kenntnis von einer Kirche des Bischofs Cle-

mit zahlreichen Reliquien, darunter denen von Gervasius und Protasius, aus (Gaudent., serm. 17, 12). Gervasius und Protasius-Reliquien wurden ferner - auch hier in Verbindung mit den Reliquien anderer Heiliger - zur Weihung einer Basilika in Fundi verwendet, von der Paul. Nol., epist. 32, 17 berichtet. Bei diesen Translationen dürfte es sich, auch wo von reliquiae, cineres oder ossa die Rede ist, um Kontaktreliquien gehandelt haben: Wie eine lexikalische Studie zu Gregor I. (590604) zeigt, existierte kein eindeutiger Sprachgebrauch, der Körper- von Kontaktreliquien unterschieden hätte (vgl. McCulloh 1976; zu Paulinus v. Nola s. ebd., 181f.).

42 Vgl. die Zusammenstellung der Belege bei Geertman 1975, 150.

43 Delehaye 1929, 8-10; ders. 1930, 10.

44 Dafür, dass bereits der Vorgängerbau der 547 konsekrierten Kirche für Vitalis, Gervasius und Protasius den drei Heiligen gemeinsam geweiht gewesen ist, gibt es keinen Anhaltspunkt. Die Grundlage für das gemeinsame Patronat bildete eine Legende, die Vitalis zum Vater der beiden anderen Heiligen machte, und die vermutlich erst zu Beginn des 6. Jh. entstanden ist (vgl. Deichmann 1969-1989, Bd. II, 2, 7f.).

45 Coll. Avell., epist. 45, 2 (Brief des Zosimos). Die Verehrung des Bischofs Clemens in Rom ist auch durch den stadtrömischen Kalender des frühen 5. Jh., der in das Martyrologium Hieronymianum integriert wurde (s. u., Anm. 50), gesichert (vgl. Kirsch 1924, 89f.). Da in Rom kein Clemensgrab bekannt war und die passio Clementis den Tod des Clemens außerhalb Roms, auf der Chersonesos, lokalisierte (vgl. passio Clementis [Mombritius I, 344, 45-47]), muss der Eintrag in dem stadtrömischen Kalender mit dem Patrozinium der römischen Titelkirche in Verbindung stehen. 
mens in Rom gehabt haben muss. ${ }^{46}$ Spätestens seit den letzten beiden Jahrzehnten des 4. Jh. bestand demnach eine dem römischen Bischof Clemens geweihte Kirche in Rom, bei der es sich in ähnlicher Weise wie beim titulus Vestinae um eine Devotionsstiftung für einen Heiligen gehandelt haben muss. ${ }^{47}$

4. Titulus Gaii. Die in der Synodalliste von 499 als Titelkirche des Gaius bezeichnete Kirche erscheint erstmals in der Synodalliste von 595 als titulus $s$. Susannae. ${ }^{48}$ Auch hier dürfte eine Weihung des titulus an Susanna jedoch bereits um 400 vollzogen gewesen sein. Das Martyrologium Hieronymianum enthält zum 11. August einen Eintrag, wonach der natale sanctae Susannae in der Titelkirche gefeiert wurde. ${ }^{49}$ Die Plazierung des Eintrags am Beginn der kalendarischen Tagesnotiz weist darauf hin, dass diese Nachricht einem stadtrömischen Kalender entstammt, der kurz nach 422 verfasst wurde und eine der Quellen des Martyrologium Hieronymianum bildete. ${ }^{50}$ Ferner signalisiert die Wendung natale - ebenso wie die Lokalisierung, ,in der Nähe der Diocletiansthermen“ -, dass hier nicht einer Märtyrerin Susanna gedacht, sondern der Grün-

46 Hier., vir. ill. 15 (geschrieben 392): nominis eius (scil. des Bischofs Clemens) memoriam usque hodie Romae exstructa ecclesia custodit. Pietri 1976, Bd. 1, 471 bezweifelt, dass sich diese Notiz des Hieronymus auf den titulus Clementis bezieht, da er aus einer Weihinschrift (de Rossi 1870, 146-148) auf die Errichtung der Kirche erst unter Siricius (384-399) schließen möchte; die Inschrift ist jedoch so fragmentarisch, dass sie jegliche Baumaßnahme innerhalb des titulus dokumentieren könnte. Zu den unterschiedlichen Bauphasen von S. Clemente vgl. o., Anm. 10.

47 Anders Kirsch 1918, 39-41; Lietzmann 21927, 86; Delehaye 1936, 160; Amore 1975, 304, Saxer 2001 (a), 559, die annehmen, es handele sich beim Namensgeber des titulus um einen Stifter namens Clemens, der nachträglich dadurch ,kanonisiert" worden sei, dass man ihn mit dem römischen Bischof identifiziert habe. Auch wenn man mit Guidobaldi (s. o., Anm. 10) davon ausgeht, dass der Vorgängerbau der Basilika von S. Clemente bereits im Laufe des 4. Jh. in eine Kirche umgewandelt wurde, erscheint es ausgeschlossen, dass in der kurzen Zeit zwischen der Errichtung der Kirche und dem Zeugnis des Hieronymus das Gedächtnis an einen Stifter Clemens sich mit dem des gleichnamigen römischen Bischofs verbunden haben könnte.

48 Die Identität der beiden Titelkirchen ist durch die passio Susannae gesichert. Der Verfasser der passio unterscheidet zwar zwischen zwei benachbarten domus, einem Wohnhaus des Gaius und einem Wohnhaus der Susanna. Diese Trennung ist jedoch offensichtlich durch das Toponym ad duas domos inspiriert, das den Teil der Alta Semita, an dem die Titelkirche lag, bezeichnete; von einer Existenz unterschiedlicher Gebäude ist daher nicht auszugehen (vgl. Kirsch 1918, 71 u. 153).

49 MH 11. 8.: ad duas domos iuxta duo clecinas natale sanctae Susannae (iuxta duo clecinas verderbt aus iuxta Diocletianas, vgl. Delehaye [1931], in: Comm. MH, 435). Die Titelkirche der Susanna befand sich an der Alta Semita, in der Nähe der Diocletiansthermen.

50 Zu diesem stadtrömischen Kalender und seinem Verhältnis zum Martyrologium Hieronymianum vgl. u., S. 456, Anm. 186. Zur Provenienz der Susanna-Notiz aus diesem Kalender vgl. Kirsch 1918, 71f. Kirsch hat später seine Meinung revidiert und die Notiz als eine nachträgliche Eintragung betrachtet (ders. 1924, 74f.); diese Zurückhaltung ist jedoch nicht nachvollziehbar, da der Eintrag formal die Kriterien erfüllt, die auch alle anderen aus dem stadtrömischen Kalender von 422 stammenden Notizen aufweisen. Kirschs Argument (ebd., 52), der stadtrömische Kalender habe grundsätzlich nur Märtyrergedenktage, keine Gründungstage von Titelkirchen enthalten, ist demgegenüber wenig überzeugend (vgl. die folgende Anm.). 
dungstag des titulus kommemoriert wurde. ${ }^{51}$ Der titulus Gaii muss demnach, obwohl dies in der Unterschriftenliste von 499 nicht zum Ausdruck kommt, spätestens seit dem beginnenden 5. Jh. über ein Patrozinium der Heiligen Susanna verfügt haben.

Es kann als sicher gelten, dass es sich bei dieser Susanna um keine römische Heilige handelt. Zwar ist in der passio Susannae davon die Rede, dass Susanna nach ihrem in der Titelkirche erlittenen Martyrium in einem Coemeterium an der via Nomentana oder an der via Salaria beigesetzt wurde. ${ }^{52}$ Man hat dies verschiedentlich dahingehend gedeutet, dass der Kult dieser Märtyrerin Susanna aus dem Coemeterium in die städtische Titelkirche verlagert worden sei ${ }^{53}$ oder aber den Anlass dazu gegeben hätte, eine Susanna, die in der Titelkirche bestattet gewesen sei, mit dieser gleichnamigen Märtyrerin zu identifizieren. ${ }^{54}$ Es existieren für ein derartiges Susannagrab jedoch weder in den Coemeterien an der via Salaria und Nomentana ${ }^{55}$ noch in der Titelkirche ${ }^{56}$ schlagkräftige Hinweise. Auch die Vermutung, dass es sich bei der heiligen Susanna um eine Titelgründerin handele, die nachträglich sanktifiziert worden sei, kann nicht überzeugen: Zum einen hätte diese Erhebung in den Rang einer Heiligen zu einem außergewöhnlich frühen Zeitpunkt - bereits zu Beginn des 5. Jh. - erfolgen müssen, zum anderen ist der Name Susanna in Rom

$51 \quad$ Üblicherweise enthält ein Kalendereintrag im Martyrologium Hieronymianum bei Heiligengedenktagen in Coemeterien nur den Namen der Heiligen im Genitiv; der Zusatz natale verdeutlicht, dass es sich im Fall von Susanna nicht um einen Märtyrergedenktag, sondern um den Dedikationstag einer nach ihr benannten Kirche handelt (für natalis ecclesiae in dieser Bedeutung vgl. z. B. Leo I., serm. 84 bis, 1). Dieser Sprachgebrauch von natale für den Jahrestag einer Titelkirchengründung begegnet auch an anderen Stellen des Martyrologium Hieronymianum (vgl. u. natale quattuor coronatorum [s. u., S. 345f.]; natale Chrysogoni [s. u., Anm. 79]). Der stadtrömische Kalender aus der Zeit unmittelbar nach 422 enthielt mehrere Beispiele für derartige Gründungstage römischer Titelkirchen; vgl. den 14. April (titulus Cyriaci; s. Kirsch 1924, 51f.), den 14. August (titulus Eusebii; s. Kirsch 1924, 171f.) und den 17. November (titulus Caeciliae; s. u., Anm. 95).

52 Die passio Susannae lokalisiert das Grab in coemeterio Alexandri, in arenario, in crypta, iuxta sanctum Alexandrum, iuxta civitatem Figlinas (passio Susannae 6). Kirsch 1918, 72; Amore 1964, 39-42 beziehen dies auf ein Coemeterium an der via Nomentana; Duchesne (1886), in: LP I, 197, Anm. 82 auf das coemeterium Iordanorum an der via Salaria.

53 Kirsch 1918, 72f.

54 Franchi de' Cavalieri 1928; ähnlich Amore 1964, 42, der ebenfalls von einer im titulus bestatteten Susanna, die dann als Heilige verehrt wurde, ausgeht.

55 Die Pilgeritinerare des 7. Jh. kennen kein Susannagrab an der via Salaria oder an der via Nomentana.

56 Ein nur aus einer frühneuzeitlichen Beschreibung Antonio Bosios überliefertes Epitaph aus der Confessio von S. Susanna (olim presbyteri Gabini filia felix bic Susanna iacet in pace patri sociata) ist offenkundig bereits von der Legendenbildung, wie sie die passio Susannae widerspiegelt, beeinflusst (so auch Delehaye [1931], in: Comm. MH, 435). Hinzu kommt, dass die von Bosio überlieferte Inschrift nicht aus der spätantiken Titelkirche stammt, sondern aus der unter Leo III. (795-816) neu errichteten Kirche, deren Verhältnis zum Vorgängerbau noch nicht abschließend geklärt ist (s. dazu o., Anm. 10). 
kaum nachweisbar ${ }^{57}$ und die Vermutung, hinter der Namenspatronin des titulus könne sich eine römische Stifterin verbergen, demnach alles andere als wahrscheinlich. Man muss vielmehr davon ausgehen, dass die zu Beginn des 5. Jh. belegte Verehrung einer heiligen Susanna im titulus Gaii auf eine Heilige nichtrömischen Ursprungs zurückgeht, möglicherweise auf eine der beiden in der Bibel erwähnten Trägerinnen dieses Namens. ${ }^{58}$ Woher der Kult nach Rom gelangte, lässt sich nicht sagen, auch wenn gewisse Indizien auf den oberitalischen und adriatischen Raum als Herkunftsgebiet hindeuten. ${ }^{59}$

5. Titulus Aemilianae/ss. Quattuor Coronatorum. Eine Titelkirche der „Vier Gekrönten" erscheint erstmals in der Unterschriftenliste der Synode von 595; dass sie mit dem titulus Aemilianae der Liste von 499 identisch ist, lässt sich anhand späterer Zeugnisse aus der Zeit Leos III. (795-816) sicher erhärten. ${ }^{60}$ Auch hier liefert die kalendarische Überlieferung des Martyrologium Hieronymianum einen deutlichen Hinweis darauf, dass die Titelkirche schon im frühen 5. Jh. über ein Heiligenpatrozinium verfügte. Die mit dem Namen der „Vier Gekrönten“ bezeichneten Heiligen, Simpronianus, Claudius, Nicostratus und Castorius, erscheinen am 8. November mit dem Hinweis, dass ihr natale am

$57 \quad$ In der „Prosopographie chrétienne du Bas-Empire“ taucht für Italien nur eine einzige Susanna auf, die bezeichnenderweise syrischen Ursprungs ist (C. Pietri/L. Pietri 1999, 2140). Die prosopographische Übersicht von Llewellyn 1981, 368 zeigt, dass hebräische Namen unter dem römischen Klerus keinen sonderlich großen Anklang fanden (die wenigen Beispiele stammen beinahe alle aus der Zeit nach 650).

58 An eine biblische Heilige (Susanna des Alten Testaments oder aus Lukas 8, 3) denken auch Duchesne 1916-1917, 40; Lanzoni 1925, 232.

59 Bei Claudian, carm. 50, 1-6 (nicht in allen Hss. vorhandene und daher häufig der Interpolation verdächtigte Verse; vom letzten Herausgeber, Hall, jedoch nicht athetiert) wird eine sancta Susanna im Kontext weiterer Heiliger (Petrus und Paulus, Bartholomäus, Jakobus, Thomas, Thekla) erwähnt, von denen - abgesehen von den beiden Apostelfürsten - keiner römischen Ursprungs ist. Thomas wurde zusammen mit weiteren Apostelreliquien unter Bischof Ambrosius nach Oberitalien und Mailand überführt (s. u., Anm. 131); auch die Hl. Thekla lässt sich seit etwa dieser Zeit in Mailand nachweisen (Delehaye ${ }^{21933,339) . ~ B a r t h o l o m a ̈ u s ~ u n d ~}$ Jakobus sind erst für das 6. Jh. in Ravenna bezeugt; zum dortigen Bartholomäuskloster und den Jakobusreliquien, die Aufnahme in die Ravennater Stephanuskirche (550 geweiht) fanden, vgl. Deichmann 1969-1989, Bd. I, 28; I, 31 u. II, 2, 373. Susanna selbst begegnet auf dem unteren Rand des Triumphbogens der Euphrasiusbasilika von Parentium/Porec in Dalmatien (Mitte des 5. Jh.). Die zwölf dort abgebildeten Märtyrerinnen bilden zwei Sechsergruppen, von denen die eine aus Märtyrerinnen römischer Provenienz bzw. in Rom verehrten Heiligen besteht (Agatha seit Symmachus [498-514] auch in Rom „beheimatet“ -, Agnes, Caecilia, Eugenia, Basilissa [= Basilla], Felicitas), während in der anderen Sechsergruppe, in der sich Susanna befindet, mit Thekla (s. o.) und Euphemia (s. u., Anm. 131) zwei Heilige erscheinen, die nachweislich im oberitalischen Raum Verbreitung fanden (Euphemia, Thekla, Valeria, Perpetua, Susanna, Iustina).

60 Vgl. Kirsch 1918, 9f.; Geertman 1975, bes. 106-111, 150-152. 
Caelius gefeiert worden sei. ${ }^{61}$ Die Plazierung der Angabe am Beginn der Tagesnotiz des 8 . November legt nahe, dass diese Nachricht bereits in dem stadtrömischen Kalender aus dem frühen 5. Jh. stand, der in das Martyrologium Hieronymianum eingegangen ist. Die Ortsangabe (kein Coemeterium, sondern der Caelius) und der Zusatz natale machen deutlich, dass die Titelkirche der „Vier Gekrönten“ gemeint sein muss, die sich auf dem Caelius erhob.

Die naheliegende Schlussfolgerung, dass man in Rom am 8. November ein Gedenken dieser Heiligen ausschließlich in der Titelkirche auf dem Caelius feierte, wird jedoch dadurch erschwert, dass die depositio martyrum im Chronographen von 354 die Verehrung von drei der vier Heiligen am 9. November mit einem als in comitatum bezeichneten Ort in Verbindung bringt. ${ }^{62}$ Da die Pilgeritinerare des 7. Jh. eine Verehrung der Quattuor Coronati im Coemeterium ad duas lauros an der via Labicana bezeugen, ${ }^{63}$ hat man das Toponym in comitatum auf dieses Coemeterium bezogen und mit dem dortigen Friedhof der equites singulares gleichgesetzt. ${ }^{64}$ Diese disparate Ausgangssituation hat zu langen Debatten geführt, wo in Rom - in der Titelkirche auf dem Caelius oder im Coemeterium an der via Labicana - sich die ursprüngliche Kultstätte der vier Heiligen befunden habe. ${ }^{65}$

Aufschluss in der Frage, ob die „Vier Gekrönten“ in Rom ursprünglich in der Titelkirche auf dem Caelius oder an der via Labicana verehrt wurden, liefert die passio IV Coronatorum, der von der Forschung aus textimmanenten Gründen ein hohes Alter (4. Jh.) zugebilligt wird. ${ }^{66}$ In der passio erscheinen

61 VI id. nov. Romae ad Celio monte Sinproniani, Claudii, Castoris Nicostrati (cod. Bernensis). Für die unterschiedlichen Varianten der Handschriften des Martyrologium Hieronymianum vgl. Kirsch 1924, 34, der deutlich macht, dass die Notiz im stadtrömischen Kalender des frühen 5. Jh. gestanden hat.

62 MGH AA IX, 72: V idus Nov. Clementis, Semproniani, Claui, Nicostrati in comitatum.

63 Notitia ecclesiarum (Codice topografico II [Valentini/Zucchetti 1942], 83): in uno loco in interiore spelunca XL martires et in altero XXX martires et in tercio IIII coronatos et sancta Helena in sua rotonda. De locis sanctis (ebd., 113): Petrus, Marcellinus, Tiburtius, sancti XXX milites, Gorgonius, Genuinus, Maximus, IIII coronati, id est Claudius, Nicostratus, Simpronianus, Castorius, Simplicius.

64 Für ältere Versuche, die Angabe in comitatum auf das Coemeterium ad duas lauros zu beziehen, vgl. das Referat von Delehaye (1910), in: AASS Nov. III, 753f., der dieser Lokalisierung seinerseits skeptisch gegenübersteht. Zuletzt hat Seeliger 1987, 64f., das Toponym in comitatum aus der Bezeichnung für das spätantike Bewegungsheer abgeleitet und mit dem Friedhof der equites singulares identifiziert, der an der via Labicana im Bereich des Coemeteriums ad duas lauros lag. Die equites singulares waren jedoch als fest in Rom stationierte Truppe kein Teil des kaiserlichen comitatus; außerdem erscheint in der depositio martyrum bei Gorgonius, einem anderen Märtyrer, der ebenfalls im Coemeterium ad duas lauros bestattet lag und bei dem in gleicher Weise das Toponym in comitatum zu erwarten wäre, nur die Angabe der Straße (vgl. MGH AA IX, 72: V idus sept. Gorgoni in Lavicana).

65 Vgl. zuletzt Guyon 1975 und Seeliger 1987, 61-67, die die ältereren Forschungspositionen zusammenfassend referieren.

66 Zur Datierung der passio IV Coronatorum ins 4. Jh. vgl. Delehaye [1910], in: AASS Nov. III, 759f., dens. 1913, 67-69; zuletzt Berschin 1986, 66-74. Skeptisch hingegen Amore 1965, 209-219. 
Simpronianus (Symphorianus), Claudius, Nicostratus und Castorius zusammen mit einem fünften Märtyrer, Simplicianus, nicht als römische, sondern als pannonische Heilige, die in den kaiserlichen Steinbrüchen in Pannonien das Martyrium erleiden. Erst ein später hinzugefügtes Schlusskapitel versuchte, eine Verbindung zwischen dem pannonischen Martyrium und dem römischen Schauplatz der Verehrung dieser Heiligen herzustellen: Diocletian reist aus dem pannonischen Sirmium nach Rom und lässt dort vier namenlose cornicularii, die das Götteropfer verweigern, hinrichten. Diese vier Märtyrer werden an der via Labicana bestattet und später, da man sich ihrer Namen nicht mehr erinnert, unter dem Namen der pannonischen Märtyrer Claudius, Nicostratus, Simpronianus und Castorius verehrt, die am selben Tag wie die cornicularii das Martyrium erlitten haben. ${ }^{67}$

Daran, dass es sich bei Simpronianus, Claudius, Nicostratus und Castorius ursprünglich um nichtrömische, pannonische Heilige handelte, ist in Anbetracht der passio nicht zu zweifeln. Wann erstmals eine Verbindung der „Vier Gekrönten“ mit der via Labicana über das abschließende Kapitel der passio IV Coronatorum hergestellt wurde, ist zwar nicht sicher. ${ }^{68}$ Sie dürfte jedoch frühestens nach dem 5. Jh. entstanden sein, da die passio Sebastiani, die in die Mitte des 5. Jh. zu datieren ist, ${ }^{69}$ eine andere und vermutlich ursprünglichere Namensgebung der fünf „Vier Gekrönten“ bietet als die passio IV Coronatorum in ihrer überlieferten Form. ${ }^{70}$ In keinem Fall besteht ein Anlass, die Angabe der depositio martyrum aus dem 4. Jh. - in comitatum - auf das Coemeterium ad duas lauros an der via Labicana zu beziehen: Das Toponym in comitatum ist für Rom sonst nicht nachweisbar, und da in der depositio auch nichtrömische Heilige erscheinen, gibt es kein Grund dafür, diese Angabe mit dem Coemeterium ad duas lauros in Verbindung zu bringen, wo die Heiligen später verehrt wurden. ${ }^{71}$

67 Passio IV Coronatorum 22. In der älteren der beiden Redaktionen, in denen die passio IV Coronatorum überliefert ist, bleiben die römischen cornicularii anonym; die jüngere Fassung gibt ihre Namen mit Severus, Severianus, Carpoforus und Victorinus an (vgl. Delehaye [1910], in: AASS Nov. III, 750).

68 Guyon 1975, 516f. weist darauf hin, dass die passio IV Coronatorum und das Pilgeritinerar de locis sanctis des frühen 7. Jh. bezüglich der Namen der - in Wirklichkeit fünf - „Vier Gekrönten“ übereinstimmen (Claudius, Nicostratus, Simpronianus, Castorius, Simplicius).

69 Morin 1913, 347, Anm. 1 macht stilistische Berührungspunkte zwischen der passio Sebastiani und Arnobius d. J. (gest. nach 455) geltend; es besteht allerdings kein Anlass, die passio Sebastiani mit der Gründung eines Klosters bei S. Sebastiano durch Sixtus III. (432-440) in Verbindung zu bringen (s. o., S. 259, Anm. 155).

70 In der passio Sebastiani erscheinen die fünf Märtyrer unter den Namen Symphorianus, Claudius, Nicostratus, Castorius und Victorinus. Die passio IV Coronatorum hat Simpronianus anstelle von Symphorianus und Simplicius anstelle von Victorinus und entspricht darin den Pilgeritineraren des frühen 7. Jh. (vgl. o., Anm. 68); sie dürfte daher jüngeren Datums sein als die passio Sebastiani.

$71 \mathrm{Zu}$ den Einwänden gegen eine Gleichsetzung von in comitatum mit dem Coemeterium ad duas lauros s. o., Anm. 64. Der einzige Hinweis auf eine Verehrung der IV Coronati im Coemeterium 
Die via Labicana ist demnach erst vergleichsweise spät - durch die römische Redaktion der passio IV Coronatorum und die Pilgeritinerare des frühen 7. Jh. - als Verehrungsort der „Vier Gekrönten“ bezeugt. Dem steht die Notiz des Martyrologium Hieronymianum gegenüber, die bereits für das beginnende 5 . Jh. auf eine Verehrung der Heiligen in der Titelkirche auf dem Caelius verweist. ${ }^{72}$ Dort wurden sicherlich, ähnlich wie in den oben vorgestellten Fällen, Reliquien der Heiligen rekondiert, ohne dass man deswegen von einer Lokalisierung ihrer Gräber im titulus ausgegangen wäre. Dazu passt auch, dass die passio Sebastiani, in der die „Vier Gekrönten“ unter den Namen Symphorianus, Claudius, Nicostratus, Castorius und Victorinus das Martyrium erleiden, ${ }^{73}$ für diese Märtyrer keinen Bestattungsort angibt: Dem Verfasser der um die Mitte des 5. Jh. geschriebenen passio Sebastiani war die Verehrung der „Vier Gekrönten“ in Rom bekannt, er verband sie jedoch offenbar nicht mit einer Grablege in einem der Coemeterien Roms. Hinzu kommt, dass die Überführung eines pannonischen Heiligenkultes in die unterirdische Grabkammer eines suburbanen Coemeteriums wenig wahrscheinlich erscheint, während eine Übertragung von Reliquien in städtische Titelkirchen für das frühe 5. Jh. mehrfach belegt ist. Auch die pannonischen Heiligen müssen demnach durch eine Reliquientranslation in den titulus Aemilianae Eingang nach Rom gefunden haben. Erst seit dem 6. Jh., als das Interesse der Rompilger an den Heiligengräbern vor den Toren der Stadt immer intensivere Formen annahm, suchte man auch für die Heiligen der Titelkirche auf dem Caelius eine Grablege und fand sie im Coemeterium an der via Labicana demselben Coemeterium, in dem auch Petrus und Marcellinus bestattet lagen, deren Titelkirche sich nur einen Steinwurf entfernt vom titulus IV Coronatorum auf dem Caelius befand. ${ }^{74}$

an der via Labicana ist ein Graffito, in dem ein Hl. Clemens angerufen wird, und das man auf denjenigen Clemens, der in der depositio martyrum zusammen mit drei der Vier Gekrönten genannt wird, beziehen könnte (ICUR VI, 15938a und Guyon 1987, 130-132).

72 So auch Delehaye, der sich zunächst kritisch gegen eine Verehrungsstätte der IV Coronati innerhalb der Stadt gestellt hatte (vgl. Delehaye [1910], in: AASS Nov. III, 754; dens. 1913, 64f.), seine Meinung jedoch später revidierte und ebenfalls von einer Kommemoration in der Titelkirche bereits im frühen 5. Jh. ausging (ders., 1936, 68f.).

73 Passio Sebastiani 76.

74 Die entgegengesetzte Position (seit dem frühen 4. Jh. Lokalisierung des Kultes im Coemeterium an der via Labicana; im 6. Jh. Übertragung auf den städtischen titulus) bezieht Guyon 1975. Auch Kirsch 1918, 35, ders., 1924, 34-38, geht davon aus, dass zunächst ein Kult der IV Coronati an der via Labicana bestanden habe und dieser dann im frühen 5. Jh. von dort auf die Titelkirche übertragen worden sei. Kirsch setzt dabei jedoch voraus, dass die Vier Gekrönten keine pannonischen, sondern römische Märtyrer gewesen seien - eine mit Blick auf die passio IV Coronatorum kaum aufrechtzuerhaltende Annahme. Folgt man hingegen der Auffassung, dass die IV Coronati ursprünglich pannonische Heilige waren, deren Kult nach Rom übertragen wurde, lässt sich, wie oben ausgeführt, nicht davon ausgehen, dass eine derartige Übertragung in ein Coemeterium und nicht in eine Titelkirche erfolgte. 
6. Titulus Chrysogoni. Die Titelkirche des Chrysogonus ist eines der Beispiele, bei denen aufgrund der Divergenz zwischen den Unterschriftenlisten der beiden römischen Synoden von 499 und 595 traditionell angenommen wird, Chrysogonus sei ursprünglich der Gründer des titulus gewesen und erst später, seit der Wende vom 5. zum 6. Jh., durch die Hinzufügung des sanctus-Attributes zu einem Heiligen geworden, wobei die Identifizierung des Titelgründers Chrysogonus mit einem gleichnamigen Märtyrer aus Aquileia diesen Prozess der Sanktifizierung erleichtert habe. ${ }^{75}$ Es ist sicher unstrittig, dass Chrysogonus ursprünglich kein römischer Heiliger war, sondern aus Aquileia nach Rom gelangte. ${ }^{76}$ Die passio Anastasiae, in der die römischen Titelheiligen Chrysogonus und Anastasia als die beiden wesentlichen Protagonisten in Erscheinung treten, trug diesem Umstand dadurch Rechnung, dass sie Chrysogonus und Anastasia zwar in Aquileia bzw. Sirmium das Martyrium erleiden ließ, jedoch die römische Herkunft dieser beiden Heiligen betonte und auf diese Weise den Umstand, dass es sich bei Chrysogonus und Anastasia um nichtrömische Heilige handelte, damit in Einklang zu bringen versuchte, dass in Rom zwei Titelkirchen nach ihnen benannt waren. Aus der Provenienz des Chrysogonuskultes aus Aquileia folgt jedoch nicht, dass die römische Titelkirche ihren Namen ursprünglich einem Gründer verdankte, der dann nachträglich aufgrund der Namensgleichheit mit dem Heiligen aus Aquileia identifiziert wurde. Wesentlich unkomplizierter ist die Annahme, dass es nie einen Titelgründer namens Chrysogonus gegeben hat, und dass die Benennung des römischen titulus Chrysogoni von vornherein auf eine Kultübertragung aus Aquileia zurückzuführen ist. ${ }^{77}$ Auf die Tatsache, dass eine fehlende ausdrückliche Bezeichnung als sanctus in der Unterschriftenliste von 499 kein aussagekräftiger Hinweis darauf ist, dass der Namensgeber des titulus nicht als Heiliger galt, wurde bereits hingewiesen. Für Chrysogonus lässt sich aber auch umgekehrt der positive Nachweis erbringen, dass er schon im Jahr 499 den Rang eines Heiligen einnahm, da bereits für das Jahr 472 von der Kirche eines Märtyrers Chrysogonus in Rom die Rede ist. ${ }^{78}$

Für die Frage nach der Genese dieses römischen titulus s. Chrysogoni liefert die kalendarische Überlieferung den entscheidenden Anhaltspunkt. Die beiden autoritativen Handschriftentraditionen des Martyrologium Hieronymianum überliefern zum 24. November in Aquileia civitate sancti Crisogoni bzw. Romae

$75 \quad$ Kirsch 1924, 182f.; Delehaye 1936, 158-162; Kennedy 21963, 137; Cuscito 1987, 268f., ders. 1992, 78f.; Saxer 2001 (a), 559.

76 Zu den Hinweisen auf die Herkunft des Chrysogonuskultes aus Aquileia s. u., Anm. 83.

77 Als Möglichkeit bereits angedeutet von Kirsch 1918, 108-111, der jedoch zu sehr seiner Grundthese, die Titelkirchen seien nach Stiftern aus vorkonstantinischer Zeit benannt gewesen, verpflichtet blieb. Für eine Übernahme des Chrysogonuskultes aus Aquileia nach Rom sprechen sich Pietri 1978, 14-16 und Cecchelli 1999, 236f. (Übertragung von Chrysogonusreliquien aus Aquileia nach Rom unter Innozenz I. [401-417]) aus.

78 Joh. Ant., fr. 301 (Roberto). 
natale Crisogoni. ${ }^{79}$ Die letztere Lesart ist durch die bessere der beiden Traditionen bezeugt und verdient daher den Vorzug. ${ }^{80}$ Das bedeutet zugleich, dass eine Notiz über die Gründung der Titelkirche (natale ${ }^{81}$ ) des Chrysogonus in dem stadtrömischen Kalender aus der Zeit Bonifatius' I. (418-422) gestanden haben muss und von dort in das Martyrologium Hieronymianum gelangt ist. ${ }^{82}$ Die Lokalisierung eines Chrysogonuskultes in Aquileia, wie sie die zweite Handschriftengruppe des Martyrologium Hieronymianum am 24. November vornimmt, ist deswegen jedoch sachlich nicht weniger stichhaltig: Archäologische, epigraphische und kalendarische Hinweise machen deutlich, dass Chrysogonus ein Heiliger aus Aquileia war, der dort bereits um die Mitte des 4. Jh. verehrt $^{83}$ und dessen Fest am 24. November begangen wurde. ${ }^{84}$ Wenn im Martyrologium Hieronymianum unter dem 24. November ursprünglich Rom und die dortige Feier des titulus Chrysogoni eingetragen war, bedeutet dies nur, dass der Verfasser des Martyrologium Hieronymianum für seine Tagesnotiz den stadtrömischen Kalender zugrunde gelegt hat, den er auch sonst ausgiebig ver-

\footnotetext{
$79 \quad$ Vgl. Kirsch 1924, 182.

80 Delehaye (1931), in: Comm. MH, 619.

81 Vgl. o., Anm. 51.

82 Inkonsequent Kirsch 1924, 4f. u. 183, der gegen den besseren Textzeugen aus rein inhaltlichen Erwägungen die Lesart in Aquileia vorzieht. Chrysogonus erscheint ferner unter denjenigen Heiligen, die bereits früh Einzug in das Communicantes des römischen Messkanons gehalten haben: Vermutlich wurde Chrysogonus zusammen mit Clemens einer älteren Schicht, die aus Sixtus II., Laurentius, Hippolytus (?), Cornelius und Cyprian von Karthago bestand, hinzugefügt (vgl. Lietzmann 21927, 83-93). Lietzmann 21927, 91f. geht davon aus, dass Chrysogonus und Clemens erst kurz vor 500 in den canon missae Einzug hielten, da er die Synodalliste von 499 als frühesten Hinweis auf die Existenz eines Chrysogonuskultes in Rom auffasst; Kennedy ${ }^{2} 1963$, 121-125; 136-138 veranschlagt einen noch späteren Zeitpunkt (Clemens unter Johannes II. [533535], Chrysogonus nicht lange vor der Mitte des 6. Jh.). Wie die vorigen Ausführungen zur kalendarischen Kommemoration des Chrysogonus in Rom und die Bemerkungen zum titulus Clementis deutlich gemacht haben, ist diese Schlussfolgerung jedoch keinesfalls zwingend: Clemens wurde nachweislich seit dem Beginn des 5. Jh. in Rom als Heiliger verehrt (vgl. o., Anm. 45), und nach dem Ausweis des stadtrömischen Kalenders von 422 ist dasselbe auch für Chrysogonus vorauszusetzen. Es spricht demnach nichts gegen die Annahme, dass Clemens und Chrysogonus bereits im frühen 5. Jh. gemeinsam in den römischen Messkanon aufgenommen
} wurden.

83 In San Canzian d'Isonzo, wenige km nordöstlich von Aquileia gelegen, befindet sich innerhalb einer Nekropole eine spätantike Memoria, die als Kultstätte der Märtyrer Protus und Chrysogonus anzusehen ist: Zwei spätantike Sarkophage, die heute in der benachbarten Kapelle S. Proto aufbewahrt werden, und einige in situ gefundene Inschriftenfragmente weisen auf eine Verbreitung des Kultes spätestens seit der Mitte des 4. Jh. hin (vgl. Cuscito 1987, 255f.; dens. 1992, 65-67). Vgl. auch die Tagesnotiz zum 31. Mai im Martyrologium Hieronymianum wo Chrysogonus zusammen mit einer Gruppe von Märtyrern aus Aquileia erscheint.

84 Der 24. November erscheint auch im Kalender von Karthago als Feiertag eines Heiligen Chrysogonus. Dieser Eintrag orientierte sich sicher nicht am Fest für einen römischen Titelkirchengründer, vielmehr gehen sowohl der karthagische als auch der römische Eintrag auf einen Heiligengedenktag - den des Chrysogonus in Aquileia - zurück (zurecht hervorgehoben von Pietri 1978, 14). 
wendete. Dies schließt jedoch nicht aus, dass auch in Aquileia am selben Tag das Gedenken dieses Heiligen gefeiert und diese Angabe zu einem späteren Zeitpunkt in das Martyrologium Hieronymianum nachgetragen wurde. ${ }^{85}$ Die Tatsache, dass Chrysogonus in Aquileia am selben Tag kommemoriert wurde wie in Rom, ist ein weiteres Indiz dafür, dass der Kult zusammen mit dem Tagesdatum aus Aquileia nach Rom übertragen wurde: Die Identifizierung eines römischen Titelgründers Chrysogonus mit dem gleichnamigen Märtyrer aus Aquileia hätte keine Angleichung des römischen Kommemorationstages an den Kalender von Aquileia zur Folge gehabt; vielmehr wäre das Fest des nunmehr „heiligen“ Chrysogonus an demselben Tag gefeiert worden, an dem man auch bis dahin des Titelgründers gedacht hatte. ${ }^{86}$

Daraus ergibt sich folgendes Ergebnis: Chrysogonus war ein Heiliger aus Aquileia, dessen Feiertag auf den 24. November fiel. Am selben Tag wurde in Rom bereits zu Beginn des 5. Jh. der Gründungstag (natale) der Titelkirche des Hl. Chrysogonus gefeiert. Bei diesem römischen Chrysogonus handelte es sich nicht um einen Titelgründer, der im Laufe des 6. Jh. zu einem Heiligen erhoben wurde. Der titulus Chrysogoni verdankt seine Entstehung vielmehr einer - vermutlich durch Reliquien erfolgten - Übertragung eines Heiligenkultes aus Aquileia nach Rom, die vermutlich im frühen 5. Jh. erfolgte.

7. Titulus Anastasiae. Ähnlich wie bei Chrysogonus wird auch für Anastasia vermutet, sie sei ursprünglich eine römische Titelgründerin gewesen, die später mit einer auswärtigen Heiligen, Anastasia aus Sirmium, identifiziert und dadurch zur Heiligen gemacht worden sei. Auch bezüglich des Zeitraums, in dem diese Sanktifizierung erfolgt sein soll, besteht in der Forschung Einigkeit: Da Anastasia in der Unterschriftenliste von 499 noch ohne ein Heiligenattribut erscheint, wird allgemein vorausgesetzt, die Titelgründerin Anastasia sei im Laufe des 6. Jh. mit der namensgleichen Heiligen aus Sirmium gleichgesetzt worden. ${ }^{87}$ Gegen diese Rekonstruktion lassen sich dieselben Einwände

85 Anders Delehaye (1931), in: Comm. MH, 619, dens. 1936, 160 (übernommen von Cuscito 1992, 71), der für den Eintrag in Aquileia ausschließlich den legendarischen Einfluss der passio Anastasiae verantwortlich macht, in der Chrysogonus am 24. November in Aquileia das Martyrium erleidet und beigesetzt wird (passio Anastasiae 8f.). Der Eintrag in Aquileia in einer Handschriftengruppe des Martyrologium Hieronymianum muss jedoch auf einer genuinen Lokaltradition zum 24. November beruhen, die später in das Martyrologium Hieronymianum aufgenommen wurde.

86 Delehayes Umkehrschluss, das Datum des 24. November sei der Feiertag des römischen Titelgründers gewesen und habe die kalendarische Überlieferung zum Kommemorationstag des Chrysogonus in Aquileia beeinflusst, ist nicht akzeptabel (vgl. die vorige Anm.).

87 Vgl. u. a. Duchesne 1887, 389; Kirsch 1918, 18-23; dens. 1924, 44; Delehaye 1936, 158-163; Kennedy 21963, 188-191; zuletzt Saxer 2001 (a), 559; Lizzi Testa 2004, 254-256. Einzig Grisar 1896 ist der - unplausiblen - Ansicht, dass die Titelkirche ursprünglich nicht nach einer Person namens Anastasia benannt war, sondern in Anlehnung an die konstantinische Auferstehungskirche im Heiligen Land als Anastasiskirche gegründet wurde; auch er geht im 
geltend machen wie im Fall von Chrysogonus: Eine direkte Kultübernahme aus Sirmium nach Rom ist die wesentlich unkompliziertere Hypothese, um zu erklären, warum Anastasia in Rom (wo man bei der Kommemoration einer Titelgründerin eine eigenständige kalendarische Tradition voraussetzen müsste) am selben Tag (25. Dezember) verehrt wurde, wie die Heilige in Sirmium. Ferner kann auch bei Anastasia die Tatsache, dass sie in der Unterschriftenliste von 499 nicht ausdrücklich als sancta bezeichnet wird, nicht als Beleg dafür dienen, dass mit dem Namen zu dieser Zeit noch die Erinnerung an eine Titelstifterin verbunden gewesen sei: Eine Predigt Leos I. (440-461), die vermutlich im Jahr 457 in der basilica sanctae (!) Anastasiae gehalten wurde, ${ }^{8}$ zeigt vielmehr, dass man die Namensgeberin des titulus bereits in der ersten Hälfte des 5. Jh. als eine Heilige ansah.

Damit stellt sich die Frage, wann die Anastasiaverehrung, vermutlich vermittelt über eine Reliquientranslation, ihren Weg von Sirmium in die römische Titelkirche gefunden hat. Die Geschichte der Titelkirche am Palatin reicht bis mindestens in die Zeit des Bischofs Damasus (366-384) zurück, der die Apsis des Baus mit Fresken ausstattete. ${ }^{89} \mathrm{Ob}$ sie bereits seit der Zeit ihrer Gründung über ein Patrozinium der Heiligen aus Sirmium verfügte, soll an anderer Stelle ausführlicher diskutiert werden. ${ }^{90}$ Für den hier interessierenden Zusammenhang bleibt festzuhalten, dass die Predigt Leos I. nicht nur einen sicheren terminus ante liefert, der die Verehrung einer Heiligen Anastasia seit der Mitte des 5. Jh. bezeugt. Es wird damit zugleich auch die üblicherweise vertretene These hinfällig, wonach die Translation der Anastasiareliquien von Sirmium nach Konstantinopel unter dem Patriarchen Gennadius (458-471) den Anlass für eine Popularisierung des Anastasiakultes gegeben und damit der Identifizierung der römischen Titelgründerin mit der Heiligen aus Sirmium Vorschub geleistet habe: ${ }^{91}$ Die Übertragung des Kultes aus Sirmium nach Rom muss bereits früher und auf anderen Wegen erfolgt sein. Bemerkenswert ist, dass Anastasia in ihrer passio als eine Schülerin des Chrysogonus erscheint und die Legenden der beiden Heiligen in eine zyklische, mehrere

übrigen - wie die sonstige Forschung - davon aus, dass Anastasia von Sirmium erst später mit der Titelkirche in Verbindung gebracht wurde, was im 6. Jh. zu ihrer Umbenennung in titulus sanctae Anastasiae geführt habe.

88 Leo I., serm. 96, vermutlich vom 25. Dezember des Jahres 457. Zur sicher bezeugten Lesart sancta Anastasia und zur Datierung vgl. den Kommentar des Herausgebers Chavasse (1973), in: CC 138A, Bd. 2, 591f

89 Die Ausmalung durch Damasus wird in einer Widmungsinschrift erwähnt, aus der hervorgeht, dass die Fresken des Damasus durch Mosaiken ersetzt wurden (de Rossi, Inscr. II, 24, nr. 25; 150, nr. 18).

$90 \quad$ S. u., S. $375 f$.

91 Zur Übertragung der Reliquien unter Gennadius s. Delehaye 1936, 161. Für die Vermutung, die Verehrung der Anastasia sei über Konstantinopel nach Rom gelangt, s. Duchesne 1887, 404f.; Grisar 1896, 730; Kirsch 1918, $22 \mathrm{f}$. 
Heilige umfassende Passio integriert wurden. ${ }^{92}$ Diese Verbindung zwischen der Heiligen aus Sirmium und dem Märtyrer aus Aquileia deutet darauf hin, dass die beiden Heiligen gemeinsam aus dem adriatischen Raum nach Rom gelangten. Wie noch zu zeigen sein wird, dürfte dafür weniger die geographische Lage Aquileias als Durchgangsstation zwischen dem Illyrikum und Oberitalien $^{93}$ ausschlaggebend gewesen sein als vielmehr die historischen Umstände, unter denen eine Übertragung der beiden Kulte nach Rom erfolgte. ${ }^{94}$

8. Titulus Caeciliae. Die Unterschriftenliste der Synode von 499, in der einer der beiden Titelpresbyter des titulus Caeciliae mit presbyter tituli sanctae Caeciliae unterschrieb, macht deutlich, dass auch Caecilia bereits im 5. Jh. als eine Heilige galt. Ähnlich wie bei der Susannaverehrung im titulus Gaii liefert auch hier das Martyrologium Hieronymianum bzw. der in ihm enthaltene römische Festkalender aus der Zeit Bonifatius' I. (418-422) einen Hinweis darauf, dass sich bereits im frühen 5 . Jh. eine derartige Kommemoration mit der Titelkirche der Caecilia in Trastevere verband. ${ }^{95}$ Schwieriger ist die Frage nach der Provenienz dieses Heiligenkultes zu beantworten. Dass es sich bei Caecilia um eine nichtrömische Heilige handelte, kommt zwar als Möglichkeit in Betracht, ${ }^{96}$ lässt sich jedoch nicht sicher erhärten. Immerhin legen zwei Indizien nahe, dass es sich auch im Fall von Caecilia ursprünglich um einen außerrömischen Heiligenkult und nicht um eine während des 5. Jh. sanktifizierte Titelgründerin handelte. Zum einen wurde Caecilia schon im stadtrömischen Kalender des frühen 5. Jh. als eine Heilige und nicht als eine Titelgründerin kommemoriert, während nachweisliche Titelgründer wie Cyriacus und Eusebius, die später als Heilige verehrt wurden, diesen Prozess einer Sanktifizierung zu

92 Die passio Anastasiae bildet einen Legendenzyklus, in dem unterschiedliche Heiligenlegenden innerhalb einer Rahmenerzählung zusammengefasst wurden (zu dieser Kompositionstechnik der „zyklischen“ Heiligenlegende vgl. o., S. 262, Anm. 167). Neben Anastasia und Chrysogonus hat der Verfasser auch legendarische Traditionen zu den Heiligen Agape, Chionia und Irene (Märtyrerinnen aus Thessaloniki) und zur Heiligen Theodote (Märtyrerin aus Nicaea in Bithynien) verarbeitet.

93 Aquileia lag an der via Aemilia, die nach Sirmium führte und die wichtigste Verkehrsachse zwischen Italien und dem Illyrikum bildete (zur engen Verbindung zwischen Aquileia und dem Donauraum vgl. auch Humphries 1999, 31f.).

94 S. u., S. 375.

95 Das Martyrologium Hieronymianum enthält am 17. November den Eintrag Romae transtibere Cecilii; die Nachricht dürfte bereits im stadtrömischen Kalender von 422 gestanden und dort den Tag der Titelheiligen Caecilia bezeichnet haben (so überzeugend Kirsch 1924, 87-89; skeptisch allerdings Delehaye (1931), in: Comm. MH, 604; Pietri 1976, Bd. 1, 501f.). Bestätigung erfährt die Vermutung, dass Caecilia bereits spätestens um die Mitte des 5. Jh. als Heilige galt, durch eine fragmentarische Inschrift, in der Caecilia mit dem Attribut sancta belegt ist und die in die Zeit zwischen 379 und 464 zu datieren ist (vgl. de Rossi, Inscr. I, 359, nr. 816).

96 Delehaye $21933,298$. 
Beginn des 5. Jh. noch nicht durchlaufen hatten. ${ }^{97}$ Will man Caecilia nicht als eine frühe Ausnahme verstehen, bleibt nur die Möglichkeit, sie nicht als eine Titelgründerin zu betrachten, sondern als eine Heilige, deren Kult in einer Titelkirche eingerichtet wurde. In diese Richtung weist auch die passio Caeciliae, die einen Hinweis darauf enthält, dass der titulus auch unter dem Namen eines Gordianus bekannt war. ${ }^{98}$ Es ist naheliegend, dass dieser Gordianus - nicht Caecilia - der Stifter des titulus war, der den Kult einer Heiligen Caecilia in der zu seiner Stiftung gehörigen Kirche etablierte. ${ }^{99}$

9. Titulus Sabinae. Bei der Titelkirche der Sabina liegt der Fall ähnlich wie beim titulus Caeciliae: Auch hier zeigt die Unterschrift eines Presbyters tituli sanctae Sabinae auf der römischen Synode von 499, dass eine Heiligenverehrung schon im 5. Jh. gegeben war. Die Weihinschrift der Titelkirche weist sie als Stiftung eines Presbyters namens Petrus aus, der den Bau unter Bischof Caelestinus (422-432) errichtete. ${ }^{100}$ Die archäologische Situation unterhalb der Titelkirche lässt nicht erkennen, dass sich diese Basilika über einer älteren Kirche erhob. ${ }^{101}$ Will man unter diesen Voraussetzungen an einer Titelgründerin Sabina festhalten, kann man sie allenfalls in einer Stifterin suchen, die das Grundstück für den Kirchenbau, das auf Kosten des Presbyters Petrus errichtet wurde, bereitstellte. ${ }^{102}$ Dass innerhalb von nur 50 Jahren eine Transformation des Stiftergedenkens in ein Heiligengedenken erfolgte, ist jedoch

${ }_{97}$ Sie erscheinen im Martyrologium Hieronymianum jeweils als conditor tituli; vgl. die Tageseinträge zum 14. April (Romae in titulo iuxta Diocletianas Cyriaci conditoris tituli nach der Restitution von Delehaye [1931], in: AASS Nov. II, 190) und zum 14. August (Romae Eusebii tituli sui conditoris; vgl. ebd., 444).

98 Passio Caeciliae 27: clarissimus vir... nomine Gordianus... sub umbratione nominis sui domum sanctae Caeciliae suo nomine titulavit, ut in occulto... ecclesia fieret. Zur Deutung vgl. Delehaye 1936, 84.

99 Zur Unterscheidung zwischen dem titulus und dem zu einem titulus gehörigen Kirchengebäude s. o., Anm. 33. Ähnlich wie bei den IV Coronati und der Hl. Susanna bildete das Heiligenpatrozinium der Titelkirche den Ausgangspunkt dafür, dass sich sekundär ein Kult an einer Grablege im römischen Suburbium entwickelte (zum Caeciliakult in der sogenannten Papstgruft an der via Appia vgl. Delehaye 1936, 86).

100 Culmen apostolicum cum Caelestinus haberet / primus et in toto fulgeret episcopus orbe / haec quae miraris fundavit presbyter urbis / Illyrica de gente Petrus... Vgl. Text und Abbildung der Inschrift bei Krautheimer, in: Corpus IV, 72 und 87 mit Abb. 85. Der Liber Pontificalis datiert den Bau der Kirche erst in die Zeit Sixtus III. (432-440) (LP I, 235).

101 Unter der vom Presbyter Petrus errichteten Kirche wurden im Bereich des Narthex Elemente einer Repräsentationsarchitektur gefunden: Teile eines aufwendig pavimentierten Raumes, durchzogen von einem $3 \mathrm{~m}$ breiten durch Schranken abgegrenzten Gang, der vermutlich auf ein monumentales Fenster zulief (vgl. Krautheiner, in: Corpus IV, 81-83). Krautheimer, ebd., 90f., erkennt darin keine liturgische Anlage einer Vorgängerkirche, sondern eine profane Architektur; ähnlich zurückhaltend bezüglich einer Vorgängerkirche ist Pietri 1976, Bd. 1, 504-506.

102 So Saxer 2001 (a), 559. 
wenig wahrscheinlich. ${ }^{103}$ Auch bei der Heiligen Sabina, nach der die Titelkirche auf dem Aventin benannt wurde, liegt daher die Schlussfolgerung nahe, dass es sich nicht um eine sanktifizierte Stifterin, sondern um eine Heilige handelte, deren Kult bereits bei der Gründung des titulus unter Caelestinus eingerichtet wurde. ${ }^{104}$

10. Titulus Pammachii. Die Titelkirche des Pammachius, wie sie in der Unterschriftenliste von 499 heißt, erscheint in der Liste von 595 als titulus ss. Iohannis et Pauli. ${ }^{105}$ Die Verehrung dieser beiden Heiligen muss in dem titulus jedoch bereits zu Beginn des 5. Jh. bestanden haben. Die Kirche des Pammachius - vermutlich handelt es sich um den im Jahr 410 beim Goteneinfall ums Leben gekommenen Angehörigen der gens Furia und Briefpartner des Hieronymus - wurde im frühen 5. Jh. errichtet, indem man über dem Sockel eines Privathauses, dessen Erdgeschoss erhalten blieb, eine dreischiffige Basilika anlegte. ${ }^{106}$ Bei dieser Gelegenheit überbaute man eine kleine

103 Denkbar wäre allenfalls, dass die Stifterin namens Sabina bereits zu Lebzeiten als sancta bezeichnet worden wäre (zum Gebrauch des Heiligenattributs für Bischöfe, Kleriker und Asket(inn)en im 5. und 6. Jh. vgl. Delehaye 1927, 38-42); doch ist diese Hypothese einer asketischen Titelgründerin nicht wahrscheinlicher als die Annahme eines Heiligenkultes in der Titelkirche.

104 Die passio Sabinae et Serapiae liefert keine verlässlichen Anhaltspunkte für die Herkunft des Heiligenpatroziniums. Zwar deutet man die Ortsangaben der passio zumeist dahingehend, dass es sich um eine Heilige aus der umbrischen Kleinstadt Vindena in der Nähe von Terni handele (Delehaye 1933, 316f.; zuletzt Verrando 1991 [a], 101-104; die von Kirsch 1918, 163-166 vertretene These, in den topographischen Angaben verballhornte Lesarten zu sehen, die sich auf Rom und auf die Lage der Titelkirche beziehen, ist hingegen nicht überzeugend). Doch ist der Kult dieser Heiligen wohl nicht aus einer umbrischen Kleinstadt nach Rom übertragen worden. Einen Hinweis liefert die Stiftungsinschrift der Titelkirche, die als Stifter einen presbyter urbis Illyrica de gente Petrus nennt (ICUR II, 5154). Möglicherweise brachte der illyrische Presbyter, der seine Abstammung in der Gründungsinschrift so pointiert hervorhob, die Titelheilige aus seiner Heimat mit. Dass Sabina kurz nach der Mitte des 6. Jh. unter den weiblichen Heiligen in den Mosaiken von S. Apollinare Nuovo in Ravenna erscheint, bringt keinen weiteren Aufschluss, da unter den beiden Heiligenreihen in S. Apollinare Nuovo zahlreiche ,fremde“ Heilige des römischen und mailändischen Messkanons erscheinen: Der Kult der Sabina ist dementsprechend vermutlich über Rom nach Ravenna gelangt (vgl. Delehaye 1929, 10-12; für eine umbrische Herkunft plädiert Deichmann 1969-1989, Bd. I, 31).

105 Die Identität ist dadurch gesichert, dass die Titelkirche später als titulus Pammachii sanctorum Iohannis et Pauli erscheint (vgl. LP I, 510).

106 Zur Basilika des Pammachius vgl. Krautheimer, in: Corpus I, 284-290, 294-296; zu typologischen Hinweisen, die eine Datierung zu Beginn des 5. Jh. nahe legen, vgl. Guidobaldi 1992, 153. Brenk 2003, 110f. spricht sich gegen die gängige Identifizierung des Titelgründers Pammachius mit Hieronymus' Briefpartner aus, da dieser seit 397 in asketischer Armut gelebt und daher die Mittel für den Basilikalbau nicht zur Verfügung gehabt habe. Diese Interpretation nimmt das Armutsideal des Pammachius, das Entäußerung, nicht aber materielle Armut signalisierte, jedoch zu wörtlich: Wie die „Armut" der asketisch orientierten christlichen Oberschicht Roms zu bewerten ist, zeigt exemplarisch Melania d. J. (383-439), die bei ihrem Weggang aus Rom und Italien alle Besitzungen im Westen des Imperiums veräußerte (Vita Melaniae 19), nach ihrer Ankunft im Heiligen Land jedoch durchaus in der Lage war, dort zwei Klöster zu errichten, die 
Hauskapelle, ${ }^{107}$ deren Wände mit Fresken versehen waren, auf denen mehrere Märtyrer - unter ihnen auch die Titelheiligen Johannes und Paulus dargestellt sind. ${ }^{108}$ Die Kapelle war kurz vor dem Bau der Basilika, gegen Ende des 4. Jh. angelegt worden, ${ }^{109}$ und die Basilika führte die Heiligenverehrung fort, indem sie die beiden wichtigsten Heiligen der Kapelle, Johannes und Paulus, als Patrone der Kirche übernahm. ${ }^{110}$

Anders als es die spätere Legende will, handelt es sich bei den beiden Heiligen nicht um zwei lokale römische Märtyrer, sondern mit hoher Wahrscheinlichkeit um Johannes d. Täufer und den Völkerapostel. ${ }^{111}$ Ein Blick auf die Kulttopographie Norditaliens macht deutlich, dass Johannes der Täufer zu einer Gruppe von Apostelkulten gehört, die seit den 380er Jahren in zahlreichen Kirchenstiftungen der Region erscheinen und unter maßgeblicher Initiative des Ambrosius in der gesamten Region bis nach Gallien verbreitet

trotz der Beteiligung anderer Geldgeber zum großen Teil durch Melania selbst finanziert worden sein müssen (vgl. auch E. Clark 1984, 92-119). Auf eine Datierung der Pammachiusbasilika vor die Mitte des 5. Jh. deutet ferner eine Bauinschrift hin, die die Ausschmückung der Vorhalle durch einen römischen Bischof dokumentiert. Der Name des antistes ist in dem nur handschriftlich überlieferten Epigramm ausgefallen, kann aber metrisch nur mit „Leo“ - zu beziehen auf Leo I. (440-461) - ergänzt werden (de Rossi, Inscr. II, 150, nr. 20; die Einwände von Brenk 2003, 109f. überzeugen nicht).

107 S. u., S. 380-382.

108 Vgl. die Abbildungen bei Brenk 2003, 327-329, Abb. 169-174. An den Seitenwänden der Kapelle zeigen zwei Szenen die Gefangennahme und Hinrichtung dreier Märtyrer, zweier Männer und einer Frau. An der Frontwand der Kapelle sind zwei, nur unvollständig erhaltene männliche Gestalten in Tunika und Pallium dargestellt, die eine Nische flankierten, die zur Aufnahme von Reliquien bestimmt war. Dass es sich bei den beiden palliati um Johannes und Paulus handelt, liegt nahe, da sie an einer besonders prominenten Stelle des Raums angebracht waren. Die Identität der drei anderen Heiligen ist unklar. Brenk 1995-1996, 203, ders., 2003, 112 möchte unter Berufung auf Franchi de' Cavalieri 1935 in den drei Märtyrern die Heiligen Cyprian, Iustina und Theoktistus erkennen, da die Kaiserin Eudokia in einer Dichtung auf Cyprian und Iustina schreibt, sie seien in Rom in der Nähe eines Claudiusforums beigesetzt worden (vgl. Phot., cod. 184). Davon abgesehen, dass bei Eudokia von einem dritten Märtyrer Theoktistus keine Rede ist, fällt es jedoch schwer, die vermutlich ohne jegliche Kenntnis der stadtrömischen Topographie verfasste Angabe eines forum Claudii auf den Claudiustempel zu beziehen, in dessen Nähe sich die Titelkirche des Pammachius erhob. Bezeichnenderweise hat Franchi de' Cavalieri später selbst von seiner ursprünglichen Vermutung Abstand genommen (vgl. dens. 1953, 14, Anm. 2).

109 Zur Datierung der Malereien s. u., Anm. 192; das Mauerwerk erlaubt keine genauere zeitliche Eingrenzung (vgl. Pietri 1976, Bd. 1, 483 mit Anm. 2).

110 Brenk 2003, 111 wendet gegen die Annahme eines Heiligenpatroziniums für den titulus Pammachii ein, dass die Basilika nach Ausweis der oben erwähnten Bauinschrift, nicht den beiden Heiligen Johannes und Paulus, sondern Christus geweiht gewesen sei (quis tantas Christo venerandas condidit aedes, / si quaeris: cultor Pammachius fider). Dies entspricht jedoch der allgemeinen Praxis der Zeit und spricht nicht gegen ein Patrozinium (vgl. Delehaye 1930, 7f.).

111 Lanzoni 1925, 209; Delehaye 1930, 15f. plädieren übereinstimmend für Johannes d. Täufer, nicht den Apostel Johannes; wenig überzeugend Pietri 1976, 489 (östliche Heilige). Zur späteren Legendenbildung um die Heiligen des titulus Pammachii vgl. u., Anm. 196. 
wurden. ${ }^{112}$ Ähnlich wie bei Gervasius und Protasius, die wohl unmittelbar aus Mailand ihren Weg nach Rom und in den titulus Vestinae fanden, dürften auch Johannes und Paulus im Zuge dieser Kultverbreitung nach Rom gelangt sein. Die Kapelle unter dem titulus Pammachii und die kurze Zeit danach angelegte Titelkirche sind nicht die einzigen Zeugen für die Ausbreitung ihres Kultes in Rom: Nur wenige Jahre nach dem Bau der Titelbasilika ließ Leo I. (440-461) bei S. Pietro ein Kloster errichtete, das ebenfalls den beiden Heiligen Johannes und Paulus geweiht war. ${ }^{113}$

\section{Titulus apostolorum, 12. Titulus sancti Matthaei und 13. Titulus sancti Laurentii.} Alle drei tituli sind in der Liste von 499 nach Heiligen benannt und verfügten demnach bereits während des 5. Jh. über Kirchen mit einem Heiligenpatrozinium. Die Kirche des titulus apostolorum wurde kurz nach dem Konzil von Ephesos (431) den beiden Aposteln Petrus und Paulus unter einem neuen Namen geweiht und ersetzte damit möglicherweise ein früheres Petruspatrozinium durch eine Weihung an beide Apostel. ${ }^{114}$ Für die beiden anderen Kir-

112 Vgl. Picard 1988, 272f. und u., Anm. 131. Delehaye 1930, 16 vermutet, dass die konstantinische Basilika in Ostia, die Petrus, Paulus und Johannes d. Täufer geweiht war (LP I, 183f.), den Ursprung des Heiligenpatronats gebildet haben könnte. Er begründet dies damit, dass Gallicanus, der in den vom Liber Pontificalis überlieferten Stiftungslisten der konstantinischen Basilika von Ostia bezeugt ist, auch eine prominente Rolle in der Legendenbildung um die Titelheiligen des titulus Pammachii einnimmt. Es ist jedoch davon auszugehen, dass erst der Verfasser der passio Gallicani in Kenntnis des Liber Pontificalis eine Verbindung zwischen dem titulus Pammachii und der Person des Gallicanus hergestellt hat, veranlasst durch die Ähnlichkeit der Heiligenpatrozinien in der Titelkirche und in der Basilika von Ostia. Für den Ursprung des Johannes- und Pauluspatroziniums in der römischen Titelkirche ist die Angabe wertlos.

113 LP I, 239 mit Anm. 11. Diesem Kloster oder der Titelkirche des Pammachius ist die Weihinschrift eines Altares zuzuweisen, die einer mittelalterlichen Handschriftensammlung ohne Ortsangabe überliefert wurde; vgl. Damas., epigr. 61: hanc aram domini servant Paulusque Iohannes / martyrium Christi pariter pro nomine passi / sanguine pupureo mercantes praemia vitae. Die Plazierung innerhalb der Sylloge deutet auf das Kloster bei S. Pietro hin (vgl. den Kommentar von Ferrua [1942], in: Epigrammata damasiana, 229).

114 Die handschriftlich überlieferte Weihinschrift weist die Titelkirche als eine kaiserliche Stiftung und als das Werk eines Presbyters Philippus aus, der sie unter Sixtus III. (432-440) errichtete, und signalisiert, dass die Kirche durch das Patrozinium der beiden Apostel einen neuen Namen erhielt (de Rossi, Inscr. II, 100, nr. 67; 134, nr. 3: cede prius nomen... Zu einer Vorgängerkirche unter S. Pietro in Vincoli vgl. o., Anm. 10). Philippus unterzeichnete bereits auf dem Konzil von Ephesus (431) als presbyter ecclesiae apostolorum und dürfte damit den neuen Namen des titulus bereits vorweggenommen haben (so überzeugend Delehaye 1930, 14f.; Pietri 1976, Bd. 1, 478). In der Kirche wurden die Ketten Petri verehrt, deren Existenz als römische Pilgerreliquie bereits für das frühe 5. Jh. bezeugt ist (vgl. Krautheimer, in: Corpus III, 181). Die pointierte Hervorhebung der Weihinschrift, dass die Kirche jetzt Petrus und Paulus gemeinsam geweiht sei (baec Petri Paulique simul nunc nomine signo / ... unum quaeso pares, unum duo sumite munus / unus bonor celebrat quos babet una fides), ist ein Indiz dafür, dass der Vorgängerbau einzig ein Petruspatrozinium besaß. 
chen, S. Matteo und (vermutlich) S. Lorenzo in Lucina, ${ }^{115}$ liegen keine archäologischen und kalendarischen Hinweise vor, die genauere Aussagen über Zeit und Umstände der dortigen Einführung eines Heiligenpatroziniums erlauben würden. Die Kirche S. Matteo in Merulana wurde zu Beginn des 19. Jh. abgerissen; 116 Spuren einer kalendarischen Kommemoration des Titelheiligen haben sich in der Überlieferung nicht erhalten. ${ }^{117}$ Beim titulus Lucinae ist unklar, ab wann er über ein Laurentiuspatrozinium verfügte. Zwar ist die Existenz der Kirche erstmals im Jahr 366 bezeugt, doch ist die Aufführung in der Synodalliste von 499 der früheste sichere Anhaltspunkt dafür, dass der titulus mit dem Heiligen Laurentius in Verbindung stand. ${ }^{118}$

115 Geertman 1975, 154-169 identifiziert den titulus s. Laurentii mit der Kirche S. Lorenzo in Formonso (später S. Lorenzo in Panisperna genannt). Der titulus s. Laurentii der Unterschriftenliste von 499 dürfte jedoch mit dem titulus Lucinae identisch sein, der in der späteren Überlieferung als titulus baeti Laurentii martyris, qui appellatur Lucinae erscheint (vgl. Kirsch 1918, 14). Zwar wird in der Synodalliste von 499 der titulus Lucinae als eigene Titelkirche neben dem titulus s. Laurentii aufgeführt, doch begegnet eine vergleichbare Doppelbezeichnung derselben Titelkirche mit zwei unterschiedlichen Namen in der Liste von 499 auch beim titulus Vizantis und dem titulus Pammachii. Der titulus s. Laurentii in der Liste von 499 kann aus denselben Erwägungen heraus auch mit dem titulus Damasi gleichgesetzt werden, der ebenfalls über ein Laurentiuspatronat verfügte (vgl. o., S. 341). Da jedoch in der Synodalliste von 595 der titulus s. Damasi neben dem titulus s. Laurentii erwähnt wird, ist letzterer mit hoher Wahrscheinlichkeit hier und in der Liste von 499 auf den titulus Lucinae zu beziehen.

116 Huelsen 1927, 386f.

117 Auch die Patrozinien in den übrigen italischen Städten helfen nicht weiter. Matthäusreliquien fanden bei der Weihe der Stephanusbasilika in Ravenna (550) Verwendung (Deichmann 19691989, Bd. I, 31, II, 2, 373); für die Herkunft und Datierung des Heiligenpatronats im titulus s. Matthaei in Rom lässt sich daraus jedoch nichts gewinnen.

118 Zur Rolle der Lucina-Kirche als Wahlort des Damasus im Herbst 366 vgl. coll. Avell., epist. 1, 5. Für die Hypothese von Sághy 1999, 526, bereits um 300 habe ein titulus Lucinae mit einem Laurentiuspatrozinium existiert, gibt es keinen Anhaltspunkt. Ein Teil der Forschung hat die Notiz des Liber Pontificalis, wonach Kaiser Valentinian III. dem römischen Bischof Sixtus III. die Genehmigung zum Bau einer Laurentiusbasilika erteilte (LP I, 234), auf den titulus Lucinae bezogen und das Laurentiuspatrozinium als zu diesem Zeitpunkt bereits bestehend vorausgesetzt bzw. mit diesem Ereignis in Verbindung gebracht (vgl. Pesarini 1913, 42-46; Kirsch 1918, 82-84; Krautheimer, in: Corpus II, 184f.; zuletzt Hillner 2002; Bertoldi 2003, 388f.). Die Angabe des Liber Pontificalis ist jedoch vermutlich auf die basilica maior an der via Tiburtina zu beziehen (s. o., S. 108). - Geertman knüpft an seine Identifizierung des titulus s. Laurentii von 499 mit der Kirche S. Lorenzo in Formonso/Panisperna die Vermutung, an diesem Ort sei bereits im 3. Jh. eine Memoria zur Erinnerung an das Martyrium des Laurentius errichtet worden (Geertman 1975, 169). Der archäologische Befund unter der im 16. Jh. errichteten Kirche S. Lorenzo in Panisperna erlaubt jedoch keine Aussagen über die Geschichte der Kirche in spätantiker und frühmittelalterlicher Zeit: Die Funde beschränken sich auf Überreste einer Bebauung aus dem 2. Jh. (vgl. Krautheimer, in: Corpus II, 187), die nicht geeignet ist, Geertmans Hypothese zu stützen. 


\section{2. Reliquientranslationen und aristokratische Kommunikation}

Was lässt sich aus diesem Befund für die Frage nach der Privatisierung und Privatisierbarkeit von Heiligenkulten in stadtrömischen Titelkirchen gewinnen? Zunächst die Erkenntnis, dass der von Kirsch begründete Forschungskonsens, wonach sich im Laufe des 6. Jh. ein grundsätzlicher Wechsel von der Stifter- zur Heiligenmemoria vollzogen habe, in dieser Form nicht aufrecht zu erhalten ist. Etwa die Hälfte der tituli müssen bereits während des 5. Jh. mit einem Heiligenpatrozinium ausgestattet gewesen sein, und bei einer nicht geringen Zahl von Heiligen weisen die Spuren dieser Übertragung bereits in das beginnende 5. Jh. Auffällig ist, dass es sich dabei in der Regel nicht um römische Heilige handelte, die ihren Weg aus den Coemeterien in die städtischen Kirchen fanden. Von besonders populären römischen Heiligen wie den beiden Aposteln Petrus und Paulus (titulus apostolorum) und dem Diakon Laurentius (titulus Damasi und S. Lorenzo in Lucina) ${ }^{119}$ abgesehen, sind die übrigen Titelpatrone auswärtige Heilige, die vorzugsweise aus dem norditalischen und illyrischen Raum nach Rom gelangt sind und insbesondere auf Mailand und Aquileia als Zentren der Verbreitung hindeuten. ${ }^{120}$ Erst während des 6. Jh. machte sich eine Verlagerung der römischen Erinnerungstopographie aus den suburbanen Coemeterien in die Stadt bemerkbar: In dieser Zeit wurden mehrere römische Titelkirchen, die erst während des 6. Jh. Heiligenpatrozinien erhielten (titulus s. Sixti ${ }^{121}$, titulus ss. Nerei et Achillei ${ }^{122}$, titulus s. Balbinae ${ }^{123}$,

119 Zur Popularität des Laurentius, der zusammen mit Petrus und Paulus eine Trias der drei wichtigsten römischen Heiligen bildete, vgl. Colella 1997, 76-79.

120 Gervasius und Protasius dürften aus Mailand nach Rom gelangt sein, ebenso wie die Reliquien der Apostel Johannes und Paulus. Aus dem Illyrikum fanden Chrysogonus und Anastasia den Weg nach Rom. Neben Anastasia sind als weitere Heilige aus dem illyrisch-pannonischen Raum die IV Coronati und möglicherweise Sabina unter den römischen Titelheiligen vertreten. Aus Pannonien stammten auch die Reliquien des Märtyrerbischofs Quirinus, der zu einem nicht genauer bestimmbaren Zeitpunkt im Laufe des 5. Jh. aus Siscia nach Rom überführt und in einem der Mausoleen bei S. Sebastiano beigesetzt wurde (vgl. Bertolino 1997, bes. $121 \mathrm{f}$.).

121 Sixtus II., der im coemeterium Callisti an der via Appia bestattet lag, wurde (erstmals 595 nachweisbar) zum Namensgeber des an der via Appia intra muros gelegenen titulus Crecentianae (vgl. Geertman 1968-1969).

122 Der titulus ss. Nerei et Achillei - vermutlich identisch mit dem titulus Fasciolae - lag schräg gegenüber dem titulus Crecentianae an der via Appia und stand damit in enger räumlicher Verbindung zum Domitillacoemeterium an der via Ardeatina, in dem Nereus und Achilleus bestattet lagen, und in dessen halbunterirdischer Basilika einige Grabinschriften von Klerikern des titulus Fasciolae gefunden wurden (vgl. Kirsch 1918, 91). Als titulus ss. Nerei et Achillei erscheint die Kirche erstmals in der Liste von 595.

123 Der titulus s. Balbinae in der Unterschriftenliste von 595 wird meist mit dem titulus Tigridae von 499 gleichgesetzt, ohne dass sich dafür allerdings zwingende Argumente anführen ließen. Ähnlich wie beim titulus s. Sixti und titulus ss. Nerei et Achillei spielte die Nähe zur via Ardeatina und via Appia und zum coemeterium Balbinae für die Benennung des titulus die ausschlaggebende Rolle. 
titulus ss. Marcellini et Petri24) nach Heiligen umbenannt, deren Grablegen an Konsularstraßen lagen, die auf diejenigen Viertel zuführten, in denen sich die entsprechenden tituli befanden: Die Heiligen wanderten so gleichsam aus den Coemeterien in die Stadt. ${ }^{125}$ Die Patrozinien der tituli des 5. Jh. hingegen folgten anderen Wegen und einer anderen Logik der Verbreitung.

Die Kanäle, über die diese Kulte und Patrozinien nach Rom gelangten, sind in den meisten Fällen nur zu erahnen. Sie dürften auf dem Weg von Reliquientranslationen erfolgt sein, die seit der 2. Hälfte des 4. Jh. im gesamten Mittelmeerraum größere Dimensionen erreichten - ein Umstand, der sich nicht nur in der literarischen Überlieferung ${ }^{126}$ und in der Gesetzgebung, ${ }^{127}$ sondern vor allem auch in der Herstellung von Reliquiaren niedergeschlagen hat, die zum Teil in Altarsepulcra von Kirchen aufgefunden worden sind und die Verbindung von Heiligenpatrozinien und Reliquientranslationen auch archäologisch eindrucksvoll dokumentieren. ${ }^{128}$ Deutlich schwieriger ist es, die an diesen Translationen beteiligten Auftraggeber, Empfänger und Vermittler zu bestimmen. In Ermangelung von präzisen Informationen zur Einführung der Heiligenpatrozinien an den römischen tituli ist man im wesentlichen auf Analogieschlüsse angewiesen, die sich aus dem Vergleich mit den besser dokumentierten Verhältnissen in Oberitalien ergeben. Dort entfaltete Ambrosius von Mailand seit den 380er Jahren eine regelrechte Auffindungs- und Distributionspolitik und gab den Anstoß zu einer Entwicklung, in deren Verlauf im oberitalischen Raum verstärkt Reliquien zwischen den Bischofsgemeinden zirkulierten und zu einer Ausbreitung von Heiligenkulten führten. ${ }^{129}$ Komplementär zu einer intensiven brieflichen Kommunikation mit seinen bischöflichen Amtskollegen und zum Einfluss, den Ambrosius bei der Beset-

124 Die Nähe zur porta Labicana verhalf dem titulus ss. Marcellini et Petri (in der Liste von 499 möglicherweise der titulus Nicomedis) zu seinem Namen; umgekehrt fanden die IV Coronati, deren Titelkirche in der Nähe des titulus Nicomedis/SS. Marcellini et Petri lag, den Weg hinaus in das Coemeterium an der via Labicana, wo man im Frühmittelalter ihre Gräber verehrte (vgl. o., Anm. 63).

125 Diese Umbenennungen der Titelkirchen waren allerdings nicht mit einer Translation der Heiligen verbunden. Erst während des 7. und 8. Jh. wurden die ersten Märtyrer aus den Coemeterien in städtische Kirchen überführt (vgl. Costambeys 2001, 172).

126 Eine umfassende Zusammenstellung der literarischen Belege für Reliquientranslationen von der Mitte des 4. Jh. bis in die erste Hälfte des 5. Jh. bietet Delehaye 21933, 50-99.

127 Für die Verbote, mit denen die Kaiser auf diese Praxis reagierten, vgl. CTh 9, 17, 7 (386); s. auch Nov. Val. 23, 1.5 (447). Der Umstand, dass in der spätantiken Gesetzgebung zur violatio sepulcri der Schutz des bestatteten Leichnams die traditionelle Auffassung zurückdrängte, nach der einzig die Spoliation von Grabbauten unter Strafe gestellt war, ist allerdings nicht auf die christliche Praxis der Reliquienerhebung und -translation zurückzuführen (vgl. Rebillard 2003, 74-83).

128 Aus Oberitalien haben sich aus dem fraglichen Zeitraum um 400 mehrere Beispiele erhalten; vgl. Buschhausen 1971, 219-223 (Pola), 223-234 (S. Nazaro/Mailand); 246-249 (Grado). Zu den literarischen Quellen (vor allem Paulinus v. Nola), die seit dem ausgehenden 4. Jh. eine zunehmende Weihung von Altären mit Reliquien dokumentieren, vgl. Brandenburg 1995.

129 Vgl. dazu Humphries 1999, 54f.; G. Clark 2001, 168-171. 
zung der oberitalischen Bischofssitze geltend machte, ${ }^{130}$ bildeten die Heiligenpatrozinien ein Mittel, durch das der Mailänder Bischof die Beziehungen zu den Gemeinden in der Region stärkte und deren Ausrichtung auf Mailand betrieb. Dabei wurde Ambrosius in vielfältiger Weise tätig - nicht nur als Auffinder und Verbreiter von Mailänder Heiligen, sondern auch dadurch, dass er Märtyrerreliquien in fremden Gemeinden erhob und nach Mailand überführte, und dass er die Weitervermittlung von Heiligenkulten betrieb, die gleichsam durch die Schaltstation Mailand weitere Verbreitung in Oberitalien und Gallien fanden. ${ }^{131}$

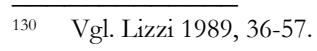

131 Unter den von Ambrosius in Mailand entdeckten Heiligen fanden besonders die anlässlich der Weihung der basilica Ambrosiana im Jahr 386 erhobenen Märtyrer Gervasius und Protasius in Italien und in Gallien weite Verbreitung, in geringerem Maße auch der 395 aufgefundene Nazarius. In Bologna war Ambrosius 393 seinem bischöflichen Kollegen bei der Auffindung von Agricola und Vitalis „behilflich“ und überführte Reliquien beider Märtyrer nach Mailand. Aus dem Osten erhielt Ambrosius Apostelreliquien (Johannes, Andreas, Thomas, Lukas), für die er im Jahr 382 die basilica apostolorum errichtete, sowie Reliquien von Johannes dem Täufer und Euphemia (zur Rekonstruktion dieses Heiligenbestandes vgl. Delehaye 1930, 13). - Einige Beispiele mögen die Verbreitungswege der Heiligenkulte und die dadurch hergestellten Vernetzungen verdeutlichen: In Florenz nahm Ambrosius selbst die Weihung einer Kirche mit den in Bologna erhobenen Reliquien von Agricola und Vitalis vor (Ambr., exhort. virg. 1, 1 - 2, 10; Paul. Med., vita Ambr. 29). Gaudentius von Brescia (387/397 - ca. 410) weihte seine Kirche mit den Reliquien verschiedener Heiliger, darunter Gervasius, Protasius, Nazarius sowie Johannes d. Täufer und die Apostel Andreas, Thomas und Lukas (vgl. Gaudent., serm. 17, der allerdings nur bei den Mailänder Märtyrern explizit erwähnt, dass er ihre Reliquien von Ambrosius erhalten habe). Verbindungen zu Ambrosius unterhielt auch Paulinus von Nola: In seiner Basilika im unteritalischen Cimitile/Nola fanden u. a. die Reliquien von Nazarius, Agricola und Vitalis, ferner Johannes d. Täufer, die Apostel Andreas, Thomas, Lukas und Euphemia Aufnahme (Paul. Nol., carm. 27, 406-439; Nazarius wird von Paulinus als eine persönliche Gabe des Ambrosius bezeichnet). Ein Teil dieser Reliquien kam auch in Paulinus' Basilika in Fundi zum Einsatz, wo neben Gervasius, Protasius und Nazarius die Apostel Andreas und Lukas rekondiert wurden (Paul. Nol., epist. 32, 17). Am deutlichsten macht sich die Verbreitung der unter Ambrosius in Mailand anzutreffenden Heiligen in Oberitalien und Gallien bemerkbar: Neben der bereits erwähnten Kirche des Gaudentius in Brescia finden sich Reliquien von Johannes d. Täufer und den Aposteln Johannes, Andreas, Thomas und Lukas in der von Chromatius von Aquileia (388-407/8) gegründeten Basilika von Concordia (vgl. Chromat., serm. 26, 3f.). Auch im benachbarten Aquileia wurde etwa zur selben Zeit eine basilica apostolorum mit Reliquien von Andreas, Lukas, Johannes und Euphemia errichtet. In Lodi, Piacenza, Novara und Verona entstanden im ausgehenden 4./frühen 5. Jh. ebenfalls Apostelkirchen (für die Verbreitung der Apostelreliquien in Oberitalien vgl. die Bestandsaufnahmen bei Villa 1957, 249253; Picard 1988, 272-284). In Ravenna wurden Gervasius und Protasius 435 Patrone eines Klosters (vgl. Deichmann 1969-1989, Bd. II, 2, 336f.). Die Einflüsse der von Ambrosius geförderten Kommunikation durch Reliquientranslationen machten sich auch außerhalb Italiens bemerkbar: Victricius v. Rouen erhielt zwischen 395 und 397 Reliquien von Gervasius u. Protasius, Agricola, Johannes d. Täufer, den Aposteln Thomas, Andreas und Lukas und der Euphemia (vgl. Victric. 6). Für die von Mailand ausgehende Verbreitung von Gervasius und Protasius-, Nazarius-, Agricola und Vitalis- und Apostelpatrozinien in Gallien vgl. die umfassenden Untersuchungen von Ewig 1960, 55-59; dems. 1960 (a), 245 f. 
Die Ausläufer dieser kirchenpolitischen Vernetzungspolitik bezogen auch Rom mit ein. So dürfte die Mailänder basilica apostolorum ihren Namen nicht allein Apostelreliquien aus dem Osten des römischen Reichs verdanken, deren Überführung nach Mailand aus der kalendarischen Tradition erschlossen werden kann, sondern an führender Stelle auch die Verehrung der römischen Apostelfürsten Petrus und Paulus mit einbezogen haben. ${ }^{132}$ In der Gegenrichtung machten sich die Einflüsse der durch Ambrosius initiierten Patrozinienwanderungen auch in Rom bemerkbar: Mit Gervasius und Protasius (titulus Vestinae) sowie Johannes und Paulus (titulus Pammachii) finden sich in zwei der römischen Titelkirchen Heilige wieder, die in der von Mailand beeinflussten Kultgeographie Oberitaliens und Galliens eine besonders prominente Rolle spielten.

Dies wirft die Frage auf, ob das ambrosianische Prinzip, durch Reliquientranslationen die Beziehungen zwischen einzelnen Ortskirchen zu stärken, auch als Erklärung für die Heiligenkulte der römischen Titelkirchen in Anspruch genommen werden kann. Die jüngsten Bemerkungen der Forschung zu den Patrozinien in den römischen Titelkirchen zielen in diese Richtung. So hat man vermutet, dass die Reliquien von Chrysogonus durch die bischöfliche Vermittlung von Innozenz I. (401-417), in dessen Episkopat die Anfänge der Errichtung eines päpstlichen Vikariats im Illyrikum fielen,

132 Das Martyrologium Hieronymianum verzeichnet für den 9. Mai einen ingressus von Reliquien der Apostel Johannes, Andreas und Thomas in die Mailänder basilica ad portam Romanam. Obwohl in der Notiz nicht ausdrücklich von einer Dedikation die Rede ist, dürften diese Reliquien den Anlass für die Weihe der Basilika an der porta Romana zur basilica apostolorum gegeben haben. Diese Apostelreliquien verweisen ebenso auf eine östliche Herkunft wie ein zweiter Eintrag des Mailänder Kalenders zum 27. November, in dem neben Johannes und Andreas die Heiligen Lukas und Euphemia erwähnt werden: Lukas und Andreas waren 336 oder 356/57 in die Apostelkirche von Konstantinopel überführt worden - dafür, dass dieser Bau als das unmittelbare Vorbild der Mailänder basilica apostolorum anzusehen ist, spricht auch deren ungewöhnliche Architektur, die vermutlich die kreuzförmige Anlage des Apostoleions in Konstantinopel aufgriff (vgl. Brandenburg 1995, 73). - Die Hypothese, dass Petrus und Paulus die Namensgeber der basilica apostolorum gewesen seien (so zuletzt McLynn 1994, 231f. und Humphries 1999, 148, 201), stützt sich auf das unter dem Hauptaltar der Basilika aufgefundene spätantike Silberkästchen, das von der Forschung als das Reliquiar angesehen wird, in dem die Apostelreliquien aufbewahrt waren: Der Deckel des Kästchens zeigt den thronenden Christus, umgeben von einer Apostelgruppe, in der Petrus und Paulus besonders hervorgehoben werden (Abbildung bei Buschhausen 1971, B Taf. 38). Nach der ausführlichen Diskussion von Alborino 1981, 32-62 handelt es sich um eine ikonographische Zwischenform, die sowohl das Motiv des zwischen den Aposteln thronenden Christus als auch die Darstellung des thronenden Christus, der von den beiden Apostelfürsten flankiert wird, aufgreift. Die Forschungskontroverse, ob die basilica apostolorum ihren Namen den aus dem Osten stammenden Apostelreliquien oder den Aposteln Petrus und Paulus verdanke, ist demnach in dieser Form zu dezisionistisch. Die Intention des Ambrosius ist vielmehr in der Verbindung beider ikonographischer Motive zu suchen: In ihr versinnbildlichte sich die Absicht, mit der Mailänder basilica apostolorum der Apostelkirche in Konstantinopel ein westliches Pendant entgegenzusetzen, indem mit Petrus und Paulus die beiden Apostel des Westens der Gruppe der übrigen Apostel vorangestellt wurden. 
nach Rom gekommen und in die dortige Titelkirche überführt worden seien ${ }^{133}$ - eine Hypothese, die sich auch auf weitere römische Titelheilige aus dem illyrischen Raum wie Anastasia, die IV Coronati und (möglicherweise) Sabina ausdehnen ließe. In Anbetracht der Tatsache, dass Rom seit dem beginnenden 5. Jh. seine Beziehungen zu den Kirchen im Illyrikum verstärkte, ist eine kirchenpolitische Dimension der Kultübertragungen nicht auszuschließen: Die römischen Bischöfe könnten - in Anlehnung an die von Ambrosius v. Mailand so virtuos betriebene Erhebungs- und Distributionspolitik - die Translation von Reliquien genutzt haben, um die Bindung der illyrischen Kirchen an Rom jenseits kirchenrechtlicher Verlautbarungen weiter zu fördern. Diese Erklärung verbleibt allerdings stark im Bereich des Hypothetischen und dürfte nicht den Schlüssel zur Frage, auf welchen Wegen die Heiligen nach Rom gelangten, liefern. Die Überführung von Heiligenkulten in die römischen tituli ging nicht in erster Linie auf das Konto von Bischöfen, die in der Vermittlung von Patrozinien ihren Einfluss und ihre Beziehungen zu anderen Ortskirchen geltend machten, sondern wurde von denjenigen Kreisen voran getrieben, denen Rom sein „,second établissement chrétien“ verdankte: vermögenden aristokratischen Familien, deren domus die Titelkirchen beherbergten, in denen die auswärtigen Heiligenkulte seit der Wende vom 4. zum 5. Jh. Aufnahme fanden.

Dass Angehörige der aristokratischen ceti dirigenti um die Wende vom 4. zum 5. Jh. an der Blüte der Heiligenverehrung und der Verbreitung von Heiligenkulten in dieser Zeit einen bestimmenden Anteil hatten, ist bekannt. Für Aristokraten wie Sulpicius Severus und Paulinus von Nola, die gegen Ende des 4. Jh. eine asketisch geprägte conversio vollzogen, waren insbesondere Asketenheilige wie Martin v. Tours oder Felix von Nola Vorbilder und Ausdruck ihrer eigenen Hinwendung zum Christentum und des damit verbundenen Ideals von Heiligkeit. ${ }^{134}$ Diese fundierende Bedeutung der Heiligenverehrung für das Selbstverständnis konvertierter Aristokraten blieb jedoch nicht auf bestimmte Typen von Heiligen beschränkt, deren asketische Ausrichtung an die traditionellen Wertmaßstäbe einer Elitenethik appellierte und damit geeignete Möglichkeiten bot, spezifisch aristokratische Haltungen in neuen Kontexten weiterzuführen. Jenseits der Vorbildhaftigkeit einzelner Heiliger beanspruchten die Heiligen und ihre Reliquien insgesamt das Interesse einer christlichen Elite, die - ähnlich wie die Bischöfe seit dem ausgehenden 4. Jh. - durch die Übersendung von Reliquien die Netzwerke zum Teil weit verzweigter Freundschaftsbeziehungen pflegte und aufrecht erhielt.

\footnotetext{
133 In diesem Sinne Cecchelli 1999, 236f. Zu den kirchenpolitischen Beziehungen zwischen Rom und den illyrischen Kirchen und zur Ernennung des Bischofs von Thessalonike zum päpstlichen Stellvertreter in Illyrien durch Innozenz I. vgl. Wojtowytsch 1981, 211-214 u. 437.

134 Zur hohen Bedeutung der Martins- und Felixverehrung für das asketische Selbstverständnis von Sulpicius Severus und Paulinus von Nola vgl. König 1985, 90-123.
} 
Exemplarisch deutlich wird diese Vernetzung anlässlich der Weihung einer Basilika in Primuliacum, die Sulpicius Severus im Jahr 403 oder 404 vornahm. Paulinus v. Nola, der zur selben Zeit eine Basilika in Fundi mit einer Vielzahl von Märtyrer- und Apostelreliquien ausstattete, übersandte seinem Freund Sulpicius eine Partikel des Heiligen Kreuzes, das zusammen mit weiteren Reliquien zur Aufnahme im Altar der neuen Kirche in Primuliacum bestimmt war. ${ }^{135}$ An diesem Umstand ist nicht allein bemerkenswert, dass Paulinus, der zu diesem Zeitpunkt noch nicht zum Bischof von Nola geweiht war, in ähnlicher Weise über Reliquien verfügte und sie zur Weihung von Basilikalbauten einsetzte wie die Bischöfe in den oberitalischen Gemeinden. Für den hier interessierenden Zusammenhang von größerer Bedeutung ist die kommunikative Funktion, die Reliquien in der von überregionalen Freundschaftsbeziehungen geprägten aristokratischen Welt des Paulinus erfüllten. Er selbst hatte die Kreuzespartikel als ein persönliches Geschenk von Melania d. Ä. empfangen, die sie wiederum aus den Händen des Bischofs Johannes von Jerusalem erhalten hatte; Paulinus leitete nun diese Gabe der conserva communis, Melania, an Bassula, die Schwiegermutter des Sulpicius, weiter, die sie zusammen mit Sulpicius in Empfang nehmen sollte - als ein gemeinsames Geschenk von Melania und Paulinus:

„Empfangt von euren gleichgesinnten Brüdern, die in allem Guten mit euch verbunden sein wollen, empfangt von ihnen das in seiner Bescheidenheit großartige Geschenk!“136

Die Bestimmung von Reliquien, Geschenke unter Gleichgesinnten und Ausdruck einer gemeinschaftlich geteilten Kultur zu sein, ${ }^{137}$ tritt in dieser Äußerung unmittelbar hervor. Der besondere Wert der Kreuzespartikel lag nicht allein in ihrer numinosen Wirkung, sondern in ihrer sozialen Funktion: Sie war ein gemeinschaftliches Gut, dessen Übermittlung unter den fratres unanimi Paulinus durch die detaillierte Aufzählung all derer, durch deren Hände sie gegangen war, beredten Ausdruck verlieh. In einer von amicitia- und Patronagebeziehungen strukturierten aristokratischen Lebenswelt, die Melania d. Ä., Paulinus von Nola und Sulpicius Severus teilten, ${ }^{138}$ erfüllten Reliquien wie die

135 Paul. Nol., epist. 31, 1. Begleitet war die Übersendung der Reliquien von Epigrammen, die Paulinus für den Altar in der Basilika von Primuliacum entwarf (ders., epist. 32, 7f.). Zu den Reliquien der Basilika in Fundi und den paulinischen Epigrammen, die dort angebracht waren, vgl. dens., epist. 31, 1 und 32, 17.

136 Paul. Nol., epist. 31, 1: quod nobis bonum benedicta Melania ab Hierusalem munere sancti inde episcopi Iohannis adtulit, hoc specialiter sorori nostrae venerabili Bassulae misit conserva communis; sed quod alteri vestrum datur utriusque vestrum est... accipite ergo ab unanimis fratribus in omni bono vestrum sibi consortium cupientibus, accipite magnum in modico munus.

137 Hervorgehoben von Brown 1981, 88-95; zuletzt ausführlich Mratschek 2002, 427-443.

138 Auch die Palästinapilgerin Silvia, deren Ankunft Sulpicius Severus erwartete (Paul. Nol., epist. 31, 1), und die Primuliacum und Brescia mit Reliquien aus dem Heiligen Land versorgte, entstammte der Aristokratie (vgl. Hunt 1972). Zur formativen Bedeutung von amicitia-Beziehungen für die 
Kreuzespartikel, die ihren Weg vom Heiligen Land über Nola bis nach Primuliacum gefunden hatte, die traditionelle Rolle von statusadäquaten Gaben und Geschenken: Sie hatten eine kommunikative Funktion, deren Bedeutung Paulinus bezeichnenderweise in einem Brief, dem Medium aristokratischer Freundschaftsbeziehungen schlechthin, ${ }^{139}$ artikulierte. ${ }^{140}$

Dass auch die in Rom ansässige Aristokratie um 400 in dieses Netz christlicher amicitia-Beziehungen einbezogen war, ist aus den brieflichen Verbindungen, die sie zu Hieronymus, Paulinus v. Nola und Augustinus unterhielt, bekannt. ${ }^{141}$ Einzelnen Angehörigen dieser Schicht dürften die wesentlichen Initiativen nicht nur zur Errichtung der römischen tituli, sondern auch zur Etablierung der Heiligenkulte in den römischen Titelkirchen zu verdanken sein - nicht den bischöflichen Gemeindeleitern und auch nicht der kaiserlichen Familie, die, anders als bei den Basilikalbauten aus der ersten Hälfte des 4. Jh., bei der Errichtung der Titelkirchen nur am Rande als Stifter in Erscheinung trat. ${ }^{142}$ Mit Pammachius und einer illustris femina Vestina können wir zwei Stifter römischer Titelkirchen fassen, die sich mit einiger Sicherheit dieser Schicht zuordnen lassen, und die ihre Kirchen jeweils mit Heiligenpatrozinien ausstatteten, die übereinstimmend auf Mailand und Oberitalien als

Aristokratie, unabhängig von Fragen der Religionszugehörigkeit, vgl. allgemein Salzman 2002, 211-213.

139 Für diese Funktion von Briefen als Medien eines standesspezifischen Kommunikationsrituals vgl. Bruggisser 1993, bes. 4-24, der als ein zentrales Element dieser Briefkultur die erfolgreiche Vermittlung von Patronage ausmacht: Sie war das zentrale Feld, auf dem sich die amicitia zu bewähren hatte und zugleich Statusdifferenzierungen zwischen den amici zutage traten (ebd., 1315). Im oben genannten Beispiel konnte Melania durch ihre Beziehungen zum Bischof von Jerusalem die Kreuzesreliquie für Paulinus erwirken und so als Maklerin für ihn tätig werden. Bei der Übersendung von Reliquien wurde neben dieser sozialen Ebene von Maklerpatronage noch eine weitere wirksam, die denjenigen, der Reliquien an einen Dritten übermittelte, zu einem Vermittler und Makler der durch den Heiligen verkörperten göttlichen Macht machte (vgl. auch Trout 1999, 191).

140 Die Bedeutung der Kreuzesreliquie als einer persönlichen Freundschaftsgabe des Paulinus an Sulpicius kommt auch darin zum Ausdruck, dass Paulinus die Möglichkeit in Aussicht stellt, dass Sulpicius die Reliquie gar nicht im Altar der neuen Kirche rekondieren, sondern eher als ein persönliches Phylakterion behalten werde (Paul. Nol., epist. 32, 8).

141 Eine umfassende Arbeit zu diesem Themenkomplex, die das gesamte prosopographische Material aus den Briefcorpora von Hieronymus, Paulinus, Augustinus und Symmachus zu einer Geschichte der stadtrömischen Aristokratie in der Spätantike verarbeiten würde, fehlt. Wesentliche Beiträge haben in jüngerer Zeit vor allem die Monographien von Rebenich 1992, Trout 1999, Mratschek 2002 und Lizzi Testa 2004 (a) geleistet.

142 Das einzige gesicherte Beispiel ist der titulus apostolorum, wo sich die kaiserliche Beteiligung allerdings nur auf den Bau und die Ausstattung, nicht auch auf das Heiligenpatrozinium erstreckte (vgl. o., S. 114). Im Unterschied dazu sind in Ravenna aus dem 5. Jh. einige Kirchenpatrozinien römischer Heiliger bekannt, die vermutlich auf Initiative des theodosianischvalentinianischen Kaiserhauses dorthin gelangt sind (vgl. Deichmann 1969-1989, Bd. II, 3, 176f.). 
Ursprungsort hinweisen. ${ }^{143}$ Auch wenn der Überlieferung nicht zu entnehmen ist, über welche Vermittlung Pammachius und Vestina die Reliquien erhielten, auf denen das Patrozinium der zu ihren tituli gehörigen Kirchen beruhte, ist davon auszugehen, dass die Heiligen auf dem Weg der oben skizzierten aristokratischen Freundschaftsbeziehungen in den Besitz der beiden Titelgründer gelangten. Diese partizipierten auf diese Weise an der allgemeinen Verbreitung der Apostel- sowie der Gervasius- und Protasiusreliquien, die, wie bereits erwähnt, ${ }^{144}$ um 400 im wahrsten Sinne des Wortes besonders hoch „im Kurs“ standen und gerade deswegen als statusadäquate Freundschaftsgaben fungieren konnte, deren Übersendung eine besondere Wertschätzung zum Ausdruck brachte.

In Ermangelung weiterer literarischer und epigraphischer Quellen bleiben dies die einzigen gesicherten Hinweise auf eine maßgebliche Beteiligung der römischen Aristokratie an der Etablierung von Heiligenpatrozinien in den tituli der Stadt. Die hagiographische Überlieferung Roms hat jedoch noch einige weitere Hinweise bewahrt, die dieser Interpretationsrichtung Nachdruck verleihen. Dabei handelt es sich zum einen um die passio Cantianorum, die das Schicksal dreier Märtyrer aus Aquileia - Cantius, Cantianus und Cantianilla - zum Gegenstand hat. Die passio ist in zwei, in einigen Punkten voneinander abweichenden Varianten überliefert, die jedoch über weite Strecken der Darstellung übereinstimmen. Danach kamen die drei Cantiani aus Rom und begaben sich von dort nach Aquileia, wo sie gemeinsam mit ihrem Erzieher Protus an einem Ort namens ad aquas gradatas (das heutige San Canzian d'Isonzo) das Martyrium erlitten. Die ursprüngliche dieser beiden Fassungen ${ }^{145}$ fügt der römischen Herkunft der drei Märtyrer

143 Pammachius war Angehöriger der gens Furia und vor 396 proconsul vermutlich der Provinz Africa. Zu seiner Identität mit dem Gründer des titulus Pammachii s. o., Anm. 106. Über Vestina ist außer der Angabe des Liber Pontificalis, sie sei eine illustris femina gewesen (LP I, 220), nichts bekannt. Anhand der von Vestina für den titulus gestifteten Immobilien, die der Liber Pontificalis überliefert, hat Palmer 1974, 146-154 auf eine Verbindung mit der Familie des Q. Valerius Vegetus (cos. 91) geschlossen. In Anbetracht der Tatsache, dass sich sämtliche städtischen Grundstücke, die für den titulus Vestinae bestimmt waren, auf die sechste Region der Stadt konzentrierten, kann es als wahrscheinlich gelten, dass sich dort auch der Wohnsitz der Vestina befand (zur topographischen Verteilung der gestifteten Immobilien vgl. die Übersicht bei Hillner 2004, 185 187 u. 289).

144 S. o., Anm. 131.

145 Die beiden Varianten der Passio werden repräsentiert durch 1) BHL 1547 (unter dem Namen des Ambrosius überliefert; Text in Mombritius, Bd. 1, 278-280) und 2) BHL 1543-1546 (den Text von BHL 1545 bietet Mabillon 1729, 467-470; AASS Maii VII, 421-423 orientiert sich an BHL 1546, nimmt jedoch Korrekturen nach dem Text von Mombritius vor. Bei BHL 1548, 1549 a und c lässt sich anhand der Angaben zum inc. und des. nicht entscheiden, welcher der beiden Varianten sie näher stehen). BHL 1543-1546 - im folgenden als „römische Fassung“ bezeichnet - ist ausführlicher als BHL 1547, da die römische Herkunft der Cantiani präzisiert und der aquileische Märtyrer Chrysogonus in die Handlung einbezogen wird. Dufourcq 19001910/1988, Bd. 2, 215; Lanzoni 1927, Bd. 2, 867-870; Cracco Ruggini 1988, 75-77 erklären BHL 
noch ein weiteres Detail hinzu: Die Cantiani sollen aus der Gens der Anicier stammen, mit dem Kaiser Carinus verwandt gewesen und im römischen Viertel Trastevere aufgewachsen sein, bevor sie sich nach Aquileia aufmachten, um dort den Märtyrer Chrysogonus zu suchen. ${ }^{146}$ In der

1547 für die ursprüngliche Fassung; die entgegengesetzte Ansicht vertritt - allerdings ohne nähere Begründung - Mesnard 1935, 37f.; unentschieden ist Cuscito 1987, 263f. Die Verfechter der These, dass Ps.-Ambrosius (BHL 1547) die ursprüngliche Variante der Passio biete, berufen sich darauf, dass sich die Darstellung auf die drei Cantiani und ihren Erzieher Protus konzentriere, während die römische Fassung den Märtyrer Chrysogonus mit einbeziehe und insgesamt stärkere Einflüsse der Chrysogonuslegende, wie sie die passio Anastasiae überliefert, erkennen lasse: So geben die meisten Handschriften von BHL 1547 den Namen des Presbyters, der die drei Cantiani bestattet, mit Zenus an, während er in der römische Fassung Zoilus heißt eine offenkundige Anlehnung an die passio Anastasiae, wo Chrysogonus von einem Presbyter Zoilus beigesetzt wird (passio Anastasiae 9). Ps.-Ambrosius enthalte demnach die ursprüngliche Version der passio Cantianorum, die unter dem Einfluss der passio Anastasiae zur römischen Fassung umgestaltet worden sei. Dieser Deutung stehen jedoch die überzeugenderen Argumente dafür entgegen, dass man von der Priorität der römischen Fassung auszugehen hat. 1. Sowohl Ps.-Ambrosius als auch die maßgeblichen Handschriften der römischen Fassung (BHL 1545, 1546) enthalten einen Prolog, der die Gattung der Heiligenlegenden gegen den Vorwurf, es handele sich um apokryphe Literatur, in Schutz nimmt, und der auch weiteren römischen Heiligenlegenden begegnet (s. u., Anm. 165 u. 168). Wie ein Vergleich mit den übrigen Legenden, die mit diesem Prolog eröffnet werden, deutlich macht, bietet die römische Fassung der passio Cantianorum den vollständigen, Ps.-Ambrosius hingegen einen gekürzten Text dieses Prologs. Hinzu kommt, dass Ps.-Ambrosius völlig unvermittelt mit der „Ankunft“ der drei Cantiani einsetzt (vgl. Mombritius I, 278, 40f.), ohne zuvor irgend etwas über den Schauplatz der Handlung oder die Herkunft der drei Ankömmlinge verlauten zu lassen - das Ergebnis dessen, dass der Verfasser von Ps.-Ambrosius den Text der römischen Fassung sinnentstellend gekürzt hat (Ps.-Ambrosius setzt im 4. Kapitel der römischen Fassung ein; vgl. Mombritius I, 278, 40f.: audientes Dulcisius praeses et Sisinius comes sanctos Dei advenisse, conveniri eos ab apparitoribus praeceperunt, ut diis tura ponerent mit passio Cantii, Cantiani et Cantianillae 4: audientes itaque iniquissimi iudices (scil. Dulcitius und Sisinnius), quod sancti Dei Cantius, Cantianus et Protus, atque Cantianilla de Roma advenissent, statim conveniri ab apparitoribus praecipiuntur, ut diis thura imponerent). 2. Nicht nur die römische Fassung, sondern auch Ps.-Ambrosius weist deutliche Einflüsse der Chrysogonuslegende auf: Die beiden Verfolger, der praeses Dulcitius und der comes Sisinnius, verdanken ihre Herkunft eindeutig der passio Anastasiae. Man kann daher nicht davon ausgehen, dass die römische Fassung eine sekundäre, stark von der passio Anastasiae beeinflusste Variante der passio Cantianorum sei, während Ps.-Ambrosius eine ursprüngliche und unverfälschte Variante der Legende biete. - Es ist demnach von der römischen Fassung als der ursprünglichen Version der passio Cantianorum auszugehen, die von einem späteren Bearbeiter (Ps.Ambrosius) gekürzt wurde. Auffällig ist, dass Ps.-Ambrosius gezielt diejenigen Aspekte unterdrückt, die auf eine Verbindung zwischen den Cantiani und Chrysogonus hinweisen: Sowohl der Hinweis auf den römischen titulus Chrysogoni als auch auf die Suche der Cantiani nach Chrysogonus und ihre Bestattung in der Nähe seiner Memoria ad aquas gradatas fehlen. Dies deutet auf eine Entstehungszeit hin, in der der Kult für die Cantiani den benachbarten Chrysogonuskult zu überflügeln begann. Mit dem Bau einer monumentalen Basilika im frühen 6. Jh. erhielten die Cantiani eine Kultstätte, die die nur wenige hundert Meter entfernte Memoria für Chrysogonus und Protus in den Schatten stellte und die Cantiani gegenüber Chrysogonus in einer Weise aufwertete, die sich auch in der späteren Namensgebung des Ortes (vicus sanctorum Cancianorum erstmals 819 für das antike Toponym aquae gradatae belegt) niederschlug (vgl. Cuscito 1987, 259).

146 Passio Cantii, Cantiani et Cantianillae 2: beatissimos igitur martyres Christi, Cantium, Cantianum et Cantianillam legimus a paedagogo suo Proto valde catholica fide fuisse edoctos, qui de genere Aniciorum, hoc est 
Forschung hat vor allem die hier ausgesprochene Verbindung zwischen den Aniciern, Kaiser Carinus und Aquileia Aufmerksamkeit gefunden und Anlass dazu gegeben, diese Nachricht in Verbindung mit einer Angabe der Historia Augusta zur angeblichen Herkunft von Kaiser Carus, dem Vater des Carinus, aus Aquileia zu setzen. ${ }^{147}$ Die passio Cantianorum und die Carusvita der Historia Augusta sollen danach eine im späten 4. Jh. lancierte kaiserliche Abstammung der gens Anicia verarbeiten und dazu auf affirmative (passio) bzw. polemische (Historia Augusta) Art Stellung beziehen. ${ }^{148}$ Gegen diese Interpretation sind jedoch zuletzt berechtigte Einwände laut geworden, die darauf hinauslaufen, die Beziehungen zwischen den Cantiani und Carinus sowie zwischen den Cantiani und den Aniciern andererseits als zwei voneinander getrennte Dinge zu betrachten, die erst von der Passio in der beschriebenen Weise miteinander verbunden wurden. ${ }^{149} \mathrm{Im}$ folgenden soll daher nicht die angeblich propagierte Abstammung der Anicier von Carinus den Ausgangspunkt der Deutung bilden, sondern der Umstand, dass die Cantiani in der Passio als Angehörige der gens Anicia bezeichnet werden.

In dieser Angabe dürfte mehr durchscheinen als rein erfundenes legendarisches Colorit, das den Heiligen in den Augen der Leser eine größere Plastizität verleihen sollte. Der Hinweis auf die Herkunft der Cantiani aus der 14. Region Roms ist vielmehr offenkundig eine präzise Anspielung auf die Kirche des titulus Chrysogoni, die sich in Trastevere erhob und den Heiligen beherbergte, der die Cantiani zu ihrem Aufbruch von Rom nach Aquileia veranlasste. ${ }^{150} \mathrm{Da}$ wiederum der Hinweis auf das genus Aniciorum aus den eben

divae memoriae Carini Imperatoris, noscuntur progeniti et intra urbem Romam in quarta decima regione generati atque educati probantur, Diocletiano Roma imperante, Maximiano partibus Illyricis, Carino quoque intra Gallias bene agente erga Christianos, qui non post multum tempus defunctus est. Vgl. auch c. 4: advenerunt enim tres germani ex urbe Roma, qui de genere Carini imperatoris esse noscuntur.

147 Hist. Aug., Car. 4, 4.

148 Mazzarino 1966, 219-221; 228f.; ähnlich Cracco Ruggini 1988, 77-81.

149 Paschoud (2001), in: Historia Augusta V, 2, 220-222, 340. Die Cantiani stammten aus einer lokal bedeutsamen, in der Gegend von Aquileia mehrfach bezeugten Familie der Cantii und wurden vermutlich im Zuge der Machtübernahme Diocletians in Oberitalien als Parteigänger des Carinus aus politischen Gründen hingerichtet. Die spätere Überlieferung machte daraus ein Martyrium und die drei Cantiani zu Familienangehörigen des Kaisers. Auf eine im 4. Jh. propagierte Verbindung zwischen den Aniciern und Carinus deutet hingegen - sieht man von den Angaben der passio Cantianorum ab - nichts hin.

150 So auch übereinstimmend Mesnard 1935, 37f.; Niero 1982, 165; Cracco Ruggini 1988, 77. Der präzise Hinweis auf das Viertel Trastevere zeigt, dass der Verfasser der passio Cantianorum über lokale Ortskenntnisse verfügte; dies verleiht auch seiner Angabe zu den Anicii historische Glaubwürdigkeit - im Unterschied zu anderen Heiligenlegenden, in denen auf die Anicier als Chiffre rekurriert wird, um die adlige Abstammung der Protagonisten aus einer christlichen Familie zu „dokumentieren“ (vgl. die passio Christinae 1). - Hinter den Wohnhäusern von Heiligen verbergen sich in den römischen gesta martyrum häufig Hinweise auf innerhalb der Stadt gelegene Kultstätten dieser Heiligen, wie sie die römischen Titelkirchen darstellten (vgl. u., S. 439). Es ist jedoch nicht bekannt, dass die Cantiani über einen solchen Kultort in Rom verfügten. Vielmehr hat der prononcierte Chrysogonusbezug der passio Cantianorum (Suche nach 
ausgeführten Gründen nicht über die von der Passio propagierte Abstammung der Cantiani von Kaiser Carinus erklärt werden kann, bleibt nur eine plausible Möglichkeit, diese Angabe zu erklären: Es muss eine historische Verbindung zwischen dem Chrysogonuskult in der römischen Titelkirche in Trastevere und der Familie der Anicier bestanden haben. Da der Chrysogonuskult ursprünglich in Aquileia beheimatet war und zu einem nicht genau bestimmbaren Zeitpunkt um die Wende vom 4. zum 5. Jh. von dort nach Rom übertragen wurde, ${ }^{151}$ liegt die Schlussfolgerung nahe, dass die Familie der Anicier an dieser Kultübertragung aus Aquileia nach Rom maßgeblich beteiligt war. Diese Hypothese lässt sich ohne weiteres mit der Haltung vereinbaren, die die Anicier in diesem Zeitraum gegenüber dem Christentum an den Tag legten. Unter den führenden aristokratischen Familien sind sie fraglos diejenige Gens, die in der zweiten Hälfte des 4. und im frühen 5. Jh. nicht nur die zahlreichsten, sondern auch die prononciertesten und prominentesten Beispiele für christliche Angehörige des Senatorenstandes in Rom aufweisen kann. ${ }^{152}$ Besondere Popularität erlangten Sextus Petronius Probus - zugleich als Erneuerer und culmen der anicischen Gens gefeiert und einer der einflussreichsten römischen Aristokraten seiner Zeit - und seine Frau Anicia Faltonia Proba, deren Großmutter bereits als Dichterin eines vergilischen Centos auf Episoden der biblischen Geschichte hervorgetreten war. ${ }^{153}$ Beide waren tonangebende Vertreter einer für die religiöse Haltung der römischen Aristokratie im 4. Jh. charakteristischen „respectable christianity“, deren religiöse Orientierung fest in den kulturellen und sozialen Grundlagen der traditionel-

Chrysogonus als Motiv für den Aufbruch der Cantiani nach Aquileia; göttliche Vision, die das Martyrium der drei Heiligen am Chrysogonusgrab ankündigt; Bestattung der Cantiani iuxta Chrysogonum in aquae gradatae) den Verfasser der Passio dazu veranlasst, die mit Chrysogonus verbundenen Örtlichkeiten der römischen Sakraltopographie auf die Cantiani zu übertragen.

151 S. o., S. 349-351.

152 Bereits in der ersten Hälfte des 4. Jh. waren zahlreiche Angehörige der gens Anicia Christen, vgl. Barnes/Westall 1991, 51-54; Sivan 1993, bes. 150-154.

153 Zu Sextus Petronius Probus und seiner Führungsrolle innerhalb der römischen Aristokratie vor der Mitte der 360er bis zur Mitte der 380er Jahre vgl. Novak 1980. Ausonius spricht ihn 371 oder 374 als Erneuerer der Amnier und der Anicier an (Aus., epist. 9b [Green], 32-34: stirpis novator Anniae (lies mit Barnes/Westall 1991, 57: Amniae) paribusque comit infulis Aniciorum stemmata); als Aniciae domus culmen erscheint Sextus Petronius Probus in einem (postumen) Epigramm auf einer Statuenbasis, die in seiner Residenz auf dem Pincio aufgestellt und der als Pendant ein vergleichbares Monument für Faltonia Proba zugeordnet war (CIL VI, 1753 und 1755). Faltonia Proba scheint nach dem Tod ihres Mannes als die wesentliche Garantin der sozialen Position der Familie angesehen worden zu sein. Dies geht nicht nur daraus hervor, dass aus dieser Zeit die (für ein weiblich Mitglied der römischen Aristokratie ungewöhnlich hohe) Zahl von drei Ehreninschriften erhalten geblieben ist, die von Probas Kindern in ihrer domus errichtet wurden. Auch die Diktion der Inschriften, in der Proba als consulis uxor, filia und mater sowie als Zierde der Amnier, Pincier und Anicier erscheint (CIL VI, 1754), macht deutlich, dass man sie nicht nur mit den exemplarischen Tugenden einer römischen matrona ehrte (vgl. Niquet 2000, 189-199), sondern ihr auch eine maßgebliche Rolle für das Ansehen und den Rang der Familie zumaß. 
len aristokratischer Lebensführung verankert war. ${ }^{154}$ So verband Probus, der als einflussreicher Freund des Ambrosius maßgeblich zu dessen Bischofswahl beigetragen hatte, Prinzipien aristokratischer Selbstdarstellung mit christlichen Frömmigkeitspraktiken, indem er an der vatikanischen Petrusbasilika, in unmittelbarer Nähe der Petrusmemoria, ein Mausoleum von beeindruckenden Ausmaßen errichtete, das u. a. ein Grabepigramm des Ambrosius v. Mailand aufnahm. ${ }^{155}$ Faltonia Proba verzichtete nach dem Tod ihres Mannes auf eine erneute Heirat, scharte in ihrem Haus eine Gemeinschaft von virgines um sich und begründete damit das in der Zeit vor dem Fall der Stadt im Jahr 410 vielleicht auffälligste Beispiel unter den Hausgemeinschaften aristokratischer Asketinnen in und um Rom, über die wir vor allem durch die Korrespondenz des Hieronymus unterrichtet sind. ${ }^{156}$

Spätestens seit der Mitte des 5. Jh. begann die zu den ersten Adressen Roms zählende Familie auch sichtbare Spuren in der christlichen Sakral- und Gemeindetopographie der Stadt zu hinterlassen. Demetrias, eine Enkelin der Anicia Faltonia Proba, die deren asketische Haltung fortführte und sich zur virgo weihen ließ, ${ }^{157}$ beauftragte Bischof Leo I. (440-461), eine im Suburbium gelegene Villa der Familie an der via Latina in eine Kirche umzuwandeln. ${ }^{158}$ Auf dem Marsfeld, im Bereich der porticus Minucia, entstand das Xenodochium Aniciorum - eines der frühesten für Rom bezeugten Beispiele für diesen Typ karitativer Einrichtungen. ${ }^{159}$ Der Angabe der passio Cantianorum, die eine

154 Zur der von Peter Brown geprägten Formel der ,,respectable aristocratic christianity“ Roms und den Aniciern als ihrem herausragendsten Beispiel vgl. Brown 1961, bes. 9f.; ebenso Novak 1980, $491 \mathrm{f}$.

155 Das Mausoleum der Anicier in S. Pietro wurde bereits in der Mitte des 15. Jh. stark zerstört, jedoch erst beim Neubau von S. Pietro Ende des 16. Jh. vollständig überbaut. Seine Lage und Dimensionen - ein dreischiffiger Bau im Scheitelpunkt der Apsis von S. Pietro - sind auf dem Plan von Alfarano (vgl. Alfarano/Cerrati 1914, tab. I, k); zur Glaubwürdigkeit von Alfaranos Angaben und der mutmaßlichen Innenarchitektur des Baus vgl. Krautheimer 1964 (a), 173-175. Zu den beiden im Mausoleum angebrachten Epigrammen und der Verfasserfrage vgl. Schmidt 1999.

156 Hier., epist. 130, 7. Zu Verortung von Probas Zirkel im Kontext ähnlich strukturierter Gruppierungen von Asketinnen im Rom des späten 4. Jh. vgl. Gordini 1956, bes. 243-247; Rebenich 1992, 154-170. Zu Proba als dem „most visible example“ aristokratischer Askese in Rom vgl. Curran 2000, 309.

157 Hier., epist. 130; Aug., epist. 188, 1.

158 Zur Kirche S. Stefano in via Latina s. u., S. 399.

159 Ein Xenodochium Anichiorum wird erstmals unter Gregor I. (590-604) erwähnt; auf dieses

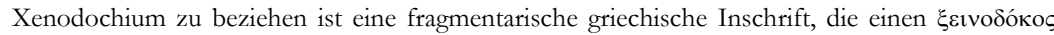
namens Faustus - ein typisches Cognomen der Anicier - erwähnt und in der vermutlich die Amtsbezeichnung als ह̈ $\pi \alpha \rho \chi 0 \varsigma$ zu ergänzen ist. Dies führt auf zwei als Stadtpräfekten bekannte Anicii Fausti des 5. Jh., Anicius Acilius Glabrius Faustus (PUR 421-423, 425 und zwischen 425 und 437) und Anicius Acilius Aginatius Faustus (PUR zwischen 473 und 482). Vgl. zum Befund Santangeli Valenzani 1996-1997, 205-207. Eine nähere Eingrenzung erscheint nicht möglich. Der Umstand, dass Anicius Acilius Aginatius Faustus die Wiederherstellung einer Minervastatue im Atrium Minervae der Senatskurie veranlasste, ist kein Ausdruck religiöser Selbstdarstellung; die 
besondere Beziehung der Anicier zum Chrysogonuskult in der Titelkirche des Heiligen in Trastevere voraussetzt, ist daher ohne weiteres Glauben zu schenken. Für den konkreten historischen Kontext bleibt man freilich auf Vermutungen angewiesen. Obwohl christliche Bauten von Angehörigen der gens Anicia erst für das 5. Jh. bezeugt sind, erscheint es durchaus naheliegend, von einer Übertragung des Chrysogonuskultes von Aquileia nach Rom noch im ausgehenden 4. Jh. auszugehen. Sextus Petronius Probus war als langjähriger PPO Illyrici, Italiae et Africae über Jahrzehnte hinweg verstärkt in Oberitalien präsent und verfügte nachweislich über intensive Verbindungen zur Region um Aquileia. ${ }^{160}$ Während des langen Zeitraums seiner Präfektur dürften die Beziehungen der Anicier zu den lokalen Eliten in Oberitalien, wo der Clan der Petronier-Anicier auch über ausgedehnten Grundbesitz verfügte, beträchtlich intensiviert worden sein. ${ }^{161}$ Die ausgeprägten Beziehungen, die Probus nach Oberitalien unterhielt, seine innerhalb der römischen Aristokratie allgemein bekannte (und geradezu notorische) Pflege von Patronagebeziehungen ${ }^{162}$ und die Annahme, dass eine Kultübertragung des Chrysogonus von Aquileia nach Rom - ähnlich wie bei Paulinus, Sulpicius und Melania auf dem Weg von aristokratischen Freundschaftsbeziehungen vermittelt wurde, lassen sich zu einer zwar nicht zwingenden, aber insgesamt ansprechenden Hypothese bezüglich der Kultübertragung des Chrysogonus von Aquileia nach Rom verbinden, die auch mit dem Befund, dass Chrysogonus nachweislich bereits im frühen 5. Jh. in Rom als Heiliger verehrt wurde, in Einklang steht. ${ }^{163}$

Bemerkenswert an der passio Cantianorum ist, dass sie in einem weiteren Kontext gesehen werden muss, der auch die legendarischen Traditionen um

pagane Götterstatue verkörpert vielmehr ein traditionsreiches Monument römischer vetustas, das als solches und in konservatorischer Absicht vor dem Verfall geschützt werden sollte (so Fraschetti 1999, 157-162; anders Niquet 2000, 226).

160 Probus erhielt die Prätorianerpräfektur als erster Christ und übte diese Funktion über einen längeren Zeitraum hinweg aus als jeder andere Prätorianerpräfekt des 4. und 5. Jh. (vgl. Pietri 1982, 98f.); er bekleidete das Amt in den Jahren 364 (Illyricum), 366 (Gallien), 368-375 und 383384 (jeweils Illyricum, Italien und Africa); für die Probleme dieser Rekonstruktion s. allerdings zuletzt Lizzi Testa 2004 (a), 316-319. Probus' enge Verbindung zur Region um Aquileia bezeugt die Ehreninschrift, die ihm die Bewohner von Venetia et Histria in der römischen Residenz ihres patronus praestantissimus errichten ließen (CIL VI, 1751[aus dem Jahr 378]: ob insignia erga se remediorum genera Veneti adque Histri, peculiares eius, patrono praestantissimo.

161 So auch Pietri 1982, 111-116.

162 Probus' allzu großzügige Förderung von Freunden und die Bereitschaft, Klienten auch sine respectu boni honestique zu verteidigen, trug ihm die Kritik von Ammianus Marcellinus ein (Amm. 27, 11, 2. 4); vgl. auch Novak 1980, $482 \mathrm{f}$.

163 Von dem Zeitraum abgesehen, in dem Petronius Probus als Prätorianerpräfekt in Oberitalien tätig war, lassen sich keine direkten Verbindungen der Anicier zu Aquileia nachweisen; eine aus dem Jahr 459 datierende Grabinschrift aus Aquileia, die einer virgo namens Anicia Ulfina gesetzt wurde (CIL V $47^{*}$ ), wird in der Forschung überwiegend als Fälschung des 18. Jh. angesehen (vgl. zuletzt Lizzi Testa 2004, 248). 
Chrysogonus und Anastasia, die den Kern des Legendenzyklus der passio Anastasiae bilden, ${ }^{164}$ mit einbezieht. Ein Vergleich der passio Anastasiae mit der passio Cantianorum weist so viele Berührungspunkte auf, dass an einem gemeinsamen Ursprung dieser beiden Texte nicht gezweifelt werden kann: Beide Passionen eröffnen mit einem identischen Prolog, der die Lektüre von Märtyrerakten verteidigt, ${ }^{165}$ der Weggang der Cantiani aus Rom nach Aquileia wird mit ihrer Liebe zu Chrysogonus begründet, und in der passio Cantianorum spielen, ebenso wie in der passio Anastasiae, Protus und Zoilus sowie die beiden Verfolger Dulcitius und Sisinnius eine zentrale Rolle als Protagonisten des Geschehens. Diese unverkennbaren redaktionellen und inhaltlichen Übereinstimmungen zwischen der passio Cantianorum und der passio Anastasiae finden ihre Fortsetzung darin, dass beide auf derselben Handlungsstruktur basieren: Ähnlich wie die Cantiani erscheinen auch Chrysogonus und Anastasia in der passio Anastasiae als Heilige römischen Ursprungs, die in aristokratischen domus der Stadt leben und deren Bewohner zum Christentum bekehren, bevor sie in Aquileia bzw. auf den palmarischen Inseln das Martyrium erleiden. ${ }^{166}$ In einer für die römischen Heiligenlegenden charakteristischen Weise verarbeitet damit die passio Anastasiae - bzw. die legendarischen Traditionen, auf denen die Passio beruht - Ursprungslegenden der beiden Titelkirchen Roms, des titulus Chrysogoni und des titulus Anastasiae. ${ }^{167}$ Angesichts der aus der passio Cantianorum erschließbaren Beteiligung Anicier an der Gründung des titulus Chrysogoni in Trastevere und an der Übertragung des Chrysogonuskultes nach Rom stellt sich die Frage, ob auch für den titulus Anastasiae etwas Vergleichbares vorausgesetzt werden kann, und ob dieser Sachverhalt der Grund dafür ist, dass in der passio Anastasiae eine Verbindung zwischen den beiden Heiligen hergestellt wird.

Für diese Frage ist es zunächst notwendig, zwischen der Abfassungszeit der passio Anastasiae in ihrer überlieferten Form und dem legendarischen Material, das sie verarbeitet, zu differenzieren. Es wurde bereits darauf hingewiesen, dass es sich bei der passio Anastasiae um eine zyklische Heiligenlegende handelt, die unterschiedliche Teillegenden eigenständiger Provenienz zu einer zusammenhängenden Handlung zusammenfügte. Während man für die passio

164 Zur Struktur der Passio s. o., Anm. 92.

165 Dieser Prolog erscheint auch noch in weiteren Märtyrerlegenden (z. B. der passio Praxedis et Potentianae), geht jedoch vermutlich auf die passio Cantianorum und der passio Anastasiae zurück, da die anderen Legenden nur eine gekürzte Fassung dieses Prologs bieten (vgl. de Gaiffier 1964, bes. 350).

166 Anastasia, Tochter eines heidnischen Vaters namens Praetextatus und einer Christin namens Fausta, wird im Haus ihres heidnischen Gatten Publius gefangen gehalten. Ihr Erzieher Chrysogonus lebt im Haus des Vicarius Rufus, den er cum omni domo sua zum Christentum bekehrt (passio Anastasiae 2f.).

$167 \mathrm{Zu}$ den aristokratischen Häusern Roms als einem typischen Strukturelement der römischen Heiligenlegenden und zur aitiologischen Dimension dieser Angaben u., S. 439. 
Anastasiae aufgrund ihres apologetischen Prologs, der dieselbe Kenntnis einer amtskirchlichen Kritik an den römischen Heiligenlegenden voraussetzt wie das frühestens unter Gelasius I. (492-496) entstandene decretum Gelasianum, nicht über den Beginn des 6. Jh. hinaus zurückgehen kann, ${ }^{168}$ müssen die legendarischen Traditionen, die in der passio Anastasiae verarbeitet werden, älter sein: Von einer Überführung der Anastasia von Sirmium nach Konstantinopel, die unter dem Patriarchen Gennadius (458-471) erfolgte, ${ }^{169}$ ist in der Passio, in der Anastasia als eine sirmische Heilige erscheint, noch keine Rede. Auch dürfte eine Version der passio Anastasiae bereits um die Mitte des 5. Jh. in Rom bekannt gewesen sein. ${ }^{170}$ Inwieweit diese legendarischen Traditionen zu Chrysogonus und Anastasia Hinweise darauf enthielten, dass beide Kulte unter ähnlichen Umständen in Rom heimisch wurden, und den Verfasser der passio Anastasiae aus diesem Grund dazu veranlassten, die beiden Titelheiligen in eine Legende aufzunehmen, lässt sich nach der Sachlage nicht zweifelsfrei entscheiden. Es ist jedoch zu berücksichtigen, dass sich die üblicherweise vertretene Ansicht, erst während des 6. Jh. seien zwei Titelgründer namens Anastasia und Chrysogonus mit den beiden namensgleichen Heiligen identifiziert worden und dies wiederum habe den Anlass dafür gebildet, diesen beiden auswärtigen Heiligen durch die passio Anastasiae eine römische Herkunft zu geben, ${ }^{171}$ nach den oben gemachten Bemerkungen zu den Ursprüngen der Heiligenpatrozinien in den beiden Titelkirchen nicht aufrecht erhalten lässt. Zur Erinnerung: Chrysogonus und Anastasia wurden bereits zu Beginn des 5. Jh. in den römischen tituli als Heilige verehrt und begründeten dort ein Patro-

168 Zum Aufbau des decretum Gelasianum, seinem auf die Lektüre der Heiligenlegenden bezogenen Passus und den gängigen Datierungsansätzen, die sich zwischen 492/496 und dem ausgehenden 6. Jh. bewegen, s. o., S. 267, Anm. 178. Fälschlicherweise wird der Prolog, den die passio Anastasiae und andere römische Legenden enthalten, in der Forschung als eine Bezugnahme auf das decretum Gelasianum selbst angesehen (de Gaiffier 1964, 347; Lizzi Testa 2004, 257). Dies ist insofern nicht korrekt, als das decretum Gelasianum die Glaubenshaltung und Katholizität der Märtyrer ausdrücklich anerkennt, die Heiligenlegenden nicht unter die Apokryphen rechnet und hervorhebt, dass die Silvesterakten von vielen Rechtgläubigen gelesen werden (s. o., S. 268, Anm. 181). Diese ausdrücklichen Zugeständnisse des decretum Gelasianum machen deutlich, dass es nicht den Ausgangspunkt der Kritik an den Heiligenlegenden bildete, sondern vielmehr seinerseits auf kritische Strömungen reagierte, die zur Zeit der Abfassung des decretum bereits bestanden haben müssen. Der hagiographische Prolog, wie er in der passio Anastasiae und der passio Cantianorum begegnet, könnte demnach durchaus älter sein als das decretum Gelasianum. Obwohl das decretum Gelasianum aus diesen Gründen nicht als terminus ante für den hagiographischen Prolog herangezogen werden kann, spiegeln beide eine aktuelle Debatte um die römischen Märtyrerlegenden wider, was darauf schließen lässt, dass sie in etwa zur selben Zeit entstanden sind; man wird daher bis auf weiteres an einer Datierung der passio Anastasiae um 500 festhalten.

169 S. o., Anm. 91.

170 Dem Verfasser des liber ad Gregoriam - vermutlich Arnobius d. J., der um 450 in Rom wirkte war die Anastasialegende in den Grundzügen, wie sie in der passio Anastasiae begegnet, bekannt (vgl. Arnob. Iun., ad Greg. 5; zur Verfasserschaft des Arnobius s. Morin 1913, 325-340).

171 Mesnard 1935, 37f., 44-46; Niero 1982, 160-166; Cuscito 1992, 74-80. 
zinium, das sich vermutlich einer Übertragung von Reliquien der beiden Heiligen nach Rom verdankte. ${ }^{172}$ Eine „Romanisierung“ der beiden auswärtigen Heiligen, wie sie die passio Anastasiae erkennen lässt, ist demnach vermutlich nicht eine späte, erst viele Jahrzehnte nach der Gründung der Titelkirchen vorgenommene Konstruktion; vielmehr waren die Voraussetzungen dafür bereits in der Frühphase der beiden Titelkirchen gegeben, und dasselbe mag auch für die passio Anastasiae gelten, die zwischen dem „römischen“ Chrysogonus und der „römischen“ Anastasia eine enge Beziehung herstellte.

Gestützt wird diese Vermutung durch die Inschrift auf einer Säule, die sich bis zum Umbau von S. Anastasia im 17. Jh. in der Nähe des Hauptaltars befand, später verloren gegangen und nur durch Abschriften erhalten geblieben ist: Clodius Adelfius v(ir) c(larissimus) ex praefectis urbis uxori incomparabili et sibi fecit. ${ }^{173}$ Die „unvergleichliche Gattin“, der Clodius Celsinus Adelphius, Stadtpräfekt im Jahr 351, sein ehrendes Andenken erwies, zählt zu den bekanntesten christlichen Familienmitgliedern, die wir aus der gens Anicia des 4. Jh. kennen: Es handelt sich um Faltonia Betitia Proba, die Verfasserin eines aus Vergilzitaten komponierten Centos auf das Heilsgeschehen der biblischen Geschichte. ${ }^{174}$ Offenbar befand sich die Säule nicht von vornherein in der Titelkirche. Die Diktion der Inschrift weist sie als einen Grabtitulus aus, ${ }^{175}$ was darauf hindeutet, dass die Säule ursprünglich zu einem Sepulkralmonument gehörte und erst sekundär in die Kirche verbracht wurde. ${ }^{176}$ Wann und unter welchen Umständen dies geschah, lässt sich nicht sagen, doch besteht kein Grund zur Annahme, dass die Säule als eine zufällig verwendete Bauspolie in die Titelkirche am Fuß des Palatin gelangte. Vielmehr dokumentiert die Inschrift - ebenso wie beim titulus Chrysogoni - auch beim titulus Anastasiae die Verbindung der gens Anicia zu einer außerrömischen Heiligen und der Etablie-

172 S. o., S. $349-353$.

173 ICUR I, 19 = CIL VI, 1712. Die Abschriften zeigen, dass sich die Inschrift über die gesamte Höhe der Säule erstreckte. Über den Aufstellungskontext innerhalb der Kirche lassen sich keine sicheren Aussagen machen: Celso Cittadini spricht von einer „columna ad altare maius“. Offenbar handelt es um eine von den sechs Säulen der Pergola, die dem 1585 errichteten Hochaltar vorgelagert war, und mit der Umsetzung des Altars 1644 aus der Kirche verschwand (vgl. Buchowiecki, Bd. 1, 326; Krautheimer, in: Corpus I, 46). Matthews 1992, 299 geht davon aus, dass die Säule bereits im 4. Jh. Teil einer ähnlichen Monumentalisierung innerhalb der Kirche (Altarbaldachin) gewesen sei. Dem widerspricht jedoch der sepulkrale Duktus der Inschrift (vgl. dazu u., Anm. 175).

174 Zur Identität der Faltonia Betitia Proba mit der Verfasserin des Centos vgl. zuletzt ausführlich Matthews 1992.

175 Die Wendung uxori incomparabili et sibi fecit entspricht der von Grabinschriften und -monumenten (vgl. CIL VI, 31956; 32041), nicht der von Votivinschriften, in denen der Zweck, den der Schenkende durch seine Gabe für sich und andere verfolgt, durch die Wendung pro salute bezeichnet wird (vgl. z. B. Caillet 1993, 224 pro salute sua et omnium suorum).

176 So auch Lizzi Testa 2004, 264. Ein Grabmonument in der Kirche - gleichsam als Frühform einer innerhalb der Stadt vorgenommenen depositio ad sanctos - ist für die Mitte des 4. Jh. praktisch auszuschließen. 
rung ihres Kultes in Rom. Unter diesen Umständen gewinnt auch der enge Zusammenhang, den die passio Anastasiae zwischen den Legenden von Anastasia und Chrysogonus herstellt, an Gewicht: Was diese beiden Heiligen miteinander verband, war nicht nur ihre gemeinsame Herkunft aus dem illyrisch-adriatischen Raum, sondern vermutlich vor allem der Umstand, dass beide durch eine Vermittlung von Angehörigen der gens Anicia den Weg von Aquileia bzw. Sirmium nach Rom fanden.

Stellt man die Frage nach dem historischen Kontext für eine derartige Übertragung von Anastasiareliquien von Sirmium nach Rom, deuten auch hier Anzeichen auf Sextus Petronius Probus als möglichen Vermittler hin. Als langjähriger Prätorianerpräfekt von Italien, Afrika und dem Illyrikum unterhielt Probus enge Verbindungen zu Sirmium, dem Verwaltungszentrum und Sitz des PPO per Illyricum. ${ }^{177}$ Mit Probus ist demnach ein Angehöriger der gens Anicia historisch fassbar, dessen Beziehungen zu Oberitalien und zum Illyrikum für eine Kultübertragung sowohl von Chrysogonus als auch von Anastasia einen plausiblen historischen Hintergrund abgeben würden, und der sich zudem auch mit der Baugeschichte der beiden Titelkirchen in Einklang bringen ließe. ${ }^{178}$ Doch wird man sich in Ermangelung klarerer Hinweise $^{179}$ nicht auf diese Lösung versteifen wollen. Entscheidend ist vielmehr,

177 Zur Rolle Sirmiums als Sitz der illyrischen Prätorianerpräfektur vgl. Demandt 1989, 246. Probus ist für die Zeit seiner sich von 368 bis 375 erstreckenden Präfektur in Illyrikum, Italien und Afrika mehrfach als Adressat von Gesetzen in Sirmium bezeugt (Zusammenstellung in PLRE I, 738); vgl. ferner den Brief, den Ausonius im Jahr 371 oder 374 an Petronius Probus in Sirmium richtete (Aus., epist. 9b, 1 [Green]) und Amm. 29, 6, 9.

178 Das früheste Zeugnis für den titulus Anastasiae führt in die Zeit des Bischofs Damasus (366-384) (s. o., Anm. 89), der ein Zeitgenosse von Petronius Probus war. Entgegen anderslautender Vermutungen gibt es keine überzeugende Veranlassung dafür, von einer Gründung des titulus bereits in konstantinischer Zeit auszugehen (s. u., Anm. 180). Man wird daher auch weiterhin mit Krautheimer, in: Corpus I, 62 die Gründung der Kirche in die Zeit des Damasus datieren. - Die Errichtung der Titelkirche des Chrysogonus wird in der älteren Forschung meist in die Mitte oder 2. Hälfte des 5. Jh. datiert (vgl. Krautheimer, in: Corpus I, 157-159, Pietri 1978, 16-21), zuletzt ist man jedoch bis in das frühe 5. Jh. hinaufgegangen (Cecchelli 1999, 232-239). Anders als bei S. Anastasia ging der Chrysogonuskirche eine domus-Anlage voraus, innerhalb derer der Kirchenbau errichtet wurde. Möglicherweise wurden die Chrysogonusreliquien - ähnlich wie beim titulus Byzantis/Pammachii - zunächst in einer Hauskapelle aufbewahrt, bevor die domus dann in eine Kirche umgewandelt wurde. Hinweise auf eine domus der Anicier in Trastevere haben sich übrigens nicht erhalten; die einzige bekannte Residenz des Petronius Probus lag auf dem Pincio in der siebten Region (vgl. die Übersicht bei Hillner 2004, 287). Doch ist diesem Umstand keine größere Bedeutung beizumessen: Zum einen lässt sich das Gros der spätantiken domus Roms nicht lokalisieren; zum anderen ist bei manchen Aristokraten von mehreren Residenzen innerhalb der Stadt auszugehen und die Zahl an Neugründungen von domus innerhalb einer Familie insgesamt hoch anzusetzen (vgl. zuletzt Hillner 2004, 165f.).

179 Ein weiteres Indiz ist mit der Person von Anastasias Vater, des vir illustris Praetextatus, gegeben, hinter der sich der nicht weniger berühmte Zeitgenosse des Petronius Probus, Vettius Agorius Praetextatus, verbergen dürfte. Natürlich ist zu berücksichtigen, dass es sich bei den Namen in den römischen Heiligenlegenden - vor allem bei den Namen von Randakteuren wie Praetextatus - häufig entweder um reine Phantasieprodukte der Hagiographen oder um mündliche 
dass bei beiden Titelkirchen die Summe der hagiographischen und archäologischen Befunde darauf hinweist, dass sie bereits vom Moment ihrer Gründung an über Heiligenpatrozinien verfügten, die den Kirchen ihre Namen gaben, ${ }^{180}$ und dass diese Patrozinien auf Reliquientranslationen zurückgehen, die durch aristokratische Kommunikationsbeziehungen vermittelt wurden.

Die Beobachtungen zum titulus Chrysogoni und zum titulus Anastasiae machen exemplarisch deutlich, dass die Einführung auswärtiger Heiligenkulte, die sich seit dem 5. Jh. für einen Teil der römischen Titelkirchen nachweisen lassen, maßgeblich auf der Initiative der ceti dirigenti Roms beruht haben dürfte, die auch als Stifter der tituli und Träger des ,,second établissement materiel" das Erscheinungsbild der römischen Sakraltopographie im ausgehenden 4. und frühen 5. Jh. entscheidend prägten. Inwieweit sich dieser Befund verallgemeinern und über weitere bekannte Beispiele (titulus Vestinae, titulus Pammachii) hinaus ausdehnen lässt, muss in Anbetracht der spärlichen Quellenlage eine offene Frage bleiben. Dass sich eine der angesehensten Familien des spätrömischen Adels um eine Übertragung von Heiligenkulten nach Rom bemühte, liefert jedoch eine Bestätigung für den Interpretationsansatz, die Patrozinien der römischen Titelkirchen in den Kontext einer allgemeinen historischen Entwicklung einzuordnen, die um 400 durch Aristokraten wie Paulinus v. Nola, Sulpicius Severus und Melania d. Ä. repräsentiert wurde und Reliquien zu kostbaren Gaben aristokratischer amicitia- und Patronagebeziehungen werden ließ.

Folgt man dieser Deutung, wonach die Ursprünge der Heiligenpatrozinien in den römischen Titelkirchen wesentlich auf die Kommunikationsbe-

Traditionen ohne historische Glaubwürdigkeit handelt (vgl. Delehaye 1936, 36-39, 165). Der auffällige Name Praetextatus ist jedoch mehr als nur „d'une rare banalitéc (Delehaye); hier könnte sich in der legendarischen Tradition ein Stück historischer Erinnerung an die Zeit der Kultübertragung nach Rom erhalten haben.

180 Mit Blick auf den titulus Anastasiae ist verschiedentlich die Vermutung geäußert worden, er sei auf kaiserliche Initiative hin entstanden: Man verweist in diesem Zusammenhang auf Anastasia, eine Schwester Kaiser Konstantins (Whitehead 1927, 413f.; Lizzi Testa 2004, 263). Mit denselben Argumenten könnte man auch eine clarissa femina Anastasia in Betracht ziehen, eine Zeitgenossin des Bischofs Damasus (366-384), die das von ihm errichtete Baptisterium mit Marmor verkleiden ließ (ICUR II, 4097 [= CIL VI, 41331a]; zu der aufgrund der philokalischen Buchstaben gesicherten Datierung der Inschrift in die damasianische Zeit vgl. Ferrua [1942], in: Epigrammata damasiana, 95): Nach einer - allerdings stark hypothetischen - Rekonstruktion soll sie eine Tochter von Constantina und Gallus und damit eine Großnichte der Konstantinschwester Anastasia gewesen sein (so Silvagni 1929, bes. 146f.; zuletzt Chausson 2002, bes. 146f.). Doch beruhen die Überlegungen, der titulus Anastasiae sei auf die Stiftungstätigkeit eines Mitglieds der kaiserlichen Familie zurückzuführen, vor allem auf der räumlichen Nähe der Kirche zum Palatin (vgl. bereits Grisar 1896, 731-733), die ihrerseits nicht aussagekräftig ist: Der Kirchenbau erhob sich über Magazingebäuden, die keine Beziehung zum Kaiserpalast hatten. Insgesamt besteht demnach kein überzeugender Anlass, von einer mit dem konstantinischen Kaiserhaus verwandten Titelgründerin namens Anastasia - ob Schwester oder Enkelin Kaiser Konstantins - auszugehen: Der titulus Anastasiae ist niemals nach einer anderen Anastasia als der Heiligen aus Sirmium benannt gewesen. 
ziehungen von Eliten zurückzuführen sind, die traditionelle Formen statusinterner Kommunikation auf Reliquien und Heiligenkulte ausdehnten, ergibt sich daraus die weiterführende Frage, wie dieser Befund mit Blick auf das übergeordnete Thema - das Verhältnis von Heiligenerinnerung und räumlich vermittelter kollektiver Identitätsstiftung - zu bewerten ist. Im Anschluss an die von Peter Brown geprägte Formel von der „Privatisierung“ von Heiligenkulten durch vermögende und einflussreiche Laien in den Gemeinden des 4. Jh. ist diese Frage von einem Teil der Forschung in der Weise beantwortet worden, dass Bischöfe und Laien um die Heiligen als öffentlichkeitswirksame Ressourcen von Autorität konkurriert hätten - eine Auseinandersetzung um die Heiligengräber und Reliquien als räumliche Kristallisationspunkte einer durch die Heiligenverehrung vermittelten Öffentlichkeit. ${ }^{181}$ Die These ist in dieser Form jedoch kaum aufrecht zu erhalten. Zum einen deutet wenig darauf hin, dass die bischöfliche Förderung des Heiligenkults, wie sie seit Damasus (366-384) in Rom und Ambrosius (374397) in Mailand und Oberitalien erkennbar vorangetrieben wurde, eine Reaktion auf drohende Privatisierungstendenzen durch einflussreiche Laien war: Die Initiative für das Aufblühen des Heiligenkults in der zweiten Hälfte des 4. Jh. lag vielmehr bei den Bischöfen selbst, die in der Bezugnahme auf die Heiligen unterschiedliche Strategien entwickelten, um ihr Ansehen als christliche Gemeindeleiter zu stärken, dies jedoch aus eigenem Antrieb heraus taten und nicht durch konkurrierende Bemühungen von Aristokraten „herausgefordert“ wurden. ${ }^{182}$

181 Brown 1981, 31-36; mit ähnlichem Ansatz McLynn 1994, 234, 363 für Mailand.

182 Auch betont von Fontaine 1982, 24. Aus dem 3. und frühen 4. Jh. haben sich keine schlagenden Hinweise darauf erhalten, dass im Heiligenkult eine Konkurrenz zwischen privater Initiative einflussreicher Laien und bischöflich-gemeindlicher Kontrolle bestand. Dass Familienangehörige in privater Initiative die Bestattung von Märtyrern übernahmen, wurde von bischöflicher Seite akzeptiert und gefordert - selbst dort, wo es sich um Kleriker handelte (Cypr., epist. 40, 1). Bestattungen von Märtyrern durch vermögende Personen, die nicht zur Familie des Märtyrers gehörten (Brown 1981, 33f. [Anastasiusmemoria in Salona]; acta Maximiliani 3, 4), sind nicht als konkurrierende „Privatisierungen“ aufzufassen, sondern als eine Form karitativer Zuwendung, für die der Klerus, in Ermangelung eines kirchlich organisierten Bestattungswesens, auf die private Initiative der Gemeindemitglieder angewiesen war (vgl. zuletzt Rebillard 2003, 108-118). Dort wo man von einer amtskirchlich nicht gewollten Privatisierung von Reliquien sprechen kann, wie etwa bei der passio Fructuosi, wird kein spezifisch aristokratischer Einfluss hinter den privaten Interessen erkennbar (passio Fructuosi, Augurii et Eulogii 6; ob dieses Kapitel im 3. Jh. verfasst oder der 2. Teil der Passio (c. 5-7) erst später hinzugesetzt wurde, ist umstritten, vgl. die unterschiedlichen Positionen von Lane Fox 1986, 446 und Wlosok 1997, 431). Das in der Forschung häufig zitierte Beispiel der nordafrikanischen potens et factiosa femina Lucilla, die während des Donatistenstreits eine einflussreiche Rolle spielte und vor dem Kommunionempfang die Reliquie eines Märtyrers zu küssen pflegte (Optat. 1, 16, 1), trägt nicht als Beleg für eine Privatisierung, die der Amtskirche ein Dorn im Auge gewesen wäre: Der spätere Bischof von Karthago, Caecilianus, verwies ihr dieses Verhalten nicht wegen der demonstrativen Inszenierung des Reliquienbesitzes, sondern weil es sich um die sterblichen Überreste irgendeines Toten handelte, der nicht nachweislich ein Märtyrer war. - Auch für die 
Zum anderen war der Umgang mit Patrozinien und Reliquien kein Feld der Konkurrenz zwischen Laien und Klerikern, sondern eher ein verbindendes Element. Bischöfliche „Impresarios“ des Heiligenkults wie Ambrosius von Mailand und Gaudentius von Brescia entstammten entweder selbst der Aristokratie oder waren durch ihre Position als Gemeindeleiter und ihre damit verbundenen Kontakte zu den munizipalen Oberschichten Teil eines Beziehungsgeflechtes, dessen kommunikative Spielregeln auch ihr eigenes Handeln bestimmten. ${ }^{183}$ Die Vermittlung von Reliquien als statusadäquate Gaben unter Freunden spielte für die Konstituierung dieser neuen christlichen Elite eine wichtige Rolle: ${ }^{184}$ Der Heiligenkult schuf Vernetzungen und Verbindungen, die im Stil traditioneller aristokratischer Freundschaftsbeziehungen gepflegt und aufrechterhalten wurden.

In modifizierter Form stellt sich demnach weniger die Frage nach einer Konkurrenz zwischen Laien und Klerikern, Euergeten und Bischöfen, sondern danach, in welcher Weise die Heiligen in den Bereich traditioneller Kommunikationsbeziehungen integriert wurden. Wie inszenierte die römische Oberschicht, für die Amicitiabeziehungen und private Kommunikation traditionell eine Fortsetzung ihres in der politischen Öffentlichkeit gewonnenen Status darstellte, ${ }^{185}$ statusrelevante Gaben wie Reliquien im privaten Raum der domus? Boten Reliquien und Heiligenkulte mit Blick auf die christliche Gemeinde Ansatzpunkte für eine öffentlichkeitsorientierte Inszenierung der privaten Sphäre, oder aber liegt der „Privatisierung“ von Heiligenkulten ein anderes Verhältnis von Privatheit und Öffentlichkeit zugrunde als es für die traditionelle Relation von privatum und publicum, die in der politischen Kultur

Zeit nach der konstantinischen Wende überzeugt die Privatisierungsthese nicht. Die bischöflichen Initiativen, die sich auf dem Feld der Heiligenverehrung verstärkt seit der zweiten Hälfte des 4. Jh. bemerkbar machten, waren keine Reaktion auf das verstärkte Einströmen von Aristokraten in die christlichen Gemeinden und eine damit einhergehende private Heiligenpatronage, sondern wesentlich darauf zurückzuführen, dass die innere Verbindung der Gegenwart zur Zeit und Kirche der Märtyrer abzureißen drohte; vgl. dazu o., S. $302 f$.

183 Vgl. Brown 1981, 89f.; Lizzi 1989, bes. 212-214; Salzman 2002, $211 \mathrm{f}$.

184 Bischöfe wie Johannes von Jerusalem waren an der Übermittlung der Reliquien, die Paulinus von Melania d. Ä. aus dem Heiligen Land empfing, beteiligt. Umgekehrt erhielt Ambrosius von einer gewissen Daedalia - möglicherweise der Schwester des Konsuls von 397, Theodorus Manlius Reliquien, die er zusammen mit den Apostelreliquien unter dem Altar der basilica apostolorum niederlegte (vgl. Buschhausen 1971, 224f.). - Die durch die Übersendung von Reliquien hergestellte amicitia wurde auch zwischen Bischöfen (und ihren Familien!) wirksam: Gaudentius v. Brescia betrachtete die Reliquien der 40 Märtyrer von Sebaste, die er in Caesarea aus den Händen der Nichten des Bischofs Basileios empfangen hatte, als Gaben einer intensiven Verbundenheit (Gaudent., serm. 17, 15). Den traditionellen Vorstellungen von amicitia zeigt sich auch Victricius v. Rouen verpflichtet: Die Reliquien, die er aus Oberitalien für seine Gemeinde erhalten hat, sind für ihn beneficia, Freundschaftsgaben ihm persönlich verbundener Bischöfe (Victric. 2).

185 Zur Komplementarität von Öffentlichkeit und Privatheit in der politischen Kultur und Gesellschaftsstruktur Roms vgl. o., S. 120. 
des spätantiken Rom komplementäre Handlungsbereiche bildeten, kennzeichnend war?

\section{3. Patronage und Kult: „private“ Kontrolle der Heiligenmemoria inner- und außerhalb der domus}

Unter den römischen Titelkirchen, die um die Wende vom 4. zum 5. Jh. in zahlreichen aristokratischen domus entstanden und mit Heiligenpatrozinien versehen wurden, haben sich vor allem im titulus Pammachii (SS. Giovanni e Paolo) am clivus Scauri Hinweise darauf erhalten, in welcher Form eine Integration der Heiligenerinnerung in den privaten Raum erfolgte. ${ }^{186}$ Die Basilika SS. Giovanni e Paolo wurde zu Beginn des 5. Jh. im ersten Stock einer domus errichtet, die um die Wende vom 1. zum 2. Jh. in einer privilegierten Wohnlage südwestlich des Claudiustempels entstanden und seitdem mehrfach grundlegend umgestaltet worden war. Im 3. Jh. wurde der südliche Teil der domus, der sich auf den clivus Scauri öffnete, in ein mehrstöckiges, im Erdgeschoss mit Botteghen ausgestattetes Gebäude umgewandelt, das offensichtlich zu kommerziellen Zwecken von Händlern und Handwerkern genutzt wurde. Dieser Wirtschaftsbereich entlang des clivus Scauri blieb über einen lang gestreckten Lichthof mit der dahinter liegenden, in ihren räumlichen Dimensionen reduzierten domus verbunden, die in bescheidenerem Maßstab als zuvor auch weiterhin als „residenza unifamiliare“ diente. Obwohl die Eigentumsverhältnisse nicht eindeutig zu klären sind, dürften die beiden Gebäude auch weiterhin in der Hand eines Besitzers geblieben sein, der einen Teil seiner Wohnanlage in einen Wirtschaftskomplex umwandelte. ${ }^{187}$ Um 300 wurde die wirtschaftliche Funktion des Botteghenhauses weitgehend aufgegeben, ein Teil der ehemaligen Verkaufsräume und der Hof hinter den Botteghen mit aufwendigen Malereien versehen, die auf eine Nutzung des Hofes als Viridarium hindeuten, und eine Treppe angelegt, die vom Hof aus in den ersten Stock dieses Komplexes führte. ${ }^{188}$ Obwohl sich unter den Ausmalungen der ehemaligen Verkaufsräume eine Orantenfigur befindet, die in der älteren Forschung als Hinweis auf einen christlichen Eigentümer und als Beleg dafür, dass die domus unter SS. Giovanni e Paolo eine

\footnotetext{
186 Die folgenden Ausführungen lehnen sich eng an Brenk 1995-1996, dens. 2003, 82-113 an.

187 Brenk 2003, 83-86; vgl. den Plan auf S. 311, Abb. 139.

$188 \mathrm{Zu}$ den Umbauten und den Malereien, die auf die Konzeption des Hofes als Viridarium und als Ort „des Otiums und des Lebensgenusses“ verweisen s. ebd., 87-97.
} 
vorkonstantinische Hauskirche gewesen sei, interpretiert wurde, ${ }^{189}$ können der Orans und die anderen Motive nicht sicher als spezifisch christliche Symbole gedeutet werden. ${ }^{190}$

Auf eine eindeutig christliche Belegung der domus weist erst die Anlage eines kleinen Raumes hin, der sich am Ende der Treppe, die aus dem Hof in den ersten Stock des Gebäudes führte, befindet. $\mathrm{Zu}$ einem nicht näher bestimmbaren Zeitpunkt in der 2. Hälfte des 4. Jh. wurde die durch die Treppe hergestellte Verbindung zum Obergeschoss der domus unterbrochen ${ }^{191}$ und man legte auf halber Höhe der Treppe einen langgestreckten Absatz von 4,60m Länge an, an dessen Ende der besagte, nur 1,21 x 1,10m große Raum eingerichtet und mit Malereien ausgeschmückt wurde, die in zwei Registerzonen angeordnet sind. ${ }^{192}$ Die Motive weisen diese Kammer eindeutig als einen Ort der Heiligenkommemoration aus: Im oberen Register sind auf der linken und rechten Seitenwand zwei Szenen aus dem Martyrium dreier Personen dargestellt; in die Rückwand des Raums wurde eine Nische eingelassen, die von zwei mit einem Pallium bekleideten Figuren, die vermutlich ebenfalls Heilige darstellen sollen, flankiert wird. Unterhalb der Nische befindet sich eine Orantenfigur, zu deren beiden Seiten zwei Personen eine Proskynese vollziehen. Dieser Verehrungsgestus im unteren Bildregister setzt sich auf den beiden Seitenwänden fort, auf denen je zwei stehende Personen dargestellt sind, die sich der Proskyneseszene auf der Rückwand zuwenden und eine Prozession andeuten sollen. ${ }^{193}$

Man hat diesen Raum mit seinen Märtyrerfresken überzeugend als eine kleine Gebetskapelle gedeutet, deren Nische in der Rückwand zur Aufnahme

189 Vgl. u. a. Krautheimer, in: Corpus I, 281; Pietri 1976, Bd. 1, 487; Cecchelli Trinci 1978. Zuletzt ist die Deutung einer vorkonstantinischen Hauskirche erneut von Holloway 2004, 62-67 aufgegriffen worden, der sich allerdings beinahe ausschließlich auf die Interpretation von Krautheimer stützt, ohne die überzeugenden Einwände, die in jüngerer Zeit von Brenk gegen diese Hypothese vorgebracht wurden (s. u., Anm. 195), angemessen zu berücksichtigen.

190 Brenk 2003, 95-97.

191 Krautheimer, in: Corpus I, 281f. geht davon aus, dass bei dieser Gelegenheit nur der Verlauf der Treppe geändert wurde, diese jedoch auch weiterhin in den 1. Stock des Gebäudes führte, wo er einen christlichen Versammlungssaal vermutet, der bereits vor der Errichtung der Basilika bestanden habe. Ähnlich bereits Junyent 1932, 112-115.

192 Mielsch 1978, 196f. datiert die Malereien zwischen 380 und 400; Brenk 2003, 105 zieht einen früheren Ansatz (zwischen 340 und 380/390) vor.

193 Zu den Malereien des Oratoriums vgl. Wilpert 1937; Bisconti 1995, 279f.; Brenk 2003, 97-101 (Abbildungen ebd., 327-329, nr. 169-174). Brenk 2003 fasst die beiden Figuren zu Füßen des Oranten als ein Ehepaar (die Hausbesitzer der domus?) auf; Brandenburg 2004, 159 hingegen meint, es handele sich um zwei weibliche Gestalten. Die beiden im Akklamationsgestus dargestellten Figuren zu den beiden Seiten der Nische werden von Bisconti - in Anlehnung an Wilpert - als Petrus und Paulus gedeutet; näher liegt jedoch eine Identifizierung mit den beiden später als Patrone des titulus bekannten Heiligen, Johannes und Paulus. 
von Reliquien unterschiedlicher Heiliger bestimmt war. ${ }^{194}$ Wie Beat Brenk zurecht hervorgehoben hat, muss der Raum unabhängig von der Basilika, die erst zu Beginn des 5. Jh. im ersten Stock der domus errichtet wurde und dabei auch die kleine Kapelle überbaute, entstanden sein: Es handelte sich ursprünglich um eine Hauskapelle, die von dem Besitzer der domus als Schrein angelegt wurde, ohne dass es sich bei dieser domus um ein Kultgebäude im Sinne einer Hauskirche gehandelt hätte. ${ }^{195}$ Anders als es ihre in der Forschung meist verwendete Bezeichnung als confessio suggeriert, war die Kapelle also nicht in Verbindung mit einem Kultbau konzipiert und errichtet worden, sondern ein eigenständiger Raum, dessen ungewöhnliche Lage unter dem Boden des Kirchenbaus später den Anlass für die Entstehung einer eigenwilligen Legende lieferte: Man deutete die Reliquienkapelle - bzw. den unterhalb der Kapelle gelegenen Raum im Erdgeschoss der ehemaligen domus - als Grablege der beiden Titelheiligen, die nach der Legende zusammen mit drei weiteren Märtyrern unter Kaiser Julian in ihrem eigenen Wohnhaus heimlich bestattet worden seien. ${ }^{196}$

Versucht man, das Oratorium im architektonischen Kontext der domus am clivus Scauri zu verorten, so fällt vor allem die ausgesprochen unauffällige und zurückhaltende Inszenierung der Anlage ins Auge: Bei einem Raum von einer so begrenzten Grundfläche, dass er nur einer einzigen Person Zugang bot, war es offenkundig nicht eine auf ein Publikum berechnete Öffentlichkeitswirkung, sondern im Gegenteil ein programmatischer Rückzug, der durch die räumliche Disposition der Heiligenmemoria signalisiert wurde. ${ }^{197}$ Daran ändert auch der Umstand nichts, dass der langgezogene Treppenabsatz vor und neben der Kammer eine ausgedehnte Grundfläche bildete, die mög-

194 Neben den an der Rückwand dargestellten palliati, die wohl als die späteren Titelheiligen Johannes und Paulus aufzufassen sind, verfügte der Raum vermutlich auch über Reliquien der drei Personen, deren Martyrium an den Seitenwänden dargestellt ist und über deren Identität nichts näheres gesagt werden kann (s. dazu o., Anm. 108).

195 Bereits Kirsch 1923-1924, 30, deutete den Raum als ein „piccolo oratorio domestico“, ging allerdings davon aus, dass es sich bei der domus, in der die Kapelle errichtet wurde, um eine Hauskirche gehandelt habe. Den Charakter des Raums als private Hauskapelle, die mit der Errichtung der Titelkirche ihre Funktion verlor, hat zuerst Franchi de' Cavalieri 1915, 49-51 erkannt. Seinen Interpretationsansatz hat zuletzt Brenk 1995-1996, 191f., ders., 2003, 98-105 erneut aufgenommen und weiter präzisiert.

196 So die passio Gallicani, die den außergewöhnlichen Umstand, dass zwei Märtyrer innerhalb der Stadt bestattet wurden, dadurch zu „erklären“ versucht, dass sie das Martyrium der beiden Titelheiligen in die tempora christiana und die Zeit Kaiser Julians verlegt, der die beiden Märtyrer heimlich in ihrem Haus verscharren ließ. Die Vorstellung, SS. Giovanni e Paolo verfüge über Heiligengräber, lässt sich seit der Mitte des 6. Jh. in der Liturgie und seit dem Beginn des 7. Jh. in den frühmittelalterlichen Pilgerführern nachweisen (s. u., Anm. 255).

197 Brenk 2003, 102f. charakterisiert die Kapelle zutreffend als einen „intimen Raum“ und macht darauf aufmerksam, dass die auffällig kleinen Dimensionen nicht durch bautechnische Notwendigkeiten bedingt waren (ebd., 98): Sie stellten offensichtlich eine bewusste Option dar, um Zurückgezogenheit zu signalisieren. 
licherweise einer größeren Zahl von Besuchern zugänglich gemacht werden sollte: ${ }^{198}$ Zurückgezogenheit und zugleich Intimität sind die dominierenden Charakteristika dieses Kultraums, die nicht nur seine Funktionsbestimmung als Gebetsraum für die Bewohner der domus erkennen lassen, sondern eine entsprechende Signalwirkung, die Annäherung an die Heiligen in Form einer individuellen Versenkung in das Gebet zu vollziehen, auch auf Besucher der Anlage nicht verfehlt haben können.

Wie repräsentativ diese Art der räumlichen Inszenierung häuslicher Heiligenkulte war, ist allein aufgrund der archäologischen Befunde nicht zu beantworten. Das Oratorium unter SS. Giovanni e Paolo ist nicht nur für Rom einzigartig. ${ }^{199}$ Auch aus dem übrigen Mittelmeerraum existieren kaum Vergleichsbeispiele, die eine Typologie von Hausoratorien im Kontext spätantiker domus ermöglichen würden. ${ }^{200}$ Eine Reihe von literarischen Nachrichten aus der Zeit, in der das Oratorium unter der späteren Titelkirche des Pammachius angelegt wurde, scheint immerhin zu bestätigen, dass seine räumliche Disposition kein Sonderfall war, und leisten der Deutung Vorschub, dass die Anlage des Oratoriums gezielt einen asketischen Gestus der Zurückgezogenheit versinnbildlichte, der in Verbindung mit der Heiligenverehrung in Szene gesetzt werden sollte. So wird von Asketinnen wie Gorgonia und Macrina, den Schwestern der drei kappadokischen Bischöfe, übereinstimmend berichtet, dass sie in der Askese des nächtlichen Gebets in häuslichen Oratorien, die vermutlich mit Heiligenreliquien ausgestattet waren, verharrt hätten. ${ }^{201}$ Handelt es sich hierbei um östliche

$198 \quad$ Zu dieser Deutung vgl. zuletzt Brandenburg 2004, $160 \mathrm{f}$.

199 Ein Raum mit einer Orantenfigur unter der mittelalterlichen Kirche S. Andrea in Vincis könnte ein Oratorium in einer domus darstellen (so Martorelli 1998, bes. 583), doch lassen sich Orantendarstellungen nicht per se als ein christliches Motiv klassifizieren. Zur archäologischen und literarischen Bezeugung von häuslichen Oratorien in Rom vgl. den jüngsten Überblick von Cerrito 2002, die früheren Versuchen zur Identifizierung von derartigen Gebetsräumen in Privathäusern insgesamt mit großer Skepsis begegnet.

200 Für die wenigen Beispiele mutmaßlicher Oratorien in Privathäusern außerhalb Roms vgl. Ellis 1988, 569 (Palast des dux in Apollonia); Brenk 2003, 76-79 (Sardis). Im Westen des römischen Reichs beschränkt sich unsere Kenntnis privater christlicher Kulträume praktisch auf Kirchen und Oratorien, die in ländlichen Villen errichtet wurden (vgl. die Materialzusammenstellung von Bowes 2005, 199-205).

201 Gr. Naz., or. 8, 18 berichtet, seine Schwester Gorgonia habe während einer Krankheit zur

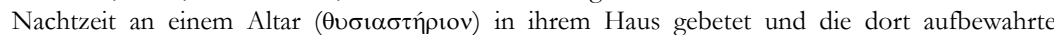
Eucharistie empfangen (Jungmann ${ }^{5} 1962$, Bd. 1, 280 spricht in diesem Zusammenhang von einer Eucharistiefeier; bei Gorgonias Eucharistieempfang handelt sich jedoch um Gaben, die während einer gemeindlichen Eucharistiefeier geweiht und von Gorgonia mit nach Hause genommen worden waren. Zu dieser Praxis vgl. die Materialzusammenstellung von Nußbaum 1979, 266 278, der allerdings in Gorgonias Fall irrtümlich davon ausgeht, sie habe eine Gemeindekirche aufgesucht [ebd., 280f.]). Dass der Altar der Gorgonia auch Heiligenreliquien enthielt, wird zwar nicht explizit überliefert, ist jedoch nicht unwahrscheinlich (zur zunehmenden Ausstattung von Altären mit Reliquien seit der 2. Hälfte des 4. Jh. vgl. Brandenburg 1995). Ähnlich wie Gorgonia verfügte auch Macrina über ein $\pi \alpha v \alpha \gamma \iota \alpha \sigma \tau$ ๆ́ ııv, das sie zum nächtlichen Gebet aufsuchte (Gr. 
Beispiele asketischer Heiligenverehrung, die nicht aus dem stadtrömischen Kontext stammen, so ist mit der Vita Melanias der Jüngeren (geb. ca. 385), die sich bis zum Jahr 408/9 in Rom aufhielt und dort zunächst im Haus ihrer Eltern, dann ihres Ehemannes Pinianus ein asketisches Leben führte, eine Lebensbeschreibung überliefert, die für die hier interessierende Zeit und den örtlichen Handlungsrahmen unmittelbar einschlägig ist. Anlässlich der Vigilfeiern zum Fest des Heiligen Laurentius verzichtete Melania bewusst darauf, am Stundengebet in der Basilika des Heiligen teilzunehmen, und brachte stattdessen die Nacht im Gebet in ihrem eigenen Hausoratorium $\mathrm{zu}^{202}$ - wohl aus derselben Motivation asketischer Zurückgezogenheit heraus, die sie auch während ihres späteren Aufenthalts in Jerusalem dazu bestimmte, die Anastasiskirche nur außerhalb der Zeiten des Kathedraloffiziums aufzusuchen, während derer sich die Basilika mit Besuchern füllte. ${ }^{203}$ Melanias Verhalten war sicher keine Ausnahme, sondern vielmehr charakteristisch für die asketische Landschaft im Rom des ausgehenden 4. und frühen 5. Jh., die vorzugsweise durch Formen weiblicher Askese geprägt war und dementsprechend in elementarer Weise auf den Häusern als der zentralen sozialen Organisationsform asketischen Lebens basierte, das die Frauen - allein oder in Gemeinschaft mit anderen Asketinnen - führten. ${ }^{204}$ Hieronymus, der als asketischer Spiritus rector auf die aristokratischen Asketinnengemeinschaften Roms einzuwirken suchte, verlieh derselben Einstellung, die Melania dazu bewegte, die Laurentiusvigil in ihrem Hausoratorium zu begehen, dadurch Ausdruck, dass er die virgo Eustochium

Nyss., v. Macr. 31) und dessen Benennung ebenfalls auf das Vorhandensein von Reliquien schließen lässt. Auch von Petrus dem Iberer, der sich von 429 bis 437 in Konstantinopel aufhielt, ist überliefert, er habe in dieser Zeit einen Reliquienschrein in seinem Wohnraum aufbewahrt (Vita Petri Hiberii 17f.).

202 Vita Melaniae (griech.) 5: Melania verweilte die ganze Nacht betend in ihrem Oratorium

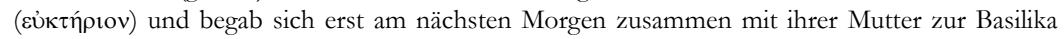
( $\mu \alpha \rho \tau$ $\tilde{\rho} \iota \mathrm{ov})$ des Heiligen Laurentius.

203 Vita Melaniae (griech.) 36: „Abends, nach Schließung der Anastasiskirche, blieb sie in der Nähe des Kreuzes, bis die ersten zum Psalmengebet erschienen. Danach zog sie sich in ihre Zelle zurück und schlief für eine kurze Zeit“. Dasselbe Motiv - asketischer Rückzug aus der Öffentlichkeit - ist auch für Melanias Entscheidung, die Nacht der Laurentiusvigil nicht in der Basilika des Heiligen, sondern in ihrem Oratorium zu verbringen, vorauszusetzen. Die lateinische Fassung der Melania-Vita führt hingegen als Erklärung an, Melanias Eltern hätten ihr wegen ihres Gesundheitszustandes - Melania erwartete ihr zweites Kind - verboten, das Haus zu verlassen (Vita Melaniae [lat.] 5: beatissima vero fervens spiritu desiderabat ire et in sancti martyris basilica pervigilem celebrare noctem; sed non permittitur a parentibus, eo quod nimis tenera et delicati corporis bunc laborem vigiliarum ferre non posset). Dies ist jedoch insofern wenig überzeugend, als Melania am nächsten Morgen zusammen mit ihrer Mutter die Basilika des Heiligen Laurentius aufsuchte.

204 Zum „house-monasticism“ als typischer Organisationsform weiblicher Askese und als Charakteristikum der asketischen Landschaft im Rom des späten 4. Jh. s. E. Clark 1984, 94. Zur familia und dem Haushalt als derjenigen sozialen Institution, auf deren Grundlage es auch im Osten während des 4. Jh. zur Ausbildung von Formen weiblicher Askese kam, vgl. Elm 1994, bes. $374 \mathrm{f}$. 
aufforderte, bei den Märtyrerfesten das Haus nicht zu verlassen, sondern dem privaten Gebet zu obliegen: „Gehe nur selten in die Öffentlichkeit, suche die Märtyrer in deiner Kammer."205 Treffender lassen sich die Funktion und die Haltung, die in der räumlichen Disposition der Kapelle in der domus am clivus Scauri sichtbar werden, kaum in Worte fassen: In einer Zeit, in der die Refrigerien und Feiern zu Ehren der Märtyrer immer vernehmbarer in die moralisierende Kritik nicht nur von Asketen wie Hieronymus, sondern auch der bischöflichen Amtskirche zu geraten begannen, ${ }^{206}$ boten derartige Hausoratorien Asketinnen wie Melania und Eustochium die Möglichkeit zur Heiligenverehrung, ohne ihren Rückzug aus der Welt durch die Teilnahme an den Märtyrerfesten zu gefährden.

Das Oratorium in der domus am clivus Scauri erfüllte dabei jedoch nicht nur eine rein pragmatische Funktion, im eigenen Haus über einen Ort zu verfügen, der geeignet war, das Bedürfnis nach Heiligenverehrung und das Postulat asketischer Zurückgezogenheit miteinander in Einklang zu bringen. Es vermittelte zugleich auch eine spezifische Haltung, die der Verehrer gegenüber den Heiligen, deren Reliquien in dem Oratorium aufbewahrt wurden, einnahm: Verbunden mit dem asketischen Rückzug aus der Welt und ihren sozialen Bindungen war die vollständige Ausrichtung der eigenen Person auf den jeweiligen Heiligen, dem man sich im solitären Gebet nahte und der als persönlicher Patron derer, die sich an ihn wandten, fungierte. Das Bildprogramm der Kapelle unterstützte diese Form der Annäherung: Die beiden weiblichen Personen, die sich auf der unteren Bildzone der Rückwand zu Füßen der Orantenfigur niederwerfen, lassen in ihrer Proskynese dieselbe persönliche Ausrichtung auf den Heiligen erkennen, die auch der Besucher der Kapelle einnehmen sollte. ${ }^{207}$ Das Oratorium fungierte somit als ein Ort des Rückzugs, der zugleich einen besonderen Modus der Interaktion mit den Heiligen ermöglichte: Er war eine Stätte der vertrauten und persönlichen Begegnung, ein abgeschlossener Raum der inneren Sammlung, die eine besondere Nähe zu den verehrten Heiligen vermittelte. ${ }^{208}$

205 Hier., epist. 22, 17 (geschrieben 384): rarus sit egressus in publicum: martyres tibi quaerantur in cubiculo tuo; vgl. auch ebd. 22, 25. Weitere Belege aus Hieronymus und Ambrosius führt Sessa 2007, $182 \mathrm{f}$. auf.

206 Zur rigoristischen Kritik an den „Gelagen und Saufereien“ bei Märtyrerfesten, die im Westen seit dem späten 4. Jh. auf breiter Ebene einsetzte, vgl. o., S. 168, Anm. 331.

207 So überzeugend Brenk 2003, 99, 104. Ähnliche Darstellungen sind auch aus den Katakomben bekannt, wo sie in vergleichbarer Weise die Haltung der Besucher im Sinne einer individuellen Frömmigkeitspraxis lenken sollten (für ein Beispiel aus dem coemeterium maius vgl. Josi 1933, 11 13 mit Abb. 4 u. 6). Die Orantenfigur im Oratorium der domus am clivus Scauri bezeichnet demnach auch keinen konkreten Heiligen. Vielmehr dient sie dazu, die Gebetsandacht auf einen Fokus zu zentrieren: Der Orant steht damit gleichsam stellvertretend für die in der Kapelle verehrten Märtyrer.

208 Zur „,intimacy“ als einem wesentlichen Aspekt der asketisch geprägten Heiligenfrömmigkeit um 400 vgl. Brown 1981, 50-68, der sich vor allem auf Paulinus v. Nola stützt (ähnlich Trout 1999, 
Mit Blick auf die Ausgangsfrage nach der „Privatisierung“ von Heiligenkulten und ihrer Überführung in Räume und Formen privater Kommunikation gilt es im folgenden zu klären, in welcher Weise Reliquien, Heiligenkulte und Oratorien, wie sie in der domus am clivus Scauri exemplarisch fassbar werden und aufgrund der literarischen Zeugnisse in ähnlicher Form vorausgesetzt werden können, in die „kommunikative Struktur“ der spätrömischen domus einzuordnen sind. Die damit verbundenen Fragen nach der Raumgliederung, Innenausstattung und sozialen Funktion der domus sind in der jüngeren Forschung vor allem für die römischen Häuser in der späten Republik und der frühen Kaiserzeit diskutiert worden. Obwohl diese Ergebnisse nicht ohne weiteres auf das Rom des 4. Jh. übertragbar sind, verdeutlichen sie eine Reihe grundlegender Strukturelemente, die auch für die Spätantike Gültigkeit haben, und können daher im folgenden als Ausgangspunkt dienen.

Die Wohnhäuser der römischen Oberschicht waren zentrale Kommunikationszentren einer politischen Kultur, in der öffentliche und private Räume und Aktionsbereiche keine strikt voneinander getrennten Felder bildeten, um Ansehen, Status und Einflussnahme zu begründen. Diese komplementäre Verbindung von Öffentlichem und Privatem äußerte sich nicht nur in der ausgeprägten Sichtbar- und Zugänglichkeit römischer Wohnhäuser, die sich in Abstufungen von stark frequentierten und durch Sichtachsen mit der Straße verbundenen Zonen wie den Atrien und Tablinia im Eingangsbereich über daran anschließende Peristylhöfe bis hinein in nur ausgewählten Gästen zugängliche Räume wie den Schlafbereich des cubiculum erstreckte, ${ }^{209}$ sondern vor allem in den Kommunikationsformen, die den öffentlichen und privaten Raum miteinander verzahnten. Trotz der terminologischen und konzeptionellen Trennung zwischen privatum und publicum und der damit einhergehenden Unterscheidung zwischen den unterschiedlichen Rollen, die ein Angehöriger der römischen Aristokratie in seiner Funktion als pater oder als Magistrat wahrnahm, war das Agieren in den jeweiligen Funktionen nicht auf private bzw. öffentliche Räume beschränkt. Klienten, die ihrem Patron vorzugsweise in den Eingangsbereichen seines Hauses ihre Aufwartung machten, bildeten auch im öffentlichen und politischen Raum, auf den Straßen und Plätzen der Stadt, das Gefolge des Hausherrn, um auf diese Weise das soziale und gesellschaftliche Ansehen ihres Patrons zu

165f., 170). Zum cubiculum als privilegiertem Ort der Sammlung und Begegnung mit Gott vgl. zuletzt Sessa 2007, 180f.

209 Grundlegend für das Modell einer skalierten Abstufung von Öffentlichkeit innerhalb der domus ist Wallace-Hadrill 1988, bes. 50-58. Zur Einbeziehung auch der cubicula in die öffentlich zugänglichen Empfangsbereiche des Hauses vgl. Riggsby 1997, $41 \mathrm{f}$. 
demonstrieren. ${ }^{210}$ Umgekehrt machten politische Kommunikationsformen nicht an der Schwelle der domus halt. Die anlässlich der pompa funebris mitgeführten imagines derjenigen Vorfahren, die hohe politische Ämter bekleidet und besondere Leistungen für die res publica vollbracht hatten, wurden in den Atrien der Häuser aufbewahrt und vermittelten dort, im privaten Raum der domus, dem Betrachter dieselbe genealogische Bezugnahme des Hausherrn auf politische Leistungsträger wie sie bei der Gelegenheit der pompa in einem politischen Ritual der Öffentlichkeit des populus Romanus präsentiert wurde. ${ }^{211}$

Die aus den spezifischen Voraussetzungen der politischen Kultur Roms in der Republik erwachsene gesellschaftliche Funktion der domus hatte in zentralen Aspekten auch in der Spätantike Bestand - trotz grundlegender Veränderungen, die sich in der dazwischenliegenden Zeit auf politischer, gesellschaftlicher und kultureller Ebene vollzogen hatten. Die Klienten und aristokratischen Gefolgschaften blieben und scheinen im Rom des 4. Jh. noch an Bedeutung gewonnen zu haben. Darauf weisen nicht nur die - freilich unter Idiosynkrasieverdacht stehenden - Romexkurse im Geschichtswerk Ammians, ${ }^{212}$ sondern vor allem die zahlreichen Konflikte innerhalb der römischen Elite hin, die Rom in der 2. Hälfte des 4. Jh. erschütterten: In einer unter Konstantin reorganisierten Senatsaristokratie,213 die sich mit dem Weggang der Kaiser aus Rom nicht mehr unmittelbar auf die monarchische Spitze als das organisierende Zentrum der Vergabe von Status und Ansehen ausrichten konnte, brachen seit der Mitte des 4. Jh. Konkurrenzkämpfe und Parteibildungen aus, die in ihrer Vitalität an die Faktionsbildungen der ausgehenden Republik erinnern und in den Magieprozessen und den kirchlichen Schismen der 350er bis 370er Jahre, der Auseinandersetzung um den Victoriaaltar und den Konflikten um Askese und christliche Lebensführung seit der Mitte der 380er Jahre lebhaften Ausdruck fanden. ${ }^{214}$

210 Zur salutatio und der Bedeutung der Atrien als Empfangs- und Warteräume für Besucher vgl. Flower 1996, 217-220.

211 Für den Charakter der pompa funebris als politisches Ritual s. o., S. 184, Anm. 395. Zur Aufbewahrung der imagines in Schränkchen, die durch Linien zu Stammbäumen verbunden waren, vgl. Bettini 1992, 137-139. - Die in den Ritualen und Kommunikationsbeziehungen zutage tretende Komplementarität von öffentlichen und privaten Räumen zeigt sich auch darin, dass Terminologie des öffentlich-staatlichen Bereichs auf die domus übertragen wurde, so in der Bezeichnung des Hauses als forum (vgl. Hales 2003, 57 mit Verweis auf Cic., ad Att. 12, 23; Plin., n. h. $34,9,17)$.

212 Amm. 14, 6; 28, 4, 6-35; vgl. dazu zuletzt Cracco Ruggini 2003, 366-376, die dem Zeugnis hohen Quellenwert zumisst.

213 Vgl. zuletzt Av. Cameron 22005, 96.

214 Für eine Verortung der kirchlichen Schismen und der Magieprozessen unter der valentinianischen Dynastie im Kontext aristokratischer Faktionsbildungen vgl. zuletzt Lizzi Testa 2004 (a). Nicht den Mailänder Bischof Ambrosius, sondern „Christian careerists in Gratian's entourage, and particularly... the increasing numbers who arrived to assume office from Rome“ 
Unter diesen Voraussetzungen gewannen amicitia- und Patronagebeziehungen einen hohen Stellenwert - und mit ihnen auch die Häuser, die die Machtzentren dieser römischen Aristokratie bildeten.

Der private Raum der domus blieb damit auch im spätantiken Rom Schauplatz einer aristokratischen Kommunikation, die auf vergleichbaren Grundvoraussetzungen beruhte, wie in der Republik. Wie bereits erwähnt, ${ }^{215}$ deuten die archäologischen Befunde darauf hin, dass die Bedeutung der Häuser im Rom des 4. Jh. im Vergleich zur hohen Kaiserzeit eher noch zugenommen haben dürfte: Die domus bildeten maßgebliche Zentren von Macht und Einflussnahme, die in stärkerem Maße als der öffentliche Raum, der der Kontrolle des Kaisers und seines Stellvertreters, des praefectus urbi, unterlag, der Oberschicht Möglichkeiten boten, ihr Bedürfnis nach Repräsentation und Statusinszenierung zu befriedigen. Diese soziale Funktion des Hauses spiegelte sich auch in der räumlichen Struktur der domus wider, die zwar im Vergleich zur späten Republik und frühen Kaiserzeit Veränderungen erfuhr, jedoch wesentliche Funktionen aufrecht erhielt, in denen die traditionelle Bedeutung der domus als gesellschaftliches Kommunikationszentrum erhalten blieb. ${ }^{216}$ So traten an die Stelle von Atrien und tablinia, die sich bereits in der frühen Kaiserzeit zurückbildeten, ${ }^{217}$ differenziertere Repräsentations- und Empfangsbereiche für Klienten und Freunde, die in unterschiedlichen Räumen empfangen werden konnten. Auch brachte die zunehmende Verwendung von Apsiden in Empfangshallen und in den meist als Trikonchen gestalteten Speiseräumen eine stärkere Hierarchisierung des Hausherrn im Verhältnis zu seinen Besuchern zum Ausdruck. ${ }^{218}$ Ähnlich wie in der Architektur änderten sich auch bestimmte Ausstattungselemente und Kommunikationsmedien, ohne dass dies jedoch zu grundsätzlichen Umgestaltungen geführt hätte: Hinweise auf imagines finden sich beispielsweise nur noch vereinzelt, ${ }^{219}$ doch hielten Statuen der Hausbesitzer und ihrer Vorfahren

identifiziert McLynn 1994, 151f. als die treibenden Kräfte in der Auseinandersetzung um den Victoriaaltar; die Konflikte innerhalb der christlichen Aristokratie Roms, die sich insbesondere an der Frage der Askese und der Bildung asketischer Hausgemeinschaften entzündeten, beleuchtet Curran 2000, 260-320.

215 S. o., S. 335-337.

216 Die Kontinuitäten zwischen der frühen Kaiserzeit und der Spätantike betont auch Simon Ellis, der die gleich bleibende Funktion des Hauses als Kommunikationszentrum hervorhebt und in der Grundstruktur des Peristylhauses verwirklicht sieht, das erst im 6. Jh. unterging (vgl. Ellis 1988; dens. 2000, 71f.).

217 Vgl. den Überblick bei Clarke 1991, 1-19.

218 Zu den unterschiedlichen Empfangs- und Repräsentationsbereichen, die um ein Peristyl herum angeordnet waren, vgl. Ellis 1988, 569-576; Baldini Lippolis 2001, 69-72.

219 Zu den wenigen späten Belegen zählt ein Gesetz Konstantins aus dem Jahr 326, mit dem er die Veräußerungen des Mündelbesitzes durch Kinder einschränkt: Das väterliche Haus, in dem sich die imagines befinden, soll nicht verkauft werden (CJ 5, 37, 22, 3). Flower 1996, 264-269 geht davon aus, dass die imagines auch noch im 6. Jh., als dieses Gesetz in den Codex Iustinianus 
deren Andenken aufrecht und führten dem Besucher weiterhin das soziale Gewicht der familia des Hausbesitzers vor Augen. ${ }^{220}$ Insgesamt blieb die domus ein öffentlichkeitsorientierter und komplementär zur politischen Kommunikation in der Öffentlichkeit existierender Raum, der die politischen Leistungen des Hausbesitzers im Bereich des privatum dokumentierte ${ }^{221}$ und seinen auch politisch wirksamen - gesellschaftlichen Rang unterstrich.

Diese Beobachtungen zu allgemeinen Strukturmerkmalen der spätantiken domus lassen sich zwar mit Blick auf die Situation im spätantiken Rom nur schwer konkretisieren, da sich aus der fragmentarischen archäologischen Überlieferung kein Bild von der Ausdehnung und Struktur der dortigen Wohnanlagen gewinnen lässt. ${ }^{222}$ Doch auch vor der allgemeinen Folie spätantiker Wohnkultur treten die charakteristischen Eigentümlichkeiten des Oratoriums in der domus am clivus Scauri hinreichend deutlich hervor. Die ostentative Zurückgezogenheit, die dieser Raum durch seine Lage signalisierte, lässt sich nicht in die Raumsprache des offenen Hauses einordnen, die neben den für die politische Kommunikation unmittelbar relevanten Repräsentationsbereichen auch die „domestic religion“ der römischen domus charakterisierte. Anders als Lararien, sacella und aediculae, deren Kultnischen sich bevorzugt auf Peristyle, Gärten oder Höfe hin öffneten, ${ }^{223}$ waren die von den beiden Heiligen flankierte Nische und das

aufgenommen wurde, als reale Objekte in den römischen domus existierten, um die senatorischen Familientraditionen zu dokumentieren. Es ist jedoch fraglich, ob es sich bei den imagines in dem konstantinischen Gesetz um mehr handelt als um eine Chiffre für die familiäre Tradition - so ist bemerkenswert, dass der Besitz von imagines hier ganz allgemein vorausgesetzt wird, obwohl die imagines keine religiöse, sondern eine politische Bedeutung hatten, die ihre Verwendung auf die Haushalte der senatorischen Oberschicht beschränkt haben dürfte (s. o., S. 184, Anm. 395). Auch, was die Existenz von imagines in senatorischen domus betrifft, muss man mit durch die antike Literatur vermittelten Traditionsüberhängen rechnen, die keine Entsprechung in der materiellen Kultur fanden. Vergleichbare Diskrepanzen zwischen vereinzelten literarischen Erwähnungen und einer bereits deutlich früher versiegenden archäologischen Evidenz finden sich auch im Bereich der häuslichen Religion, beim Genius und den Laren (Bakker 1994, 12).

220 Vor allem in Form von Ahnengalerien, die sich zum Teil in spätantiken Domus und privaten Platzanlagen nachweisen lassen (vgl. Niquet 2000, 25-27, 253-259; Hillner 2004, 163).

221 Dies verdeutlichen die Ehrungen von Provinzen, Gemeinden und Kollegien, die politischen Verdiensten galten, jedoch nicht im öffentlichen Raum, sondern in den domus Aufstellung fanden (vgl. Niquet 2000, 27-29 u. die Übersicht 270-281); zu den rechtlichen Voraussetzungen s. o., Anm. 22.

222 Vgl. auch die entsprechenden Bemerkungen von Niquet 2000, 31; Hillner 2004, 3f. In Anbetracht der vergleichsweise beengten Bausituation in einer Metropole wie Rom wird man davon ausgehen müssen, dass zahlreiche Häuser mit einer begrenzten Grundfläche auskamen und auf die Anlage groß dimensionierter Räumlichkeiten - wie beispielsweise Peristyle verzichteten (vgl. Guidobaldi 1999 [a], 56).

223 Zur Differenzierung der unterschiedlichen Bereiche römischer Hausreligion innerhalb der domus vgl. Foss 1997, der darauf hinweist, dass Lararien nach dem Verschwinden des Atriumhauses meist nicht in Repräsentationsbereichen, sondern in den Küchen zu finden waren (vgl. dazu auch Bakker 1994, 37-42) und die Ausübung des Kultes für die Laren häufig den Sklaven 
Andachtsbild des Oranten im Oratorium der domus am clivus Scauri für den Besucher des als Viridarium genutzten Lichthofes praktisch nicht einzusehen: Die räumliche Disposition der Anlage versinnbildlichte und verlangte den asketischen Rückzug aus der Öffentlichkeit, den auch die literarischen Zeugnisse zum Kennzeichen der Heiligenverehrung im privaten Raum der domus erhoben. Im Unterschied zu Statuen und Ausstattungsluxus, die den sozialen Rang des Hauseigentümers gegenüber seinen Besuchern vor Augen führten, ${ }^{224}$ wurde der Heilige in dem kleinen Gebetsraum zum Fokus einer ganz auf die Relation zwischen ihm und seinem Verehrer begrenzten, nicht auf eine öffentliche Wirkung ausgerichteten Memoria.

Nichts wäre irreführender, als aus diesem Befund auf einen christlich bedingten paradigmatischen Strukturwandel in der Relation des privaten Raums zur Öffentlichkeit zu schließen. Die Wohnhäuser im Rom des späten 4. und frühen 5. Jh. waren - unabhängig von der religiösen Zugehörigkeit ihrer Besitzer - Orte gesellschaftlichen Ansehens und Einflusses. Dies betrifft nicht nur ihre Funktion als reale Machtzentren von Patronage und Einflussnahme, ${ }^{225}$ sondern vor allem auch die Kommunikationsformen, in denen sich

überlassen blieb. Häuser von mittleren und großen Dimensionen verfügten jedoch über eine große Zahl an Kultstätten, häufig mit eigenen Kultbereichen für das Personal und für den Besitzer der domus und seine Gäste - letztere mit bevorzugter Ausrichtung auf Peristyle und Gartenanlagen (Foss 1997, 207-216). Brenk 2003, 98 vergleicht das Oratorium in der domus am clivus Scauri mit einem Lararium, doch wird dies dem Charakter der Anlage nicht gerecht; das Oratorium ist mit der öffentlichen Ausrichtung eines Larariums wie z. B. dem in der villa von Piazza Armerina nicht vergleichbar (vgl. dazu Carandini, in: Carandini u. a. 1982, 125f., der den „aspetto pubblico“ des Sacellums betont).

224 Mit Blick auf die domus am clivus Sacuri lässt sich dies leider nicht näher konkretisieren. Obwohl sie aufgrund ihrer vergleichsweise bescheidenen Ausmaße wohl nicht zu den allerersten Adressen der Stadt zählte, kann es als wahrscheinlich gelten, dass ihre Bewohner der städtischen Elite zuzurechnen sind. Zur Einreihung der domus am clivus Scauri unter die römischen Häuser „di medie o piccole dímensioni“" vgl. Guidobaldi 1986, 223-228, der allerdings hervorhebt, dass im Rom des 4. Jh. eine deutliche Zunahme an domus zu verzeichnen ist, die über vergleichsweise geringe Dimensionen verfügten (ders. 1999 [a], 56). Guidobaldi erklärt dies u. a. mit dem Zuzug neuer Angehöriger des unter Konstantin erweiterten Senatorenstandes, die sich aufgrund der hohen Preise für Baugrundstücke und Mieten in Rom keine größeren Anwesen hätten leisten können (vgl. Guidobaldi 1993, 70-72); anders Hillner 2004, 230f., die nur von einer geringen Zahl von senatorischen Neuankömmlingen ausgeht und meint, dass die führenden Familien Roms in dieser Zeit verstärkt Nebenresidenzen für einzelne Familienmitglieder angelegt hätten. Pammachius, der Bauherr der später über der domus am clivus Scauri errichteten Titelkirche, lässt sich zwar mit hoher Wahrscheinlichkeit dem Senatorenstand zuweisen (s. o., Anm. 106); es ist jedoch nicht klar, ob ihm das Haus auch vorher gehörte, oder ob er es erst für den Bau der Basilika erwarb bzw. der Kirche die finanziellen Mittel für den Kauf bereitstellte.

225 Zur Bedeutung der domus und der in ihnen wirksamen Patronagebeziehungen für die Verbreitung und Organisation häretischer Gemeinschaften im spätantiken Rom s. Maier 1995. Für die Verankerung der zum Christentum konvertierten Oberschicht in den traditionellen Kommunikations- und Repräsentationsformen ihrer aristokratischen Standesgenossen und für die Widerstände, die diese ,respectable christianity“ rigoristischen Askeseforderungen, die den Bestand ihrer Häuser gefährdeten, entgegensetzte, vgl. zuletzt Curran 2000, 260-320. 
dies äußerte. Aus der domus der christlichen Anicier auf dem Pincio - einer über die Grenzen Roms für ihren Ausstattungsluxus bekannten Wohnanlage 226 - sind die Überreste einer Ahnengalerie erhalten geblieben, die die öffentliche Ausrichtung des privaten Raums nachhaltig unterstreicht. ${ }^{227}$ Auch machte Hieronymus in seinen Invektiven gegen die aristokratischen Haushalte von Christen, die aus seiner Sicht den Forderungen nach einer asketischen Distanzierung vom saeculum nicht entsprachen, präzise das zur Zielscheibe seiner Kritik, was im spätantiken Rom ein religionsübergreifendes Moment der aristokratischen Wohnkultur darstellte: die Funktion des Hauses als Schauplatz und zugleich als Erinnerungsort einer Kommunikation, die das „private“ Verhältnis des Besitzers zu seinen amici und Klienten widerspiegelte und in Erinnerung hielt - sowohl durch den Ausstattungsluxus, der den Besuchern die Ressourcen und Möglichkeiten des Hausherrn immer neu vor Augen führte, als auch durch Statuen, die von Gemeinden und Korporationen als Dank und Gegengabe für die Leistungen ihres Patrons errichtet wurden. ${ }^{228}$ Es stellt sich jedoch die Frage, ob auch Heiligenkulte und Reliquien Teil dieser öffentlichkeitsorientierten Wohn- und Residenzkultur waren. Zwar wurden Reliquien durch aristokratische Kommunikationsbeziehungen vermittelt und fungierten als statusadäquate Geschenke, doch deuten die Anlage des Oratoriums am clivus Scauri und die literarischen Nachrichten über Hausoratorien nicht darauf hin, dass Heiligenkulte und Reliquien öffentlichkeitswirksam in Szene gesetzt wurden, um im privaten Raum der domus den Besuchern und Klienten das gesellschaftliche Ansehen ihres Besitzers vor Augen zu führen.

Die in dieser Hinsicht außerordentlich beschränkten Möglichkeiten zur „Privatisierung“ von Heiligenkulten werden auch deutlich, wenn man den Raum der domus verlässt und die Orte der Heiligenverehrung innerhalb der

\footnotetext{
226 Vermutlich auf diese domus des Petronius Probus auf dem Pincio ist eine Bemerkung des Manichäers Secundinus zu beziehen, der den Marmorglanz der domus Aniciana hervorhebt (CSEL 25, 895); vgl. auch Paul. Med., vita Ambr. 25, 2.

227 Niquet 2000, 27.

228 Die Kritik des Hieronymus an der aristokratischen Wohnkultur tritt besonders deutlich in seinem berühmten Brief an Eustochium (geschrieben 384) hervor: Die Häuser der Witwen seien voller adulatores und Schauplätze von aufwendigen Gastmählern; auch Geistliche antichambrierten in den domus dieser Damen; ihre Diener begleiteten sie in der Öffentlichkeit und demonstrierten auch an christlichen Schauplätzen wie der Petrusbasilika das soziale Ansehen ihrer Herrinnen (vgl. Hier., epist. 22, 16. 28. 32). Hieronymus' satirisch gefärbte Polemik weist auffällige und bezeichnende Übereinstimmungen mit dem Bild auf, das in derselben Zeit auch Ammian von der senatorischen Oberschicht entwirft (Amm. 14, 6, 12-17; 28, 4, 8f. 12f. 17): Die Darstellungen der beiden Autoren verdeutlichen, dass die religiöse Orientierung geringen Einfluss auf die Formen aristokratischer Selbstdarstellung hatte. - Zur Errichtung von Statuen durch Kollegien und Gemeinden, die die Leistungsfähigkeit eines Patrons dokumentierten und in Erinnerung hielten, vgl. Niquet 2000, 27f.; s. auch Amm. 14, 6, 8.
} 
Stadt und im Suburbium mit einbezieht. Als Kontrastfolie für die Situation in Rom um die Wende vom 4. zum 5. Jh. können die zeitgleichen Verhältnisse in einer anderen Metropole, Konstantinopel, dienen, wo die städtische Heiligentopographie ausgeprägte Möglichkeiten zur Ausbildung von privaten Patronagebeziehungen eröffnete, die sich einer Kontrolle durch den Bischof entzogen. In Konstantinopel war bereits seit den Tagen von Kaiser Constantius II. (337-361) ein städtisches Mönchtum entstanden, das sich nicht nur in Klöstern, sondern vor allem im Umfeld von karitativen Fürsorgeeinrichtungen und Märtyrerschreinen organisierte. ${ }^{229}$ Die Bedeutung und organisatorische Vernetzung dieser Zentren tritt vor allem anlässlich der starken Spannungen hervor, die sich zwischen diesem Mönchtum und den Bischöfen Konstantinopels entwickelten: Von der zweiten Hälfte des 4. Jh. bis zum Konzil von Chalkedon (451) bildete das Mönchtum der Stadt eine nahezu geschlossene, häufig vom Bischof von Alexandria unterstützte Front gegen einzelne Bischöfe wie Johannes Chrysostomos, Nestorius und Flavian, die sich der Opposition einflussreicher Mönchsführer wie Isaak, Dalmatios und Eutyches gegenüber sahen. ${ }^{230}$ Wie Daniel Caner unlängst herausgearbeitet hat, spielten in diesen lokalen Auseinandersetzungen Fürsorgeeinrichtungen und Heiligenschreine als Zentren von Patronage eine wesentliche Rolle: In ihnen konzentrierten sich materielle Ressourcen, die eine vom Bischof unabhängige Versorgung der dort lebenden Mönche sicherten und vor allem durch die - als „Archimandriten der Klöster“ oder „Vater der Mönche“ bezeichneten - Mönchsführer vermittelt wurden, die als Makler zwischen den Patronen und den an den Schreinen und Fürsorgeeinrichtungen lokalisierten Asketengruppen fungierten. ${ }^{231}$ Auch wenn sich die damit verbundenen topographischen Gegebenheiten im Detail nur schwer rekonstruieren lassen,232 ist die strukturelle Bedeutung der Heiligenschreine als

229 Grundlegend zum frühen Mönchtum in Konstantinopel und seiner Formation im Umfeld von Heiligenschreinen und Fürsorgeeinrichtungen ist Dagron, 1970, bes. 253-261. Für eine differenzierte Darstellung des konstantinopolitanischen Mönchtums bis zum Konzil von Chalkedon (451) im Kontext der asketischen Bewegung in den Städten der Osthälfte des Imperium Romanum vgl. zuletzt Caner 2002, 158-241. Nach Dagron 1970, 238f., 244-253 ist die unter dem Diakon Marathonios erfolgte Etablierung eines städtischen Mönchtums und seine Symbiose mit den Fürsorgeeinrichtungen Konstantinopels auf den prägenden Einfluss des Eustathius von Sebaste zurückzuführen (vgl. bes. Soz., h. e. 4, 27, 4). Diese Verbindung ist zumindest, was die Genese von Xenodochien und ähnlichen Fürsorgeeinrichtungen betrifft zuletzt von Brown 2002, 34-42 in Zweifel gezogen worden; dass Konstantinopels $\pi \tau \omega \chi \varepsilon i \alpha$ und vобоконєі̃ $\alpha$ bevorzugte Anlaufstellen des städtischen Mönchtums bildeten, bleibt davon jedoch unberührt.

230 Dagron 1970, 261-275.

231 Caner 2002, bes. 192-198, 217-223, 227-239.

232 Die spätere Überlieferung hat zahlreiche dieser Martyrien mit dem Namen Konstantins in Verbindung gebracht (vgl. die Übersicht bei Dagron 1974, 388-401), doch fällt die Ausbauphase dieser Sakraltopographie in die Zeit der theodosianischen Dynastie, als sich Konstantinopel von 
ideelle und organisatorische Bezugspunkte des städtischen Mönchtums von Konstantinopel deutlich erkennbar. Sie tritt vor allem während des Konzils von Chalkedon hervor, das zugleich einen Wendepunkt in der Entwicklung dieses städtischen Mönchtums einleitete. Als einzelne Anhänger des Eutyches sich mit einer Petition an das Konzil wandten, trat man ihnen mit der Bemerkung entgegen, sie seien in der überwiegenden Zahl keine Archimandriten, sondern allenfalls einfache Asketen, die nicht in Klöstern, sondern an Märtyrerschreinen lebten und dort kleinere Gruppen von Gleichgesinnten um sich scharten. ${ }^{233}$ Die Märtyrerheiligtümer Konstantinopels bildeten Anlaufpunkte für ein Mönchtum, das sich nicht in die Abgeschiedenheit hinter Klostermauern zurückzog, sondern unmittelbar in das Leben der Stadt integriert war, und das sich in kleinen und instabilen Gruppen formierte, die für Zuwanderungen von außen offen blieben und nur schwer zu kontrollieren waren.

Vergleichbare Strukturen lassen sich für Rom in diesem Zeitraum nicht aufzeigen: Weder finden sich hier überzeugende Anhaltspunkte für Heiligenschreine und Martyrien, die Zentren und Kristallisationspunkte für asketische Gemeinschaften gebildet hätten, noch begegnen in der Überlieferung Hinweise auf ein städtisches Mönchtum, das der monastischen Landschaft Konstantinopels ihr spezifisches Gepräge gab. Was die Existenz von Heiligenoratorien im städtischen Raum betrifft, bleibt man in Ermangelung literarischer Quellen ${ }^{234}$ auf die epigraphischen und archäolo-

einer Residenz zur Hauptstadt entwickelte und zahlreiche Märtyrer nach Konstantinopel überführt wurden (ebd., 400f.; Diefenbach 2002, 24).

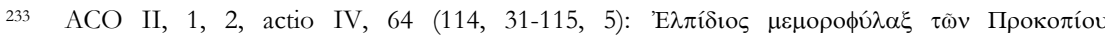

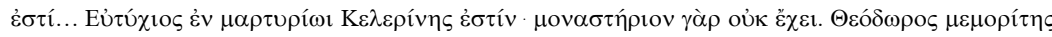

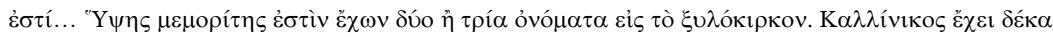

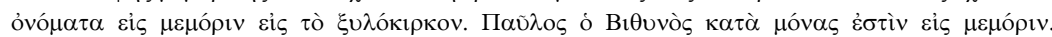

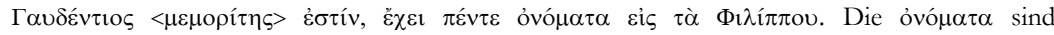
vermutlich weitere Mönche, die gemeinsam mit den Genannten an den Memorien lebten (zur Stelle und ihrer Interpretation vgl. Caner 2002, 228f.). Die Bedeutung der Märtyrerschreine als organisatorische Zentren der Mönche geht auch aus der Petition an Kaiser Markian selbst hervor, in der die Anhänger des Eutyches darum bitten, kein Mönch solle bis zur Entscheidung des Konzils aus einem Kloster, einer Kirche oder einem Martyrion vertrieben werden (ACO II,

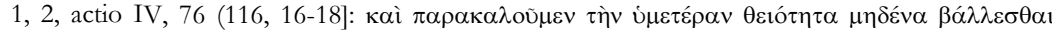

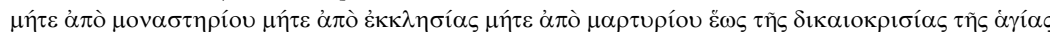

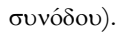

234 Hinweise auf die Existenz von Memorien oder Martyrien, die im Unterschied zu den Hauskapellen wie dem Oratorium in der domus am clivus Scauri nicht in Häusern angesiedelt, sondern als eigenständige Bauten an Straßen und Plätzen zu finden waren, haben sich in der literarischen Überlieferung zu Rom im 4. und früheren 5. Jh. nicht erhalten. In der Forschung wird zuweilen auf die Anweisung des Kaisers Honorius an den Stadtpräfekten Symmachus, er solle die kaiserliche Verfügung per omnes titulos vel loca, quae conventu celebri frequentantur bekannt machen (coll. Avell., epist. 31, 7), verwiesen. Die neben den Titelkirchen genannten loca sind jedoch nicht als Oratorien zu verstehen (so zuletzt Cerrito 2002, 401, Anm. 20 im Anschluss an Pietri 1976, Bd. 1, 638); vielmehr beziehen sich die kaiserlichen Publikationsbestimmungen auf 
gischen Befunde angewiesen. Deren Bilanz fällt ausgesprochen spärlich aus: Für das 4. und frühere 5. Jh. beschränkt sie sich auf einige unter dem ehemaligen Ospedale di S. Giovanni in Laterano freigelegte Räume, die leider nur unzureichend erfasst und dokumentiert sind, jedoch am ehesten an eine Anlage denken lassen, die denen der Memorien und Märtyrerschreine Konstantinopels geähnelt haben dürfte. ${ }^{235}$ Von diesem vereinzelten Beleg abgesehen, haben sich jedoch keine weiteren Hinweise auf öffentliche Heiligenoratorien erhalten: Die frühesten Beispiele für derartige Oratorien stammen aus dem 6. Jh.;236 sonstige Zeugnisse, die auf eine frühere Existenz von Memorien und Heiligenschreinen in Rom hinweisen, halten einer näheren Überprüfung nicht stand. ${ }^{237}$

nicht-kirchliche öffentliche Plätze wie Foren, die für die Bekanntmachung von Gesetzen genutzt wurden (für das Trajansforum vgl. Bauer 1996, 95f.).

235 Dokumentation und Deutung der Anlage durch Scrinari 1995, 215-241 sind zuletzt von Brenk 2003, 121-128 stark kritisiert worden. Zwei Räume enthalten Fresken aus der 2. Hälfte des 4. Jh. mit Motiven, die z. T. aus der Katakombenmalerei bekannt sind (Erweckung des Lazarus; Jesus und die Samaritanerin am Brunnen), z. T. in ihrer Deutung unsicher bleiben (männliche Figur, die einem Jüngling die Hand auflegt; Beischrift Genovius servus sanctorum servit in eodem loco). Ein dritter Raum wurde erst im späten 5. oder 6. Jh. mit Malereien versehen, die in ähnlicher Frontalstellung drei Heilige und eine Bekränzung zweier weiblicher Personen durch Christus darstellen. In Anbetracht der nahe gelegenen Lateranbasilika, laufen die Deutungen darauf hinaus, dass der Besitzer entweder ein Kleriker war oder eine kirchliche Aufgabe wahrnahm: Cerrito 2002, 410-416 bringt die Anlage mit einem zum Lateran gehörenden Kleriker in Verbindung und datiert sie in die zweite Hälfte des 5. Jh. (was allerdings mit Blick auf die Fresken der beiden ersten Räume etwas spät erscheint); anders Brenk, der die Szene der Handauflegung als Hinweis auf eine Katechetenschule eines Laien deutet, der die Vorbereitung auf die Taufe übernommen habe. Dass Genovius sich als servus sanctorum bezeichnete, dürfte jedoch eher auf eine Funktion als Schreinwächter hindeuten, wie sie in ähnlicher Form aus der

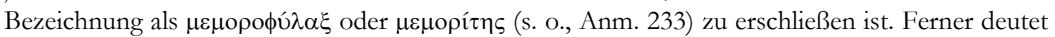
die Inschrift auf einen gewissen Publikumsverkehr hin; mehr lässt sich über die Funktion der Anlage nach dem gegenwärtigen Forschungsstand, der vor allem zum architektonischen Kontext, in dem diese Räume standen, wenig Aussagen ermöglicht, nicht sagen.

236 Ein nur noch aus Zeichnungen bekanntes Oratorium der Hl. Felicitas ist nicht vor dem 6. Jh. entstanden (Cerrito 1998); in noch spätere Zeit (Mitte des 7. Jh.) gehört das Oratorium für die 40 Märtyrer von Sebaste neben S. Maria Antiqua (s. Gulowsen 2001). Unklar ist die Funktion eines neben der heutigen Kirche S. Martino ai Monti gelegenen Magazingebäudes aus dem 3. Jh., das im frühen 6. Jh. mit christlichen Malereien versehen wurde (zur Datierung vgl. DavisWeyer/Emerick 1984, 54-57). Pietri 1976, Bd. 1, 20 denkt bei dem von der älteren Forschung als titulus Aequitii angesehenen Bau an ein Oratorium für Silvester; Krautheimer, in: Corpus III, 123f. meint, dass es sich um den titulus Silvestri handele, der um 500 den titulus Aequitii ersetzt habe. Cecchelli 2000 (a), 428-431 deutet die Anlage als eine von Bischof Symmachus (498-514) errichtete Diakonie, obwohl die Institution der Diakonie für die römische Kirche erst seit dem späten 7. Jh. sicher bezeugt ist (vgl. die Forschungsbilanz bei Hermes 1996, 21-23). Unabhängig von der umstrittenen Funktion des Gebäudes bleibt festzuhalten, dass sich Hinweise auf eine christliche Nutzung nicht vor dem beginnenden 6. Jh. nachweisen lassen.

237 Dies gilt vor allem für die memoria Hippolyti, die man aufgrund einer um das Jahr $400 \mathrm{zu}$ datierenden Inschrift in der Gegend des Esquilin in der Nähe der Titelkirche S. Pudenziana lokalisierte; die Angabe ist jedoch vermutlich auf die Grablege des Hippolytus an der via Tiburtina zu beziehen (s. o., S. 273, Anm. 200). Ob Bischof Iulius (337-352) seine basilica ad Callistum, die 
Obwohl man diesen mageren Überlieferungsbefund angesichts der Schwierigkeiten, die Existenz derartiger Oratorien allein aufgrund der archäologischen und ikonographischen Befunde sicher nachweisen zu können, nicht überbewerten sollte, bestätigt er doch das Bild, das man auch aus den literarischen Quellen gewinnt: Ein städtisches Mönchtum, das in Konstantinopel bis 451 eine so prägende Wirkung entfaltete und eine gegen den Bischof mobilisierbare Klientel im Umfeld der Märtyrermemorien und Fürsorgeeinrichtungen bildete, ist in Rom nicht nachweisbar. Die Askese blieb dort - bei aller Vielgestaltigkeit in der Umsetzung asketischer Postulate $^{238}$ - im wesentlichen auf die aristokratischen domus selbst zentriert. Dies bedeutet zwar nicht, dass es nicht auch in Rom, ähnlich wie in Konstantinopel, Ansätze zur Ausbildung eines städtischen Mönchtums und von Patronagebeziehungen gegeben hätte, die diese Schicht an vermögende Wohltäter banden: Auch in Rom begegnete man Wanderasketen, die durch ihre radikale Kleidungs- und Körperaskese auffielen und um Aufnahme in aristokratischen Haushalten nachsuchten, ${ }^{239}$ und auch dort war Askese ein Phänomen, das auf den Straßen der Stadt und in der Öffentlichkeit präsent war. ${ }^{240}$ Im Unterschied zur zeitgleichen Situation in Konstantinopel unterlagen die Askese und ihre Organisationsformen in Rom jedoch einer stärkeren Kontrolle durch den römischen Bischof und einer wirksamen Einbindung in die klerikale Hierarchie.

später titulus Iulii et Callisti genannte Kirche, in der Nähe einer memoria Callisti errichtete (so Pietri 1976, Bd. 1, 20), ist höchst zweifelhaft - ob und in welcher Weise das Toponym Callistum mit dem römischen Bischof des 3. Jh. zusammenhängt, ist eine offene Frage (vgl. zuletzt Brandenburg 2004, 112). Bei dem sogenannten Oratorium am Monte della Giustizia, das im 19. Jh. abgerissen wurde, dürfte es sich nicht um ein Oratorium, sondern um die Kirche S. Agata in Esquilino handeln (Testini 1968, bes. 251-258). Ein Oratorium bei S. Prisca, dessen Malereien von Giovanni B. de Rossi irrtümlich in das 4. Jh. datiert wurden, ist frühmittelalterlichen Ursprungs und gehört vermutlich zu einem unter Bischof Leo III. (795-816) erwähnten Kloster S. Donato (Cerrito 2002, 403f.). Belege für weitere Oratorien, die erst im frühen Mittelalter entstanden sein dürften, stellt Pietri 1976, Bd. 1, 513f., Anm. 6. zusammen.

238 Vgl. Curran 2000, 295-298.

239 Hier., epist. 22, 28: viros quoque fuge, quos videris catenatos, quibus feminei contra apostolum crines, bircorum barba, nigrum pallium et nudi in patientiam frigoris pedes. Hieronymus benennt im Anschluss zwei prominente Beispiele, die in Rom noch in lebhafter Erinnerung waren. Als Wanderasket gelangte auch der ägyptische Mönch Sarapion nach Rom (vgl. Pall., h. Laus. 37). Nicht sicher unmittelbar mit Rom in Verbindung zu bringen sind die remnouth, kleine Gruppen von Asketen, die nach dem Zeugnis des Hieronymus vorzugsweise in den Städten in nostra provincia anzutreffen waren (Hier., epist. 22, 34. nostra provincia ist hier wohl gleichbedeutend mit „unserer Gegend“; der Brief wurde in Rom verfasst).

240 Hier., epist. 22, 13 über Asketinnen, quae per publicum notabiliter incedunt et furtivis oculorum nutibus adulescentium gregem post se trahunt. Bei dem von Hieronymus so dezidiert betonten Auftreten und Suchen der Öffentlichkeit sind allerdings gezielte polemische Verzerrungen des Verfassers in Rechnung zu stellen; wie genau dieses Bild die historischen Verhältnisse widerspiegelt, ist schwer zu sagen. 
Dies spiegelt sich vor allem in mehreren Schreiben des römischen Bischofs Siricius (384-399) an auswärtige Bischöfe wider, in denen er deutlich machte, dass die Askese keine eigenständige Quelle von Autorität neben dem klerikalen Amt bilden solle. Siricius erwartete von den Klerikern, dass sie sich aufgrund ihres Amtes zu einer asketischen Lebensführung verpflichteten, ${ }^{241}$ stellte jedoch gleichzeitig heraus, dass die Askese als solche, losgelöst vom kirchlichen Amt, keine qualifizierende Wirkung hatte: Die asketische Bewährung war zwar Voraussetzung für ein Durchlaufen des klerikalen Cursus bis in die höchsten Ämter hinein, doch bildete dieser Cursus mit geregelten Weihestufen und Altersgrenzen eine Ämterstruktur, die durch besondere asketische Leistung nicht außer Kraft gesetzt werden sollte. ${ }^{242}$ Die daraus resultierende klerikale Domestizierung der Askese ${ }^{243}$ und ihre Bindung an das kirchliche Amt machte sich nicht nur in den Normen bischöflicher Schreiben bemerkbar, sondern prägte offensichtlich auch das Klima, das Asketen im ausgehenden 4. Jh. in Rom vorfanden. Hieronymus, der zwar selbst Priester war, der Askese jedoch eine höhere Autorität zuerkannte als dem kirchlichen Amt, und der die Präsenz von Klerikern in den Haushalten asketisch lebender Frauen scharf kritisierte, ${ }^{244}$ hatte Rom bereits bald nach der Wahl des Siricius zum Bischof den Rücken gekehrt. ${ }^{245}$ Als sich der Aristokrat Paulinus von Nola im Sommer 395, bald nach seiner aufsehenerregenden conversio, aus Spanien auf den Weg zum Felixgrab nach Nola machte und dabei für kurze Zeit Station in Rom bezog, hatte er Anlass,

241 Siricius., epist. 1, 8-10 (PL 13, 1138f.) (Antwortschreiben an Himerius von Tarraco): Die ordines clericorum - Presybter und Diakone - sollen nach ihrer Weihe in der Ehe enthaltsam leben. In ähnlicher Weise hatte sich bereits Siricius' Vorgänger Damasus (366-384) in einer Dekretale an die Bischöfe Galliens geäußert (Damas., epist. ad Gallos 5: Bischöfe, Presbyter und Diakone sind zur Keuschheit verpflichtet). Zur zunehmenden Asketisierung des Klerus seit dem späteren 4. Jh. vgl. Rousselle 1977, 341-344; Jenal 1995, Bd. 2, 694-697.

242 Siricius, epist. 1, 17 (PL 13, 1144f.): Die Aufnahme von Mönchen in den Klerus ist möglich, doch müssen die Abfolge der Weihestufen und ihre Mindestalteranforderungen beachtet werden.

243 Sie äußerte sich auch in der Skepsis des Siricius gegenüber Wanderasketen, deren Weihe zu Diakonen, Presbytern oder gar Bischöfen er strikt ablehnte (Siricius, epist. 6, 4 [PL 13, 1165f.] an die Bischöfe im mittleren und südlichen Gallien). Dies richtete sich nicht gegen die Askese, wohl aber gegen asketische Formen, die sich der kirchlichen Aufsicht und Kontrolle entzogen (transeuntes.., quorum nec vitam possumus scire nec baptismum, quorum fidem incognitam babemus nec probatam).

244 Hier., epist. 22, 16. 28. Zum Verhältnis von Amt und Askese bei Hieronymus vgl. König 1985, bes. 38-70. Hieronymus war - ebenso wie Paulinus v. Nola - Priester, ohne jedoch einer Gemeinde zugeordnet zu sein und ohne die mit dem Amt verbundenen Aufgaben auszuüben; zu dieser Form der absoluten Ordination, die besonders im Osten des Reichs häufig den Charakter einer Devotionsweihe annahm, vgl. Häußling 1973, 151, 154f.

245 Hieronymus verließ im Jahr 385 Rom, vermutlich veranlasst durch Widerstände gegen die Propagierung seiner rigoristischen asketischen Ideale (Brief an Eustochium [epist. 22] vom Frühjahr 384) und durch den unter Siricius eingeleiteten Kurswechsel in der Bewertung einer vom Klerus nicht kontrollierten Askese. 
sich über den Hochmut der römischen Kleriker und die kühle Aufnahme durch den Bischof Siricius zu beklagen. ${ }^{246}$ Die Gründe für den abweisenden Empfang liegen auf der Hand: Der Aristokrat im Mönchsgewand, ${ }^{247}$ der sich einer Einbindung in die klerikale Ämterhierarchie dadurch widersetzt hatte, dass er trotz seiner Priesterweihe in Barcelona die Gemeinde verlassen und seine asketische Berufung über den Dienst des Amtes gestellt hatte, ${ }^{248}$ musste Siricius geradezu als die Verkörperung einer nicht kontrollierbaren, außerhalb und unabhängig vom kirchlichen Amt existierenden Askese erscheinen, die er in seinen Verfügungen zu unterbinden suchte.

Diese Formen klerikaler Kontrolle machten sich in Rom nicht zuletzt an denjenigen Orten bemerkbar, die in Konstantinopel bevorzugte Anziehungspunkte und Zentren für ein städtisches Mönchtum gebildet hatten: den Heiligengräbern. Trotz der hohen Bedeutung der Märtyrer als Sinnbilder asketischer mortificatio und als ideelle Bezugspunkte des asketischen Gebetes und Rückzuges aus der Welt haben sich in Rom praktisch keine Hinweise auf monastische Gemeinschaften erhalten, die sich im Umfeld von Heiligengräbern im römischen Suburbium angesiedelt hätten. Die seit dem späteren 4. Jh. mehrfach bezeugten Übersiedlungen von Asketinnen in das Suburbium Roms ${ }^{249}$ waren anachoretische Rückzüge dieser vermögenden Damen auf ihre Landgüter, keine Gründungen monastischer Gemeinschaften in der Nähe verehrter Heiligengräber. Dass die Heiligentopographie des römischen Suburbiums Pole für die Ansiedlung von Asketen und monastischen Gemeinschaften gebildet hätten, ist auch sonst nicht nachweisbar. ${ }^{250}$ Vielmehr macht sich in der Märtyrer- und Heiligen-

246 Paul. Nol., epist. 5, 13f.; zum Kontext vgl. Trout 1999, $113 f$.

247 Zu Paulinus' äußerer - und demonstrativer - Sichtbarmachung der conversio durch die mutatio vestis vgl. Ambr., epist. 6, 27 (58), 3 (geschrieben 395).

248 Paulinus war Weihnachten 394 per saltum, ohne die niederen Weihestufen durchlaufen zu haben, zum Priester geweiht worden (vgl. König 1985, 113-115), auch dies im übrigen gegen die von Siricius verfochtenen Weihebestimmungen (s. o., Anm. 242).

249 Marcella war nach dem 385 erfolgten Rückzug des Hieronymus aus Rom von diesem aufgefordert worden, die Stadt ebenfalls zu verlassen und sich in die Abgeschiedenheit des Landlebens zurückzuziehen - eine Aufforderung, der sie zu einem nicht näher bestimmbaren Zeitpunkt auch nachkam, indem sie im ager suburbanus eine monastische Gemeinschaft gründete (Hier., epist. 43, 3 [geschrieben 385]: quam primum licet quasi quendam portum secreta ruris intremus; dens. epist. 127, 8: suburbanus ager vobis pro monasterio fuit, et rus electum propter solitudinem). Auch die mit Marcella befreundete Asketin Lea (gest. 384), die in Ostia ihre letzte Ruhestätte fand (Hier., epist. 23, 1), könnte ihr monasterium für Jungfrauen (ebd. 23, 2) auf einem Gut im römischen Suburbium gehabt haben (Gordini 1956, 245). Melania d. J. und ihr Mann Pinianus zogen sich auf ein Landgut vor den Mauern der Stadt zurück, um dort ihre asketischen Tugenden zu vervollkommnen, bevor sie im Jahr 408/9 der Stadt Rom endgültig den Rücken kehrten (vita Melaniae 7; zum asketischen Rückzug Melanias und ihrer Mutter Albina auf das Land vgl. auch

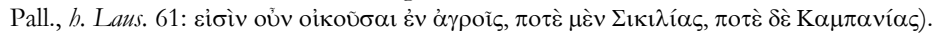

250 Entsprechende Versuche, vereinzelte epigraphische Zeugnisse für virgines in suburbanen Grabbasiliken wie S. Lorenzo f.l.m., S. Paolo f.l.m. und S. Sebastiano als Zeugnisse für dort 
topographie des römischen Suburbiums dieselbe Tendenz zur klerikalen Kontrolle bemerkbar, die insgesamt für die Entwicklung der asketischen Bewegung in Rom charakteristisch ist. Seit der Mitte des 5. Jh. entstanden an den römischen Coemeterialbasiliken von den römischen Bischöfen gegründete monastische Gemeinschaften, die für die Abhaltung des Basilikaloffiziums verantwortlich waren, während nicht zu diesen Klöstern gehörige Presbyter die Feier der eucharistischen Liturgie in den Basiliken übernahmen. ${ }^{251}$ Dies unterstreicht die Wirksamkeit, mit der Postulate nach einer Einbindung und Domestizierung der Askese, wie sie Siricius in ihren Grundzügen formuliert hatte, in der Praxis wirksam wurden. Die auf bischöfliche Initiative ins Leben gerufenen Basilikalklöster verpflichteten ihre Angehörigen durch die Wahrnehmung des öffentlichen Stundengebets auf einen regulierten liturgischen Dienst an der Gemeinschaft, der sie dem gottesdienstlichen Aufgabenbereich des Klerus annäherte, und kanalisierten das asketische Heils- und Vollendungsstreben in Institutionen, die der Aufsicht durch den römischen Klerus unterstanden. ${ }^{252}$

In einer von Patronagebeziehungen durchzogenen Gesellschaft, wie sie die stadtrömische im späteren 4. und früheren 5. Jh. darstellte, fungierte die Heiligenmemoria nicht als eine Ressource zur Begründung von privater Autorität - weder innerhalb der domus, noch im städtischen Raum oder im Suburbium der Stadt. In keinem dieser Bereiche entwickelten sich Orte der Heiligenverehrung zu Kristallisationspunkten einer Öffentlichkeitsbildung, die nicht kirchlich kontrolliert gewesen wäre. Auch in der domus am clivus Scauri wurde die kleine Reliquienkapelle erst nach der Umwandlung der domus in eine Kirche zu einem gemeindeöffentlichen Raum: Die Wohnanlage, deren Erdgeschoss als Substruktion für den Basilikalbau genutzt wurde und dadurch erhalten blieb, verschwand unter einer dreischiffigen Basilika, die bei dieser Gelegenheit auch die kleine Märtyrerkapelle mit ihren Reliquien überbaute. Mit der Umwandlung der domus in eine Kirche war eine grundlegende Umstrukturierung des räumlichen Kontextes der Heiligenmemoria verbun-

angesiedelte monastische Gemeinschaften zu deuten, werden zurecht skeptisch beurteilt (in diesem Sinne auch zuletzt Jenal 1995, Bd. 1, 128f.; weniger zurückhaltend Gordini 1956, 246f., Pani Ermini 1981, 28f.). Eine in der passio Agnetis erwähnte Gemeinschaft von virgines bei S. Agnese kann erst für die Zeit, in der die passio redigiert wurde (spätes 5. Jh. [?]) vorausgesetzt werden. Den einzigen Beleg für eine - allerdings nicht monastisch geprägte Gemeinschaftsbildung im Umfeld eines Heiligengrabes ist das Grabkollegium, das eine Gruppe von Tertullianisten (= Montanisten) unter dem Usurpator Eugenius (392-394) bei der Grablege der Märtyrer Processus und Martinianus an der via Aurelia errichtete (Arnob. iun., praedest. 1, 86).

251 Zur Gründung eines Klosters bei S. Sebastiano (in catacumbas) durch Sixtus III. (432-440) vgl. LP I, 234; ähnliche Gründungen nahmen Leo I. (440-461) bei der vatikanischen Petrusbasilika (LP I 239) und Hilarus (461-468) bei S. Lorenzo f.l.m. (LP I, 245) vor. Zur Funktion dieser römischen Basilikalklöster vgl. allgemein - mit Schwerpunkt auf der mittelalterlichen Entwicklung - Ferrari 1957, 365-375.

252 Häußling 1973, 135-137. 
den: Die durch ihre zurückgenommene, auf Abschließung von der Öffentlichkeit ausgerichtete Inszenierung der Heiligen in der Hauskapelle wich einer Basilika, deren raison d'être darin bestand, als öffentlicher Versammlungsraum und als Gemeindekirche zu fungieren. Auch wenn nicht genau bekannt ist, in welcher Weise das kleine Oratorium mit der Basilika, unter derem zentralen Mittelschiff es nach der Überbauung zu liegen kam, verbunden war, ${ }^{253}$ ist sicher, dass die Kapelle unter der Kirche zugänglich blieb ${ }^{254}$ und durch ihre außergewöhnliche Lage die Vorstellung begründete, die Reste der domus unter der Kirche beherbergten die Gräber der beiden Titelheiligen Johannes und Paulus. Dem ehemaligen Hausoratorium wuchs eine außerordentliche Popularität als Pilgerziel zu, ${ }^{255}$ die ihm allerdings erst mit der Umwandlung der domus in eine Kirche zuteil wurde. ${ }^{256}$

Mit diesem Umbau war jedoch zugleich auch eine konsequente Entprivatisierung der in einen titulus umfunktionierten domus verbunden. Obwohl bei der Errichtung von Titelkirchen häufig Teile von Domusanlagen in Kirchengebäude umgewandelt wurden, vollzog sich mit der Gründung einer Titelkirche eine grundlegende Änderung der Kontroll- und Eigentums-

253 Krautheimer, in: Corpus I, 282 berichtet von Stufenansätzen an der linken Außenmauer der Kapelle (,sopra la metà sinistra del corridoio“), die als Überreste einer Treppe zu deuten sind, die nach der Errichtung der Basilika von der Kirche zu der Kapelle hinunterführte. Im Mittelalter und in der frühen Neuzeit erhob sich der Altar der Kirche im zentralen Mittelschiff der Basilika über der Stelle, an der sich das Oratorium befand (Junyent 1932, 122), doch ist nicht sicher, ob diese Anlage bereits spätantiken Ursprungs ist.

254 Bischof Symmachus (498-514) ließ den Bau einer Treppe hinter der Apsis von SS. Giovanni e Paolo vornehmen (ad beatum Iohannem et Paulum fecit grados post absidam [LP I, 262]), was auf die Schaffung eines Zugangs zum Bereich unter der Titelkirche vom clivus Scauri aus hindeutet (so auch Prandi 1953, 135). Graffiti, die im ehemaligen Lichthof am Fuß der Treppe, die zum Oratorium führte, gefunden wurden, belegen, dass das Erdgeschoss der ehemaligen domus zugänglich war (s. ebd., 123f.).

255 Das Sacramentarium Veronense, dessen Redaktion um 560 anzusetzen ist, hebt eigens hervor, dass die Titelkirche der einzige Ort innerhalb der Stadtmauern sei, an dem sich Gräber befänden (Sacramentarium Veronense 14, 271: ut non solum passionibus martyrum gloriosis urbis istius ambitum coronares, sed etiam in ipsis visceribus civitatis sancti Iohannis et Pauli victricia membra reconderes). Auch die Pilgeritinerare notitia ecclesiarum und de locis sanctis aus dem frühen 7. Jh. unterstreichen die Besonderheit, dass die Titelkirche von Johannes und Paulus als eine in der Stadt gelegene Kirche die Gräber der beiden Heiligen beherberge (vgl. notitia 72; de locis 124).

256 Wenig überzeugend ist die Auffassung von Brenk 2003, bes. 101f., 104, 108, 110, 112, mit der Umwandlung der domus in eine Kirche sei der „private“ (= inoffizielle) Heiligenkult in der Kapelle von der Amtskirche ausgelöscht worden, da der obere Teil des Raums beim Bau der Basilika abgetragen und der Raum mit Schutt verfüllt worden sei. Dass die Kapelle unmittelbar nach der Errichtung der Kirche verschüttet wurde, ist angesichts der Bekanntheit und Popularität dieses Raums als Pilgerort, der spätestens seit dem 6. Jh. nachweisbar ist, undenkbar; der Schutt, der von den modernen Ausgräbern vorgefunden wurde, muss aus einer späteren Zeit stammen. Auch das „Kappen“ der Kapelle ist nicht als ein zielgerichteter Akt zu verstehen; dass die Popularität der beiden Heiligen auch von amtskirchlicher Seite gefördert wurde, zeigt ihre Aufnahme in die Heiligenreihe des Communicantes im römischen Messkanon, die vermutlich um die Mitte des 6. Jh. erfolgte (vgl. Kennedy 21963, 139-145). 
rechte. Die Einrichtung einer Titelkirche und ihre Ausstattung mit liturgischem Gerät und mit Liegenschaften ging zwar von einem Stifter aus, war durch seine Auflagen nicht vom titulus übertragbar und schob dadurch bischöflichen Eingriffen in das Stiftungsgut einen Riegel vor, sie wurde jedoch vom Bischof selbst vorgenommen: NN titulum constituit lautete die übliche Eintragung im Liber Pontificalis, um diese Gründung einer Titelkirche durch einen römischen Bischof zu dokumentieren. ${ }^{257}$ Ferner weisen einige Indizien darauf hin, dass die Errichtung von Kirchen in privaten Wohnanlagen in der Regel erst nach dem Tod der Stifter erfolgte, die eine Umwandlung ihrer Häuser in Kirchen testamentarisch verfügten. Beim titulus $V$ estinae ist dies durch die Notiz des Liber Pontificalis bezeugt, wonach die femina Vestina die Errichtung ihrer Kirche und ihre Ausstattung mit einem Stiftungsvermögen vermittels eines Nachlasses vornahm. ${ }^{258}$ Auch für zwei weitere Kirchenstiftungen des 5. Jh., die zwar keine tituli waren, aber Teile von aristokratischen Wohnanlagen in Kirchen umwandelten, dokumentieren die Dedikationsinschriften, dass diese Umbauten erst post mortem stattfanden: Die Kirche S. Stefano in via Latina, die Amnia Demetrias, Enkelin der Anicia Faltonia Proba, unter Leo I. (440-461) in einer suburbanen Villa errichten ließ, war die Ausführung der extrema vota, die Demetrias erließ, als sie „im Begriff stand, die Welt zu verlassen“. ${ }^{259}$ Einige Jahrzehnte später ging Flavius Valila ähnlich vor, indem er den Bischof Simplicius (468-483) für die Zeit nach seinem Tod mit der Umwandlung einer Domusaula in die Kirche S. Andrea in Catabarbara beauftragte und gleichzeitig klarstellte, dass die Kirche als Erbin und Nachfolgerin der domus über den Raum der Aula mit

257 Zur rechtlichen Stellung der tituli und zu ihrer Eigenschaft als vom Bischof vorgenommene Auslagerungen aus dem Kirchengut der Bischofsgemeinde s. o., Anm. 7.

258 LP I, 220: quae femina suprascripta testamenti paginam sic ordinavit, ut basilica sanctorum matyrum ex ornamentis et margaritis construeretur, venditis iustis extimationibus. Aus der Notiz geht nicht hervor, dass Vestina die Kirche in ihrer domus errichten ließ; der Bereich um S. Vitale wurde bisher nicht eingehend archäologisch untersucht (Guidobaldi 1989, 391). Aus der Liste der Liegenschaften, mit der Vestina ihre Stiftung ausstattete, geht jedoch zumindest hervor, dass Vestina den Bauplatz für die Basilika am vicus Longus bereits im vorhinein festgelegt hatte, da sich zahlreiche in der Nähe der Basilika befinden (die Stiftungsliste LP I, 220-222, führt u. a. eine domus iuxta basilicam, in vicum Longum; ein pistrinum in vico Longo; ein balneum in vicum Longum auf; außerdem die Steuerabgaben an der porta Nomentana, auf die der vicus Longus zulief). Dass es sich bei diesem anvisierten Bauplatz um eine domus im Besitz der Vestina handelte, ist sehr wahrscheinlich (die Vermutung von Palmer 1974, 146-158, Vestina habe ihre Kirche am vicus Longus über den Tempeln der Fortuna Bonae Spei und der Pudicitia errichtet, lässt sich nicht hinreichend erhärten).

259 ICUR VI, 15764: cum mundum li[nqu]ens Dem[etri] as Amn[ia virgo] / cla[ud] eret extremum non morit [ura diem / bae]c tibi, pap[a L]eo, votorum extrem[a suorum / trad]idit ut s[a]crae surgeret aula d[omus]. / m[a]ndati comple[t] a fides, sed glor[ia maior / al]terius votum [s]olvere quam propr[ium.] / in[lus]trat culmen Steph[a]nus qui primus in or [be / r]aptus mort [e t] ruci regn[a]t in arc[e poli. / pr]aesulis ba[ec nut]u Tigrinus pr[esbyter instans] / excolit ins[ig]nis mente labor[e fide]; vgl. auch LP I, 238. Zur Basilika und der Villa der Anicier an der via Latina vgl. Krautheimer, in: Corpus IV, 230-242. 
rechtmäßigen Besitztiteln verfügen solle. ${ }^{260}$ Diese Beispiele für postume Umwandlungen privater Wohnarchitektur in Kirchenbauten lassen sich zu der Hypothese zuspitzen, dass eine Errichtung von Kirchen in aristokratischen domus zu Lebzeiten der Stifter bewusst vermieden wurde, um auf diese Weise mögliche Kontrollansprüche der Gründer über „ihre“ Kirche auszuschließen. In einer Zeit, in der die Häuser der römischen Oberschicht blühende Zentren einer aristokratischen Wohnkultur bildeten, war auf diese Weise ein klares Signal gegeben, dass mit der Gründung einer Kirche die ehemalige domus zu einem gemeindeöffentlichen Besitz und Kommunikationsraum wurde: Mit der Gründung einer Titelkirche verlor die domus, in der sie errichtet wurde, ihren Charakter als privater Raum. ${ }^{261}$

\section{4. Ergebnisse}

Seit der Wende vom 4. zum 5. Jh. blieb die Heiligenmemoria in Rom nicht mehr allein auf das Suburbium und seine Topographie heiliger Gräber beschränkt, sondern begann auch in die Kirchen der Stadt Einzug zu halten. Entgegen der traditionellen Auffassung, wonach sich erst während des 6. Jh. in den städtischen Kirchen Roms ein struktureller Wandel von einem Stifterhin zu einem Heiligengedenken vollzogen habe, lässt sich für etwa die Hälfte der römischen Titelkirchen nachweisen, dass sie bereits während des 5 . Jh. über Heiligenpatrozinien verfügten. Anders als im 6. Jh., in dessen Verlauf mehrere Titelkirchen nach Heiligen benannt wurden, die in angrenzenden Bereichen des römischen Suburbiums ihre Grablegen hatten, handelte es sich bei den Patronen, die im 5. Jh. in den städtischen Kirchen Aufnahme fanden, um auswärtige Heilige. Auch wenn die Umstände der Kultübertragung in den meisten Fällen unklar sind, kann man davon ausgehen, dass die Einführung eines Patroziniums in der Regel mit der Translation von Reliquien verbunden war. Rom partizipierte damit an einer Entwicklung, die in dieser Zeit vor

260 ILCV 1785: haec tibi mens Valilae devovit praedia, Christe, / cui testator opes detulit ipse suas. / Simplicius quae papa sacris caelestibus aptans / effecit vere muneris esse tui / et quod apostolici deessent limina nobis / martiris Andreae nomine composuit. / utitur hac heres titulis ecclesia iustis / succedensque domo mystica iura locat... Das Gebäude war von Iunius Bassus (consul 331) als eine basilica errichtet worden (vgl. die Stiftungsinschrift CIL VI, 1737); zur umstrittenen Funktion dieser Basilika vgl. Guidobaldi 1995, 69.

261 Kirchen wie der titulus IV Coronatorum oder der titulus $S$. Balbinae wurden in Aulen eingerichtet, die Elemente größerer aristokratischer Wohnkomplexe - im Falle des titulus S. Balbinae der domus des L. Fabius Cilo - waren. Da die archäologischen Untersuchungen zu den römischen Titelkirchen sich bisher überwiegend auf die Kirchengebäude konzentrierten (vgl. den Diskussionsbeitrag in Cecchelli 1999, 250), lässt sich über die Relation der tituli zu den sie umgebenden aristokratischen Wohnanlagen insgesamt wenig sagen; es besteht jedoch kein Anlass zu der Vermutung, dass die übrigen Teile einer domus, innerhalb derer eine Kirche errichtet wurde, weiterhin in der Hand eines privaten Besitzers verblieben. 
allem in Norditalien sichtbare Spuren hinterließ und dort maßgeblich von Ambrosius v. Mailand gefördert wurde, der durch die Vermittlung von Reliquien an Bischöfe in Oberitalien und Gallien deren Bindung an Mailand und an seine eigene Person stärkte.

Als Übermittler dieser römischen Heiligenpatrozinien kommen - anders als in Oberitalien - weniger die Bischöfe Roms in Betracht, als vielmehr vermögende und einflussreiche Aristokraten, die seit dem letzten Drittel des 4. Jh., insbesondere durch die Errichtung von Titelkirchen, maßgeblich zum Ausbau der christlichen Sakraltopographie Roms beitrugen. Für zwei der römischen Titelkirchen, den titulus Vestinae und den titulus Pammachii, lässt sich zeigen, dass Angehörige der senatorischen Oberschicht nicht nur die Gründung einer Titelkirche veranlassten, sondern diese Titelgründung zugleich mit der Einführung eines Heiligenpatroziniums verbanden. Zwei weitere Titelpatrozinien - im titulus s. Chrysogoni und im titulus s. Anastasiae können durch die Kombination unterschiedlicher hagiographischer Quellen mit der Familie der Anicier in Verbindung gebracht werden, die zu den angesehensten Adressen der „respectable christianity“ Roms zählte. Der spröde Quellenbefund der römischen Hagiographie gewährt jedoch keine weiterreichenden Einblicke in die näheren Umstände der Kultübertragungen. Man bleibt dafür auf Analogieschlüsse aus besser bezeugten Kontexten angewiesen, die jedoch - in Anbetracht dessen, dass die römische Aristokratie an einer allgemeineren Entwicklung partizipierte - herangezogen werden können, um sich die kulturellen Rahmenbedingungen zu verdeutlichen, in die auch die römischen Verhältnisse seit dem ausgehenden 4. Jh. einzuordnen sind.

Wie insbesondere das Zeugnis des zu Beginn des 5. Jh. schreibenden Paulinus v. Nola nahe legt, bildeten Reliquien - und vor allem ihre Über- und Vermittlung - wichtige Bindeglieder einer neuen, Kleriker und Laien umfassenden christlichen Elite. Als statusadäquate Geschenke innerhalb einer Oberschicht, die traditionell durch den Austausch derartiger Gaben persönliche Wertschätzung, amicitia und aristokratisches Statusbewusstsein signalisierte, betonten sie eine Verbundenheit, die auch über weite Distanzen hinweg wirksam war. Gleichzeitig waren Reliquien aber auch ein wirksames Mittel, um auf dieser verbindenden Ebene interne Statusdifferenzen zum Ausdruck zu bringen: Ihre Übersendung oder erfolgreiche Weitervermittlung an Dritte eröffnete den Zugang zu gefragten Ressourcen, die dem Übermittler der Gaben ein besonderes Ansehen unter seinen Standesgenossen sicherten. Die Heiligen und ihre sterblichen Überreste wurden damit zu Bestandteilen eines Kommunikationssystems von amicitia und Patronage, das in der römischen Gesellschaft tief verankert war. Insbesondere im spätantiken Rom entfalteten die auf Freundschafts- und Patronagebeziehungen gründenden Bindungsverhältnisse während des 4. Jh. eine intensive Wirkung, die sich vor 
allem in ausgeprägten Faktionsbildungen äußerte und mit einer zunehmenden Verlagerung der Repräsentation in die domus, die traditionellen Zentren einer nicht politisch vermittelten Autoritätsbildung, einherging. Trotz dieser Voraussetzungen entwickelten sich Heiligenkulte im spätantiken Rom nicht zu einem Feld, auf dem private Formen der Autoritätsbildung und Formen kollektiver Identitätsstiftung, die auf der sozialen Bindungskraft von Patronage- und amicitia-Beziehungen beruhten, wirksam wurden. Dies hatte unterschiedliche Gründe.

Zum einen fehlte es in Rom an einer spezifischen Klientel, die durch die Heiligen hätte gewonnen werden können. Dies verdeutlicht ein vergleichender Blick auf die ganz anders gelagerten Verhältnisse in Konstantinopel, wo sich im Umfeld von Heiligenschreinen und Memorien Gruppen von Mönchen formierten, die in den innerkirchlichen Auseinandersetzungen bis zum Konzil von Chalkedon eine wichtige und schlagkräftige Rolle spielten, und die vermutlich an den Memorien der Stadt durch die finanzielle Unterstützung von Patronen unterhalten wurden. Im Unterschied dazu haben sich aus Rom keine Hinweise auf ein solches städtisches Mönchtum erhalten. Die vor allem von Bischof Siricius (384-399) vorangetriebenen Bemühungen, die Askese an das kirchliche Amt zu binden, äußerten sich nicht nur in offiziellen Verlautbarungen gegenüber anderen Kirchen, sondern hatten Auswirkungen auch auf das asketische Leben in Rom selbst: Außerhalb der aristokratischen Haushalte, in denen sich insbesondere Gemeinschaften weiblicher Asketen bildeten, entstanden keine monastischen Organisationsformen, die nicht, wie die Basilikalklöster, kirchlich kontrolliert gewesen wären. Auch fehlen archäologische Hinweise auf öffentliche Oratorien und Heiligenschreine, die in vergleichbarer Weise wie in Konstantinopel die räumlichen Bezugspunkte von asketischen Gemeinschaften und Patronagestrukturen hätten bilden können.

Die Grenzen einer Privatisierung von Heiligenkulten traten jedoch auch innerhalb der domus selbst zutage. Das Oratorium, das in dem Haus unter der späteren Titelkirche des Pammachius eingerichtet wurde, vermittelt einen exemplarischen Einblick in die Inszenierung der Heiligenverehrung im privaten Raum und in das Selbstverständnis, das dieser Art der Inszenierung zugrunde lag. Die kleine, nur für eine Person begehbare Kammer versinnbildlicht einen asketischen Gestus der Zurückgezogenheit, der auch in literarischen Quellen der Zeit als der Grund für die Einrichtung privater Oratorien erscheint: Sie dienten dem Rückzug aus der Welt und der uneingeschränkten Ausrichtung der ganzen Persönlichkeit auf den Heiligen. Im privaten Raum der domus vollzog sich damit eine Form der Annäherung, die Privatheit in einem modernen Sinne signalisierte, jedoch die öffentlichkeitsorientierte Raumstruktur der domus und ihren Charakter als gesellschaftliches und Sozialbeziehungen strukturierendes Zentrum 
konterkarierte: Für das privatum im Sinne eines komplementär zum publicum existierenden Handlungsbereichs, der den gesellschaftlichen Rang des Patrons gegenüber Freunden und Klienten unterstrich, ${ }^{262}$ spielte die Heiligenmemoria keine Rolle. Die Heiligen waren im privaten Raum der domus keine identitätsstiftenden Bezugspunkte für die unterschiedlichen Gruppen von Freunden und Klienten, die in einer sozialen Beziehung zum Hausherrn standen. Vielmehr bildeten sie umgekehrt die Zentren einer individuellen Annäherung, für die eine Lösung aus den sozialen Beziehungen und die alleinige Ausrichtung auf den verehrten Heiligen charakteristisch war. Seine Eigenschaft als himmlischer Fürsprecher begründete eine eigene Form der Patronage, die in soziale Patronagebeziehungen nur bedingt integrierbar war.

262 Dies soll selbstverständlich nicht bedeuten, dass es in der römischen domus keine Privatheit in einem modernen Sinne gegeben hätte; für Beispiele vgl. zuletzt Sessa 2007, 177-180. Dennoch ist zu berücksichtigen, dass unter begriffsgeschichtlichen Aspekten das römische Binom publicum privatum vor allem die Handlungsbefugnis und das Interesse von Akteuren beinhaltet, nicht aber die perzeptive Dimension des Sichtbaren oder Zugänglichen, die für den modernen Begriff von Privatheit eine zentrale Bedeutung hat (vgl. L. Hölscher 1978, 419f.; dens. 1979, 43. Zu den im Begriffspaar „öffentlich - privat“ enthaltenen Dimensionen agency [Tätigkeit, Handlungsbefugnis], interest [Interesse] und access [Zugänglichkeit] vgl. Benn/Gaus 1983; erweitert um die Dimension des Sichtbaren von v. Moos 1998, 27-29). 